\title{
Issue 50 (August 2021)
}

ISSN 2627-9827 - DOI 10.21570/EDGG.PG.50

IAVS

( )

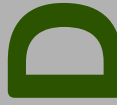

7

윽

Aili

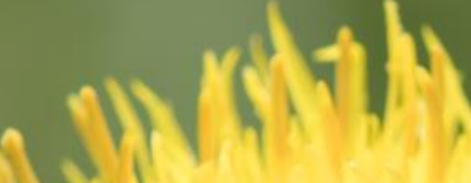

1.1.

(ก)

(ก) $\frac{\pi}{y}$

要

10

(1) ำ

()

ᄃ

$\frac{\pi}{4}$

U

$0 \stackrel{2}{ \pm}$

$-\frac{4}{6}$

II

-1 ㅇํㄱ
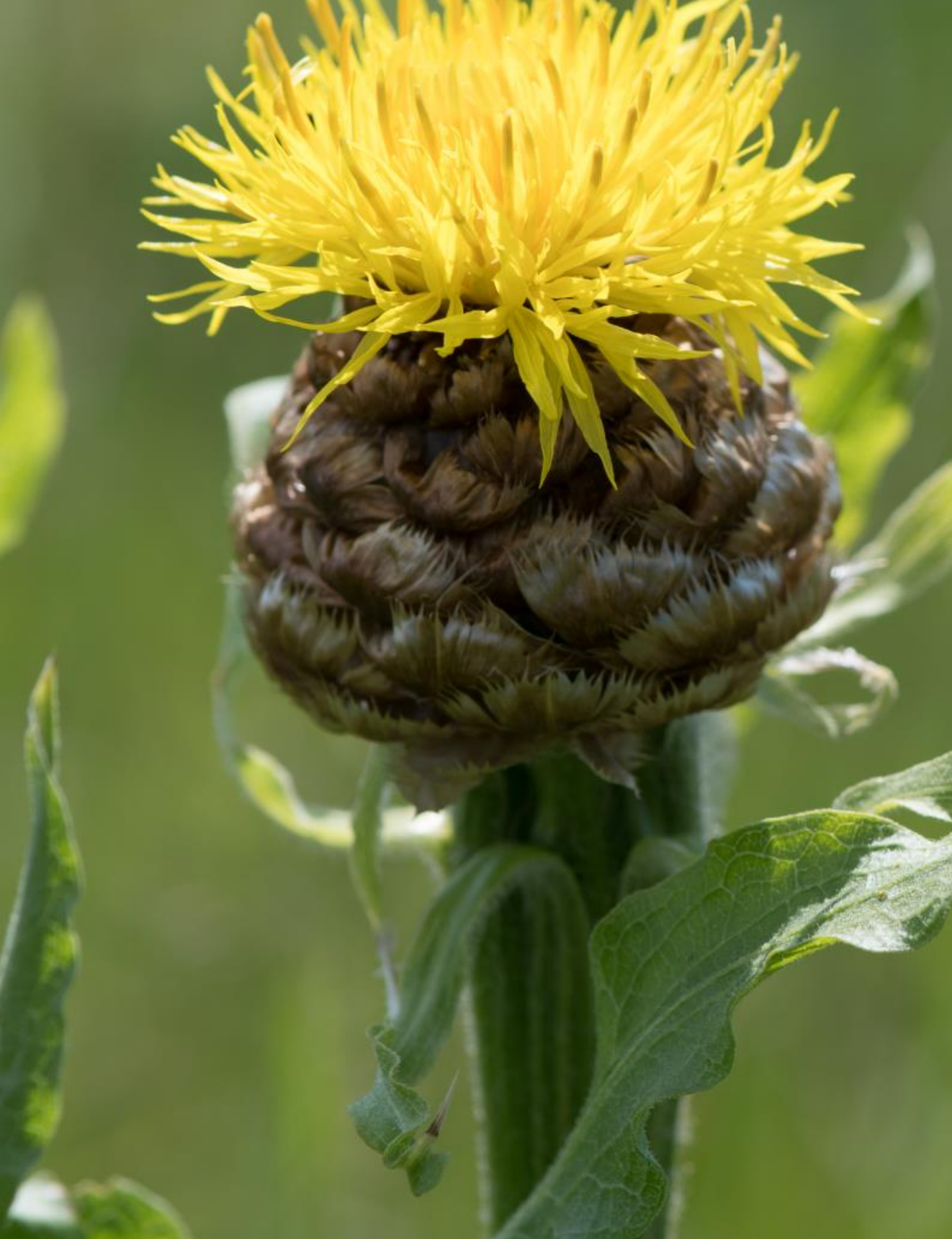


\section{Table of Contents}

Editorial

News

EDGG Event

Photo Story: Budzhak et al.: "Sinozhati" - the sacred place of Pokuttya (Western Ukraine) as a center of meadow-steppe diversity preservation

Glimpses of a Grassland

Best shots on

"Spirit of grasslands"

Book Reviews

Recent Publications of our Members

Forthcoming Events

\section{Palaearctic Grasslands}

ISSN 2627-9827

DOI 10.21570/EDGG.PG50

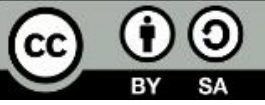

Palaearctic Grasslands, formerly published under the names Bulletin of the European Dry Grassland Group (Issues 1-26) and Bulletin of the Eurasian Dry Grassland Group (Issues 27-36), is the journal of the Eurasian Dry Grassland Group (EDGG). It appears in four issues per year. Palaearctic Grasslands publishes news and announcements of EDGG, its projects, related organisations and its members. It also serves as an outlet for scientific articles and photo contributions.

Palaearctic Grasslands is freely available at http://edgg.org/publications/bulletin and new issues are announced to all EDGG members. All content (text, photos, figures) in Palaearctic Grasslands is open access and available under the Creative Commons license CC-BY-SA 4.0 that allow re-use provided proper attribution is made to the originators ("BY") and the new item is licensed in the same way ("SA" = "share alike").

Submissions following the Author Guidelines are welcome by the deadlines of the four issues: 31 January, 30 April, 31 July and 31 October.

Scientific articles (Research Articles, Reviews, Forum Articles, Scientific Reports) should be submitted to the Receiving Editor Jürgen Dengler (dr.juergen.dengler@gmail.com) and will then undergo peer review, so publication in a certain issue cannot be guaranteed.

All other text contributions (News, Announcements, Short Contributions, Book Reviews, Glimpses of a Grassland...) should be submitted to Anna Kuzemko (anyameadow.ak@gmail.com) AND Idoia Biurrun (idoia.biurrun@ehu.es).

Photo contributions (photos for general illustrative purposes with captions; Photo Stories; should be submitted to Rocco Labadessa (rocco.labadessa@gmail.com).

Contributions to Photo Competitions should be submitted to Edy Fantinato (edy.fantinato@unive.it)

Contributions to the section "Recent Publications of our Members" should be sent to Iwona Dembicz (i.dembicz@gmail.com) and those for "Forthcoming Events" to Alla Aleksanyan (alla.alexanyan@gmail.com). Any member of EDGG who would like to see their book reviewed in Palaearctic Grasslands should communicate with our Book Review Editor Péter Török (molinia@gmail.com).

Palaearctic Grasslands is published by EDGG c/o Prof. Dr. Jürgen Dengler, Plant Ecology, BayCEER, University of Bayreuth, Universitätsstr. 30, 85447 Bayreuth, Germany.

Palaearctic Grasslands on ResearchGate

Palaearctic Grasslands on Google Scholar

Palaearctic Grasslands on vegsciblog.org

\section{Editorial Board}

CHIEF EDITORS: Idoia Biurrun, Jürgen Dengler, Anna Kuzemko, Rocco Labadessa

SCIENTIFIC EDITORS: Alla Aleksanyan, Didem Ambarlı, Idoia Biurrun, Iwona Dembicz, Jürgen Dengler, Edy Fantinato, Riccardo Guarino, Frank Yonghong Li, Anna Kuzemko, Rocco Labadessa, James Moran, Alireza Naqinezhad, Jalil Noroozi, Arkadiusz Nowak, Salza Palpurina, Ricarda Pätsch, Nina Polchaninova, Solvita Rūsiṇa, Laura Sutcliffe, Péter Török, Atushi Ushimaru, Orsolya Valkó, Stephen Venn

LINGUISTIC EDITORS: Dolores Byrne, Sean Cooch, Magdalena Firganek-Fulcher, Paul Goriup, Richard Jefferson, Ashley Lyons, Lorna Marcham, Jim Martin, James Moran, Hallie Seiler, Stuart Smith, Laura Sutcliffe, Stephen Venn

\section{PHOTO EDITOR: Rocco Labadessa}

PHOTO JURY: Edy Fantinato (Chair), Magdalena Firganek-Fulcher, Anna Kuzemko, Rocco Labadessa, Jim Martin, Jalil Noroozi, Salza Palpurina

BOOK REVIEW EDITOR: Péter Török

LAYOUT AND TYPESETTING: Rocco Labadessa 


\section{Editorial}

Dear readers,

While wishing that you are spending a nice time during this summer season, we are pleased to present you Palaearctic Grasslands issue 50 . We are very happy to celebrate with you this milestone issue and thank all the people that have contributed to the growth of Palaearctic Grasslands, since the first Bulletin of the EDGG in 2008, retracing over ten years of EDGG's lively history!

Whilst the troubles due to the Covid-19 pandemic are still affecting many territories of the Palaearctic, EDGG's activities are continuing with several items of good news for EDGG members.

While we sadly had to postpone our live conference in Tolosa, Spain, to September 2022, we are proud to announce an international online conference specifically devoted to the grasslands of Asia! Researchers are invited to the very first Asian Grassland Conference to share studies on many different topics regarding these precious habitats. On pages 9-16 you can find more information about the conference, which will take place in February 2022 with keynote talks, regular and speed presentations, as well as several side events, where we hope to meet many researchers from all over the world interested in grassland research and conservation. In these days, we also hope that the political turmoil in Afghanistan will not affect the freedom and safety of our colleagues from Central Asia.

EDGG ongoing activities are also underlined by two new interesting videos launched on our YouTube channel (see $p$. 4) and three papers based on GrassPlot data, recently published in the Journal of Vegetation Science (see p. 5-7). Furthermore, we are pleased to present you a new Photo Story from an important meadow-steppe site in Western Ukraine (see pp. 18-26), as well as two Glimpses of Grasslands, from the Tibetan plateau and the Apennines, respectively (see pp. 27-30).

We wish you a pleasant reading of this summer issue,

Rocco Labadessa

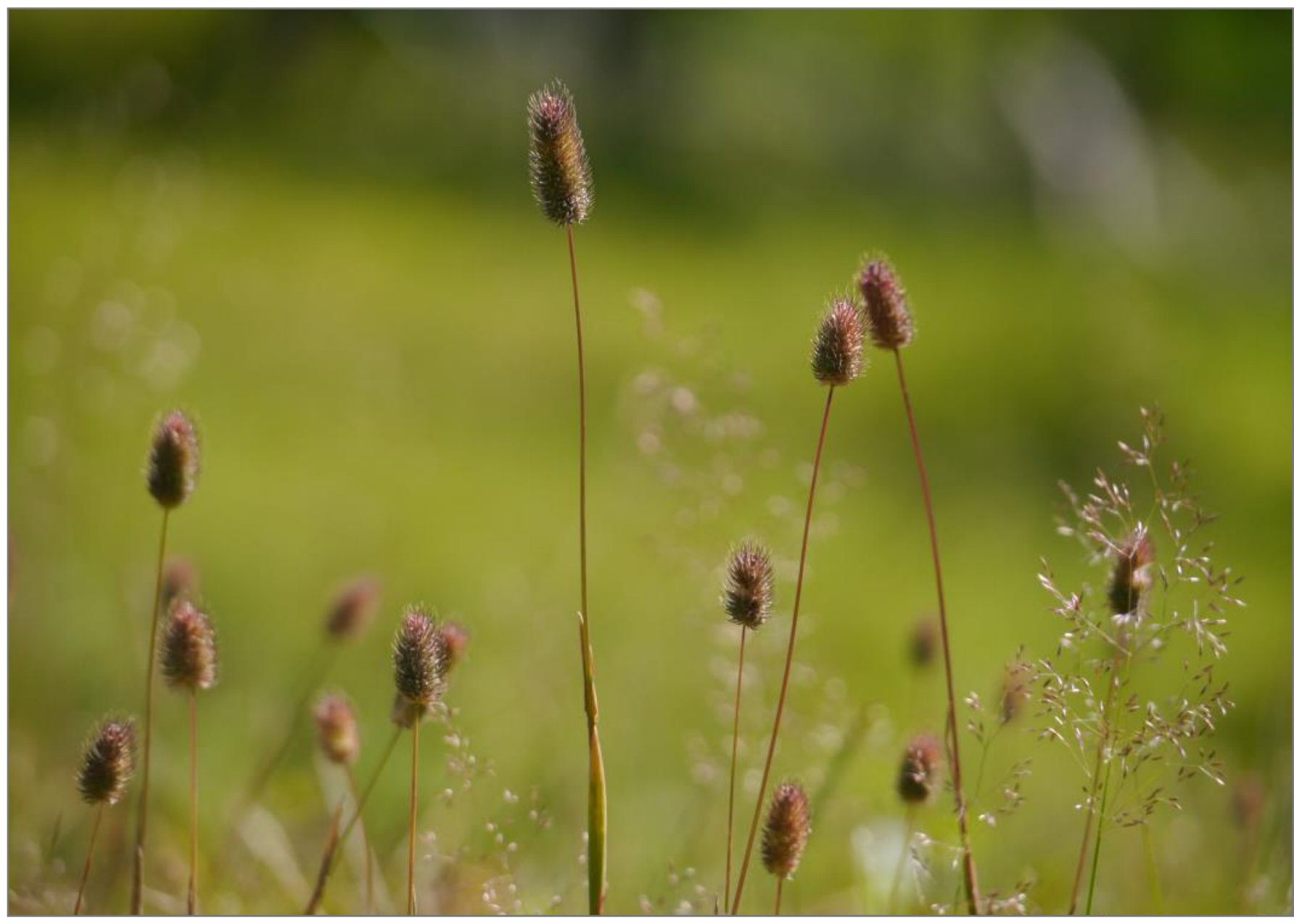




\section{News}

\section{Two new videos available in EDGG's YouTube channel}

Recently two new EDGG videos have been launched in our YouTube channel:

- Jürgen Dengler, Iwona Dembicz and Hallie Seiler produced "The EDGG Biodiversity Plot - Recording multiscale plant diversity" (41:10 min). This didactical video provides all the details of EDGG's standardised vegetation-plot sampling across multiple scales as it is used during the EDGG Field Workshops and by many other researchers (Dengler et al. 2016) and forms the core part of EDGG's GrassPlot database (Dengler et al. 2018; Biurrun et al. 2019, 2021; https://edgg.org/databases/GrassPlot).

- Riccardo Guarino and co-authors produced "The EDGG activities on Palearctic grasslands: research, networking and passion for biodiversity" (13:53 $\mathrm{min})$ : This attractive video produced in the context of a rangeland conference in Iran introduces Palaearctic grasslands as an interesting research topic, the activities of EDGG and particularly EDGG's GrassPlot database. One can nicely use this video to attract new members.
You find these two videos in EDGG's growing YouTube channel at https://www.youtube.com/channel/UCuAZ2vOFIW3WL2Yz2PzH9A.

\section{References}

Biurrun, I., Burrascano, S., Dembicz, I., Guarino, R., Kapfer, J., Pielech, R., Garcia-Mijangos, I., Wagner, V., Palpurina, S., (...) \& Dengler, J. 2019. GrassPlot v. 2.00 - first update on the database of multi-scale plant diversity in Palaearctic grasslands. Palaearctic Grasslands 44: 26-47.

Biurrun, I., Pielech, R., Dembicz, I., Gillet, F., Kozub, t., Marcenò, C., Reitalu, T., Van Meerbeek, K., Guarino, R., (...) \& Dengler, J. 2021. Benchmarking plant diversity of Palaearctic grasslands and other open habitats. Journal of Vegetation Science 32: e13050

Dengler, J., Boch, S., Filibeck, G., Chiarucci, A., Dembicz, I., Guarino, R., Henneberg, B., Janišová, M., Marcenò, C., (...) \& Biurrun, I. 2016. Assessing plant diversity and composition in grasslands across spatial scales: the standardised EDGG sampling methodology. Bulletin of the Eurasian Dry Grassland Group 32: 13-30.

Dengler, J., Wagner, V., Dembicz, I., García-Mijangos, I., Naqinezhad, A., Boch, S., Chiarucci, A., Conradi, T., Filibeck, G., (...) \& Biurrun, I. 2018. GrassPlot - a database of multi-scale plant diversity in Palaearctic grasslands. Phytocoenologia 48: 331-347.

Jürgen Dengler, Switzerland dr.juergen.dengler@gmail.com

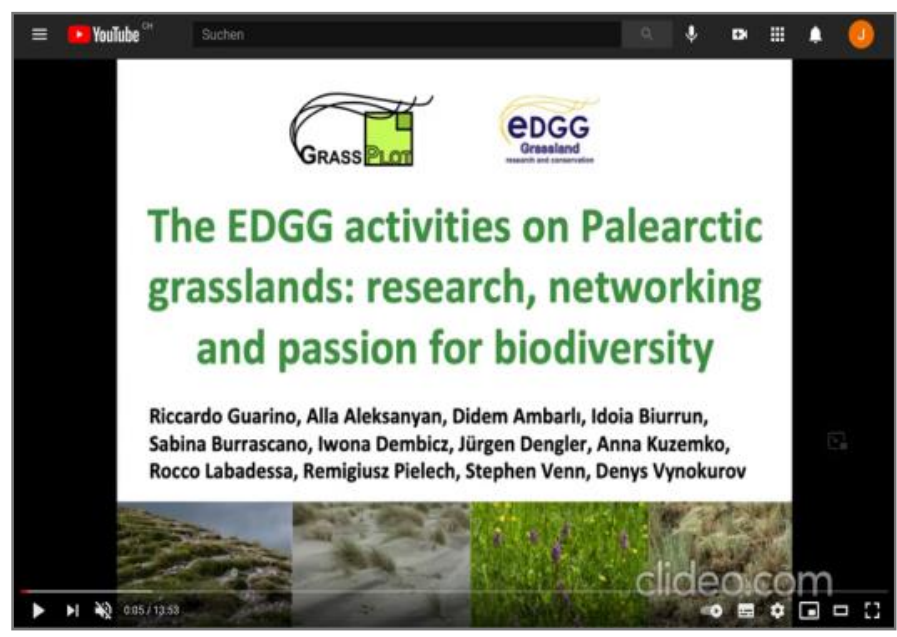

The EDGG activities on Palearctic grasslands: research, networking and passion for biodiversity
The EDGG Biodiversity Plot - Recording multi-scale plant diversity 


\section{Three GrassPlot papers published in the "Macroecology of Vegetation" Special Issue of the Journal of Vegetation Science}

GrassPlot is the EDGG-affiliated database of multi-scale plant diversity in Palaearctic grasslands (https://edgg.org/ databases/GrassPlot). It includes high-quality phytodiversity data from grasslands and other open habitats sampled on precisely delimited plots of eight standard sizes: 0.0001 , $0.001,0.01,0.1,1,10,100$ and $1000 \mathrm{~m}^{2}$.

GrassPlot focuses on nested-plot data with at least two different plot sizes, but multi-scale nested plot series are preferred, preferentially the so-called EDGG Biodiversity Plots, many of them sampled in EDGG Field Workshops. These nested-plot series have facilitated studies of the species-area relationships (SARs) and small-scale beta diversity (see VegSciBlog post by Dengler et al. 2021). In the first macroecological GrassPlot paper published in Journal of Biogeography, Dengler et al. (2020) tested which function best describes the shape of fine-grain SARs in continuous vegetation, finding that the power function is, in general, the best model. Using power function, Dembicz et al. (2021) analyzed SARs of more than 4,600 nested-plots series with at leat four different grain sizes looking for the drivers of its slope parameter $z$, and this way explored the environmental factors influencing fine-grain beta diversity as well as its variation across taxonomic groups (vascular plants, bryophytes, lichens and complete vegetation). In paralell, Zhang et al. (2021) analyzed the scale-dependance of $z$ values by means of local $z$-values. In this case, they selected all nested -plot series with at least two grain sizes, and thus could use more than 6,600 series to conclude that the scale dependancy of $z$-values is generally weak for data sampled using the "shoot presence" method.

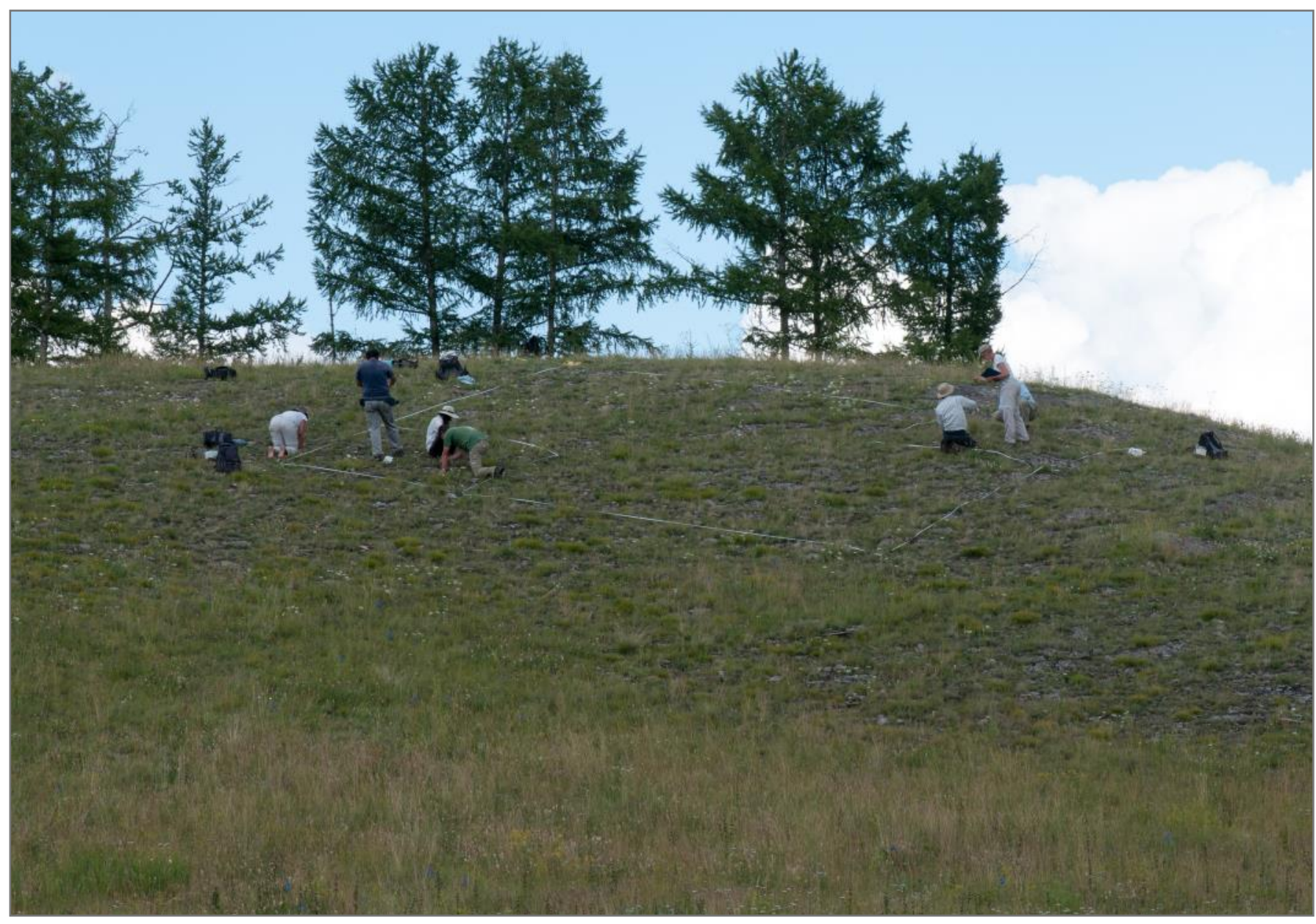

EDGG Biodiversity Plot in a rocky steppe in Khakassia, Siberia. Photo: J. Dengler. 


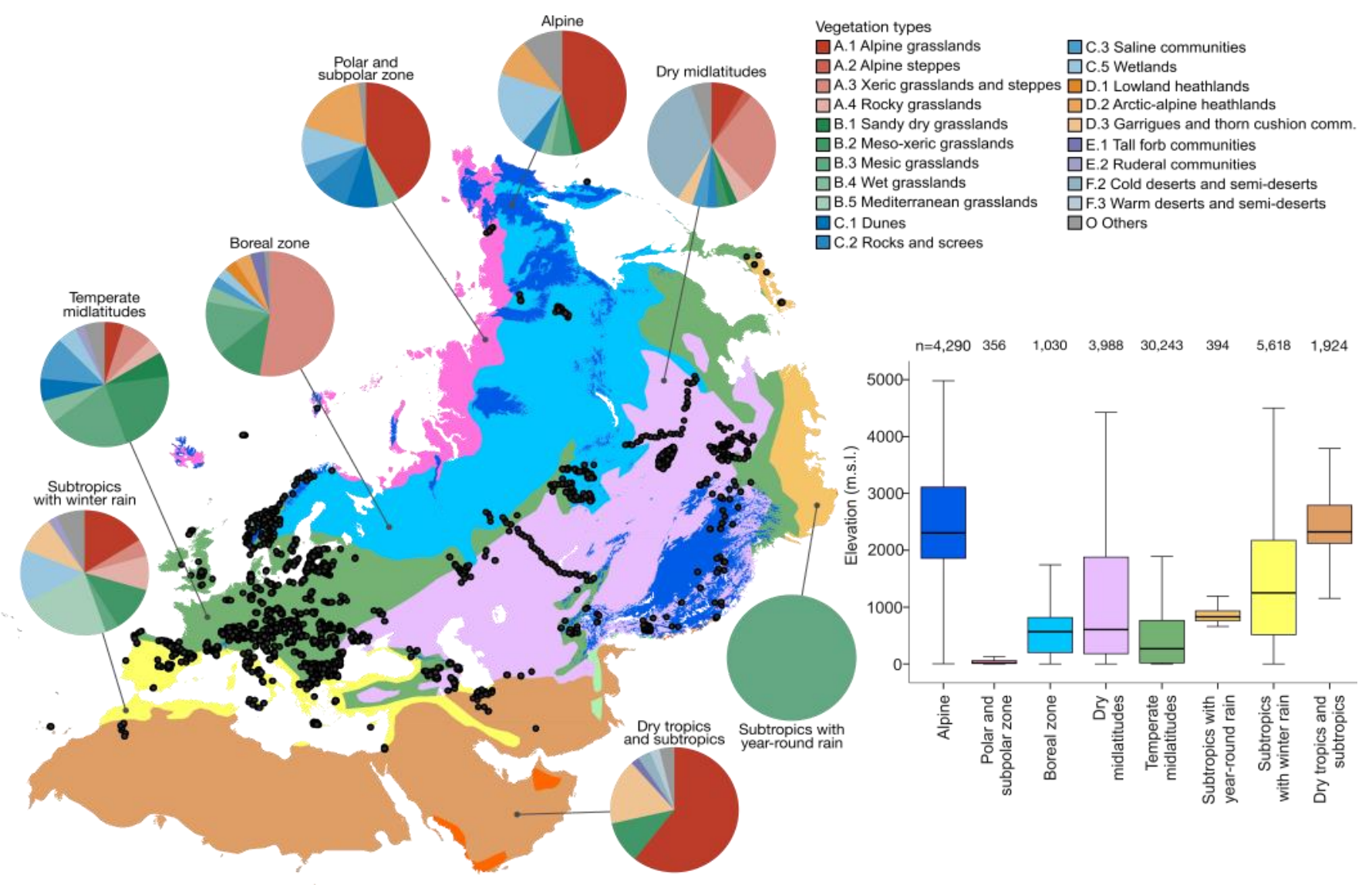

Distribution of plots of the standard grain-sizes in GrassPlot across the biomes of the Palaearctic realm; pie-charts show the fraction of vegetation types represented by the plots (black dots) included in each biome (From Biurrun et al. 2021).

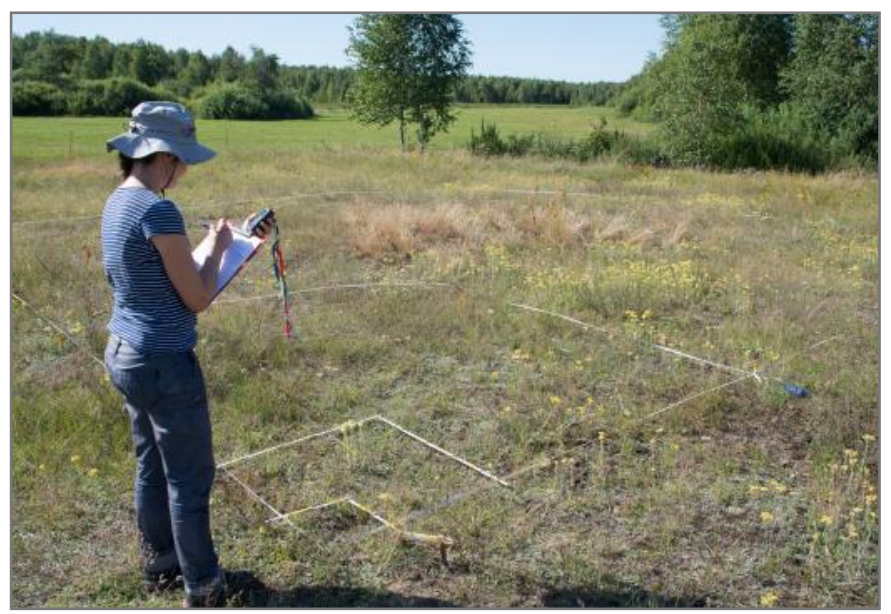

EDGG Biodiversity Plot in a sandy dry grassland (Helichryso-Jasionetum) in NE Poland. Photo: J. Dengler.

The third GrassPlot paper in the "Macroecology of Vegetation" Special Feature presents plant diversity benchmarks in Palaearctic grasslands and other open habitats (see VegSciBlog post by Biurrun et al. 2021). Biurrun et al. (2021) used more than 126,000 vegetation plots of the above mentioned standard grain sizes to provide mean richness and standard deviations as well as maximum, median, and first and third quartiles for all combinations of grain size, taxo-

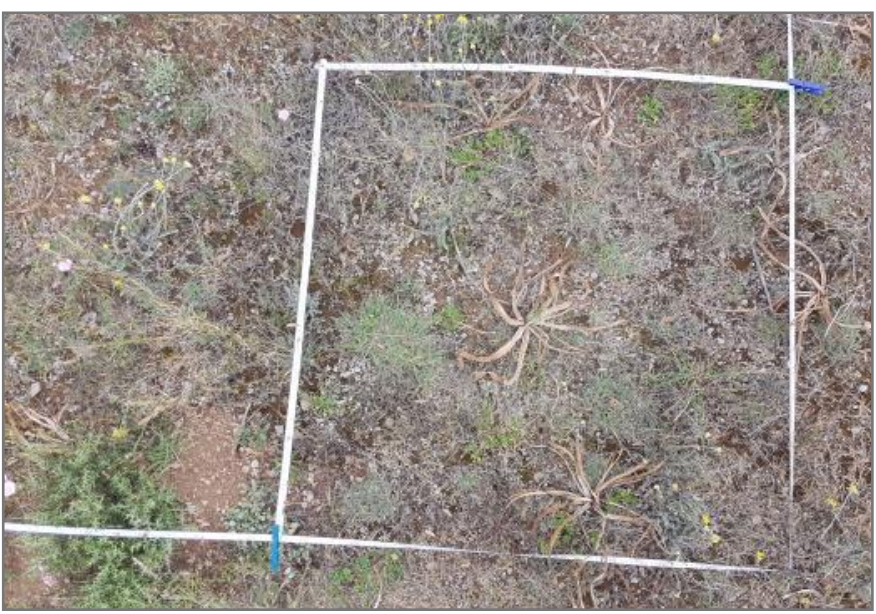

1- $\mathrm{m}^{2}$ subplot in a EDGG plot in a cryptogram rich dry grassland in the Basque Country (Spain). Photo: J.A. Campos.

nomic group (bryophyte, lichen, vascular plants and all combined, i.e. the complete vegetation), biome, region, vegetation type and phytosocociologic class. These benchmarks are available as the open-access file "GrassPlot Diversity Benchmarks" and as the online interactive tool "GrassPlot Diversity Explorer", providing users flexibility in exploring and visualizing richness data from GrassPlot. While the paper is static, the online versions of the Explorer and the 
Benchmarks will be regularly updated when new data are added to GrassPlot.

The publication of these three papers in this Special Issue finalizes the first objectives of GrassPlot, but there are other projects that have been initiated when GrassPlot was established in 2017, and new ones have started since then, which analyze other aspects of biodiversity, such as alpha diversity, broad-scale beta diversity, functional diversity, speciesabundance distributions, etc. In parallel, GrassPlot continues growing, as new data are contributed. If you are willing to contribute data and thus participate in further projects, please consult our webpage (https://edgg.org/databases/ GrassPlot) and contact the GrassPlot manager Idoia Biurrun (idoia.biurrun@ehu.es).

\section{References}

Biurrun, I., Pielech, R., Dembicz, I., Gillet, F., Kozub, $Ł$, Marcenò, C., Reitalu, T., Van Meerbeek, K., Guarino, R., (...) \& Dengler, J. 2021. Benchmarking plant diversity of Palaearctic grasslands and other open habitats. Journal of Vegetation Science 32: e13050.

Dembicz, I., Dengler, J., Steinbauer, M.J., Matthews, T.J., Bartha, S., Burrascano, S., Chiarucci, A., Filibeck, G., Gillet, F., (...) \& Biurrun, I. 2021. Fine-grain beta diversity of Palaearctic grassland vegetation. Journal of Vegetation Science 32: e13045.

Dengler, J., Matthews, T.J., Steinbauer, M.J., Wolfrum, S., Boch, S., Chiarucci, A., Conradi, T., Dembicz, I., Marcenò, C., (...) \& Biurrun, I. 2020. Species-area relationships in continuous vegetation: Evidence from Palaearctic grasslands. Journal of Biogeography 47: 72-86.

Zhang, J., Gillet, F., Bartha, S., Alatalo, J.M., Biurrun, I., Dembicz, I., Grytnes, J.-A., Jaunatre, R., Pielech, R., (...) \& Dengler, J. 2021. Scale dependence of species-area relationships is widespread but generally weak in Palaearctic grasslands. Journal of Vegetation Science 32: e13044.

Idoia Biurrun, Spain idoia.biurrun@ehu.es

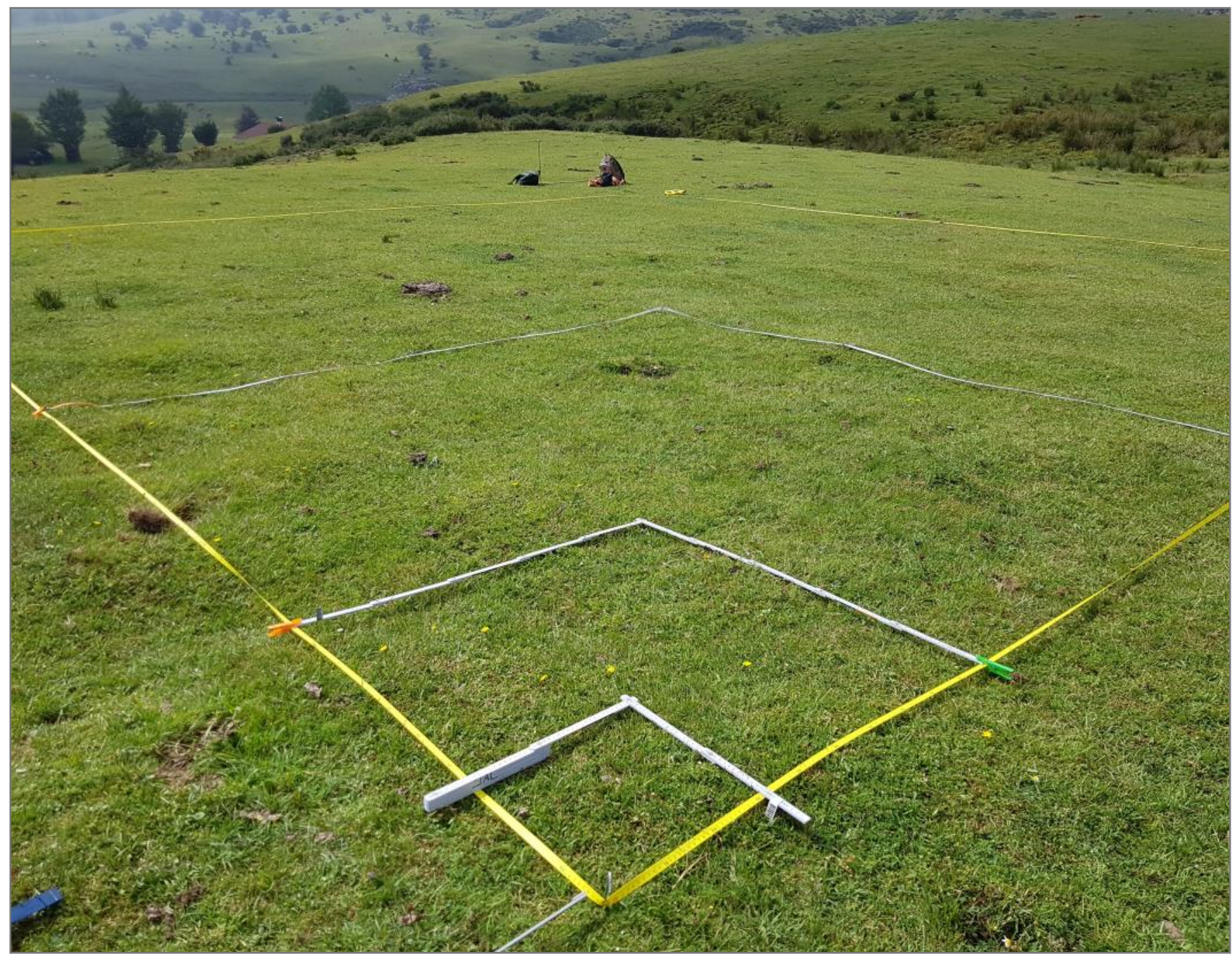

EDGG Biodiversity Plot in a mesic mountain pasture (Jasonio-Danthonietum decumbentis) in the Basque Country (Spain). Photo: I. Biurrun. 


\section{Photos in Palaearctic Grasslands}

As usual, we are looking forward to your contributions to the Photo Story section, as well as your photographs for general illustrative purposes.

Submissions for the Photo Story section are always welcome. Photo Story is an open space where members can submit their own photo collection on a certain grassland-related topic of their choice. High-quality photos should be provided together with their captions (at least species names or landscape description), a brief text and possibly other graphical elements (like a map or a drawing). The selection of photos should fit within 3-8 pages and the contributors should propose a preliminary layout (in PDF or MS Word format), which will be finally typeset by Editors. As an example, you can look at the Photo Stories published in the previous issues.

As with scientific articles, Photo Stories undergo a review process with a focus on photo quality. There is no guarantee that they will be accepted without changes, and late submissions may be published in subsequent issue.

As announced in the last issue of Palearctic Grasslands, we would also like to encourage you to contribute to the Global Vegetation Project with your vegetation photographs:

1) If your photos have already been published in Palaearctic Grasslands, you can submit them to the global map citing DOI of your article or of the whole issue (you can find all published issues here: https://edgg.org/publications/ bulletin);

2) If you are submitting new vegetation photographs to Palaearctic Grasslands, either within an article, a photo story or for general illustrative purposes, you can provide each photo file with the following information $\left(^{*}=\right.$ required fields):

- Date (year/month/day),

- author's full name*,

- place name,

- latitude and longitude*,

- vegetation type,

- vegetation classification system,

- naturalness,

- dominant species list*,

- additional comments.

Please take a look at the project website (http:// gveg.wyobiodiversity.org) for an overview of the global map and the data entry form.

If you want to contribute to Photo Stories, or if you simply want to help us with enriching this aspect of the journal, please submit your photos together with required information to Rocco (rocco.labadessa@gmail.com).

Deadline for photo submissions is $\mathbf{3 1}$ October 2021.

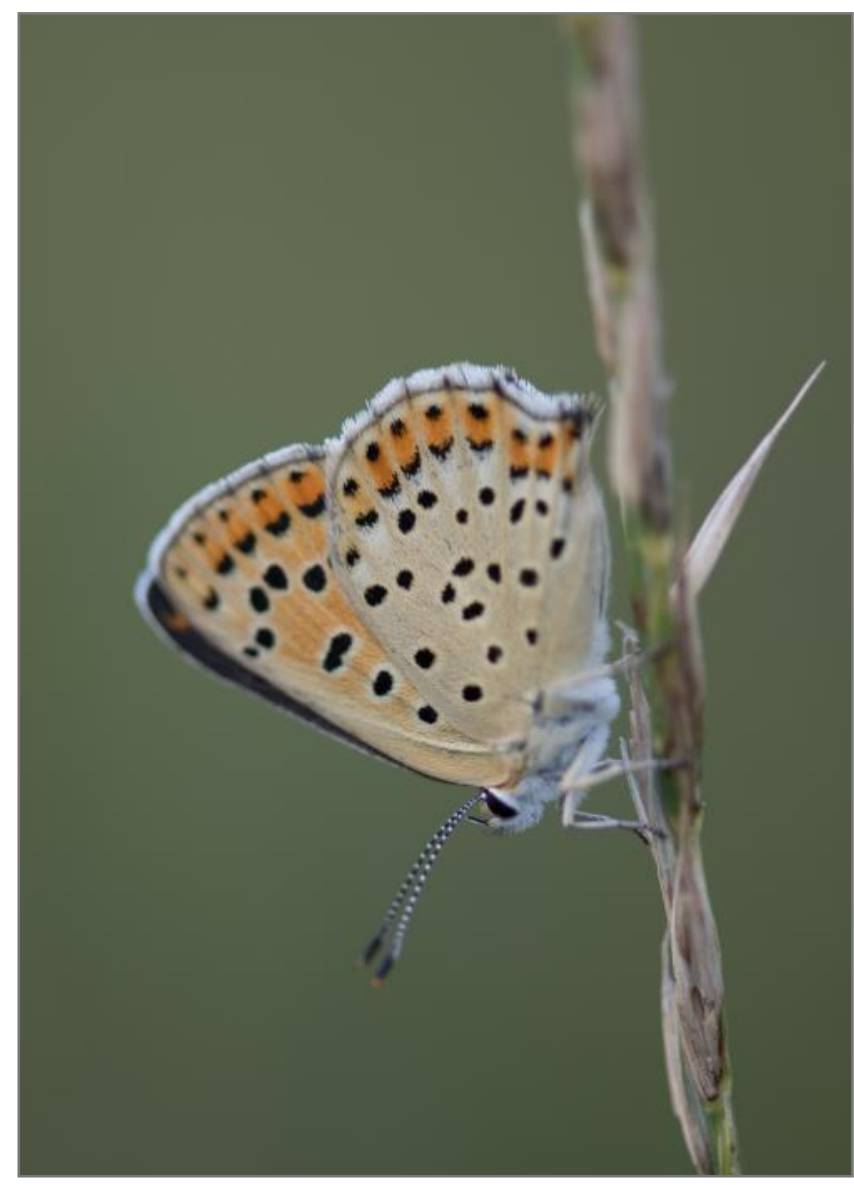

Lycaena tityrus in NE Poland. Photo: J. Dengler.

\section{Call for Photo Competition}

The theme of the new Photo Competition is "Grassland birds", dedicated to the bird species enlivening grassland ecosystems with their songs and colours.

You are invited to send up to three high-quality photographs within the competition theme (full size JPEG or TIFF images, at least $300 \mathrm{dpi}$ ) together with captions giving a short title or description and information on the subject (species name, date, place name).

The Photo Jury (see imprint) will select the best photographs. The three best shots will be awarded with full space in the next issue, but we reserve the right to use other submitted materials for illustrative purposes in other parts of the issue.

If you want to take part in the competition, please submit your photos together with required information to Edy (edy.fantinato@unive.it) by 31 October 2021.

Edy Fantinato, Italy edy.fantinato@unive.it 


\section{EDGG Event}

\section{eDGG}

Grassland

research and conservation

\section{Asian Grassland Conference (AGC) Virtual Conference, 22-24 February 2022 First Call https://edgg.org/AGC}

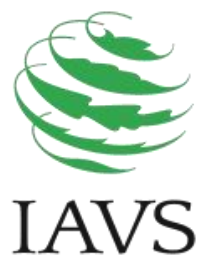

As the largest continent of the world, Asia offers great opportunities for researchers with its vast grasslands, diverse and unique environmental conditions, rich biodiversity, and varied ecological and evolutionary processes, some of which are not observed elsewhere. Simultaneously, it poses great challenges for nature conservation and sustainable livelihoods due to climatic and land use changes. Since 2008, the Eurasian Dry Grassland Group (EDGG), with more than 1300 members from over 60 countries, has aimed to strengthen the exchange of scientific information and collaboration on Palaearctic grasslands in general, including the organisation of annual Eurasian Grassland Conferences (EGCs). Due to the Covid-19 pandemic, no EGC could be conducted in 2020 or 2021 as a live event. Therefore, we have seized the opportunity to organise an international online event specifically devoted to the grasslands of Asia. We invite researchers from all over the world to the very first Asian Grassland Conference to present or listen to studies on the flora, fauna, biodiversity, ecology, management and conservation of these precious habitats.
The conference will take place during three-half days on an online platform from 22nd to 24th February 2022. We will ensure a broad level of regional representation in the event, highlighting research from less well-known parts of the continent. Besides keynote talks, regular oral presentations and speed-talks with posters, we will offer networking events, workshops and happy hours. In conjunction with the conference, we also plan to produce Special Features in a number of international peer-reviewed scientific journals.

Participation in the Asian Grassland Conference is free of charge. In autumn 2021, we will launch the online registration on the conference website. Further details will be announced in forthcoming issues of Palaearctic Grasslands, via the EDGG mailing list as well as on the conference website (https://edgg.org/AGC). If you don't want to miss out anything, you can pre-register your interest via e-mail to edgg.agc@gmail.com.

We hope to meet many researchers interested in grassland research and conservation in Asia! Colleagues from other continents are, of course, very welcome to join us.

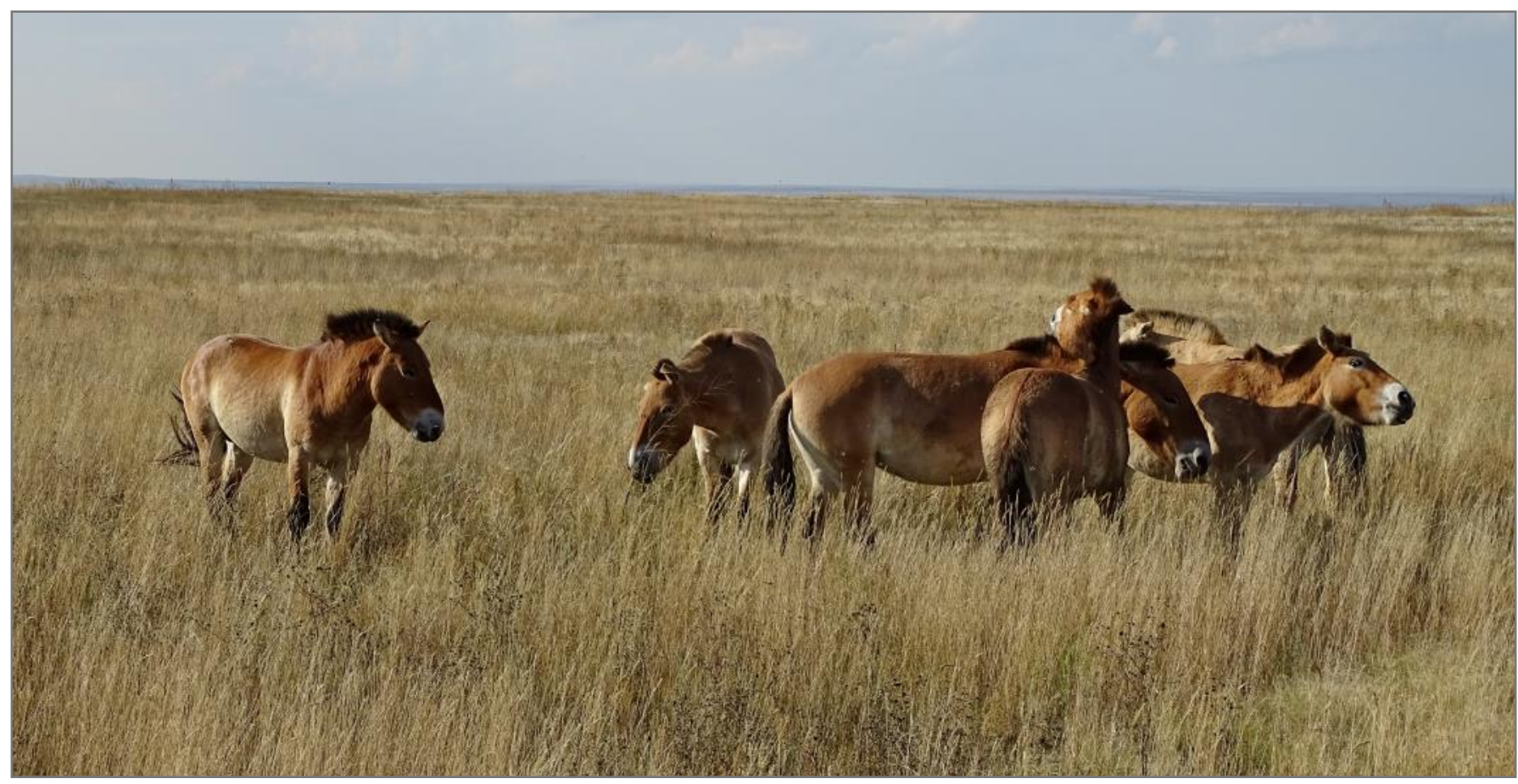

Przewalski's horses (Equus przewalskii) in a typical steppe in the Orenburg SNR, Russia. Photo: I. Smelansky. 


\section{Topic and sessions}

We intend to cover any aspect of research and conservation in Asian natural and semi-natural grasslands. Below you can find a preliminary session list with short explanations. Presentations on other subjects of grassland research are also welcome.

1. Biodiversity of grasslands: patterns and drivers of a wide range of biodiversity facets

2. Ecology and taxonomy of plant and fungi species in grasslands: studies with a focus on individual species

3. Ecology and taxonomy of grassland vertebrate species: studies with a focus on individual species, including wildlife management

4. Ecology and taxonomy of grassland invertebrate species: studies with a focus on individual species

5. Grassland ecosystems under global change, including climate change, land use change, habitat destruction, biotic invasions and eutrophication

6. Functional ecology of grasslands

7. Grassland conservation, management and restoration

8. Vegetation and habitat classification of grasslands, at any level and with any approach

9. Remote sensing, mapping and modelling of grasslands

10. Livelihoods and sustainability of pastoral communities, including payment schemes for conservation

Full details on the sessions will be provided in the Second Call.

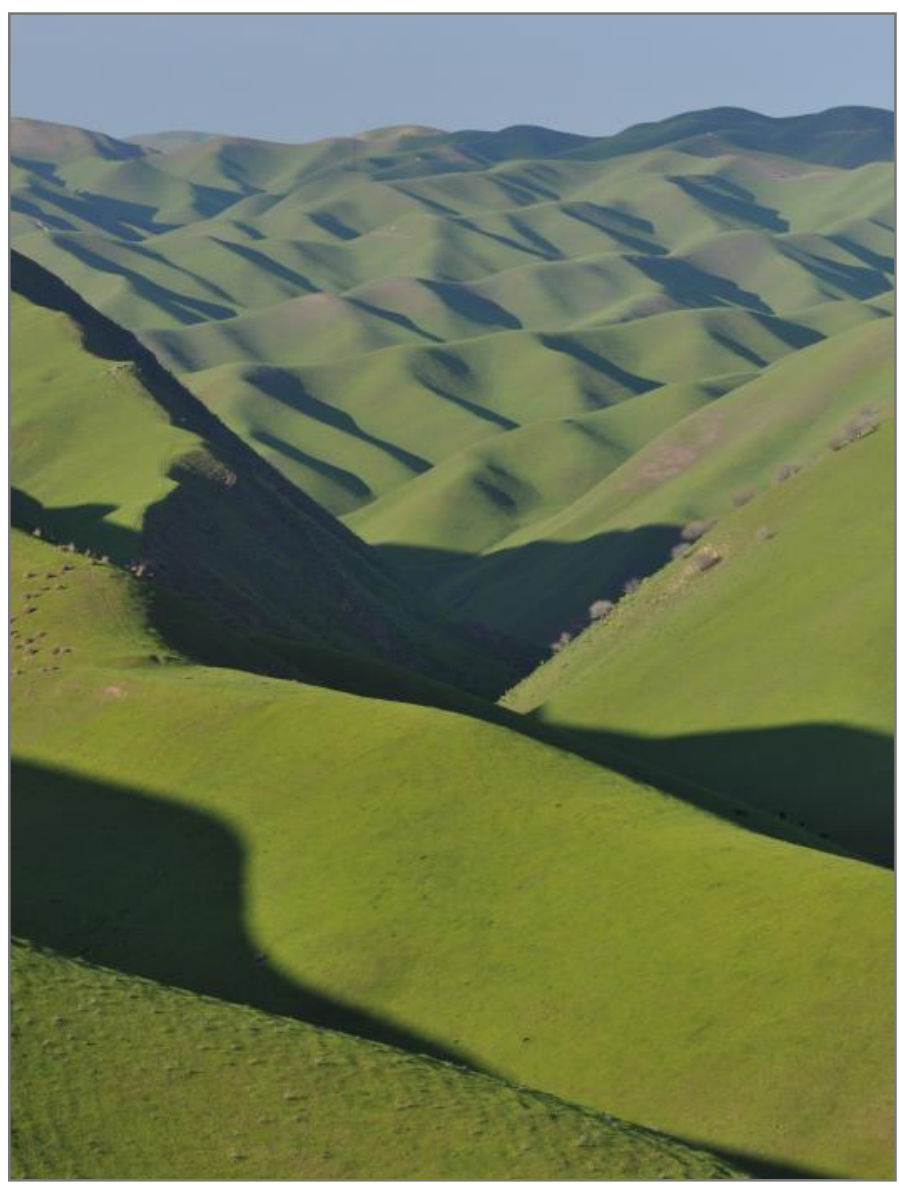

Pseudosteppes of the Cryptosporo falcataeBrachypodietum distachyi in Kulab district, Tajikistan. Photo: A. Nowak.

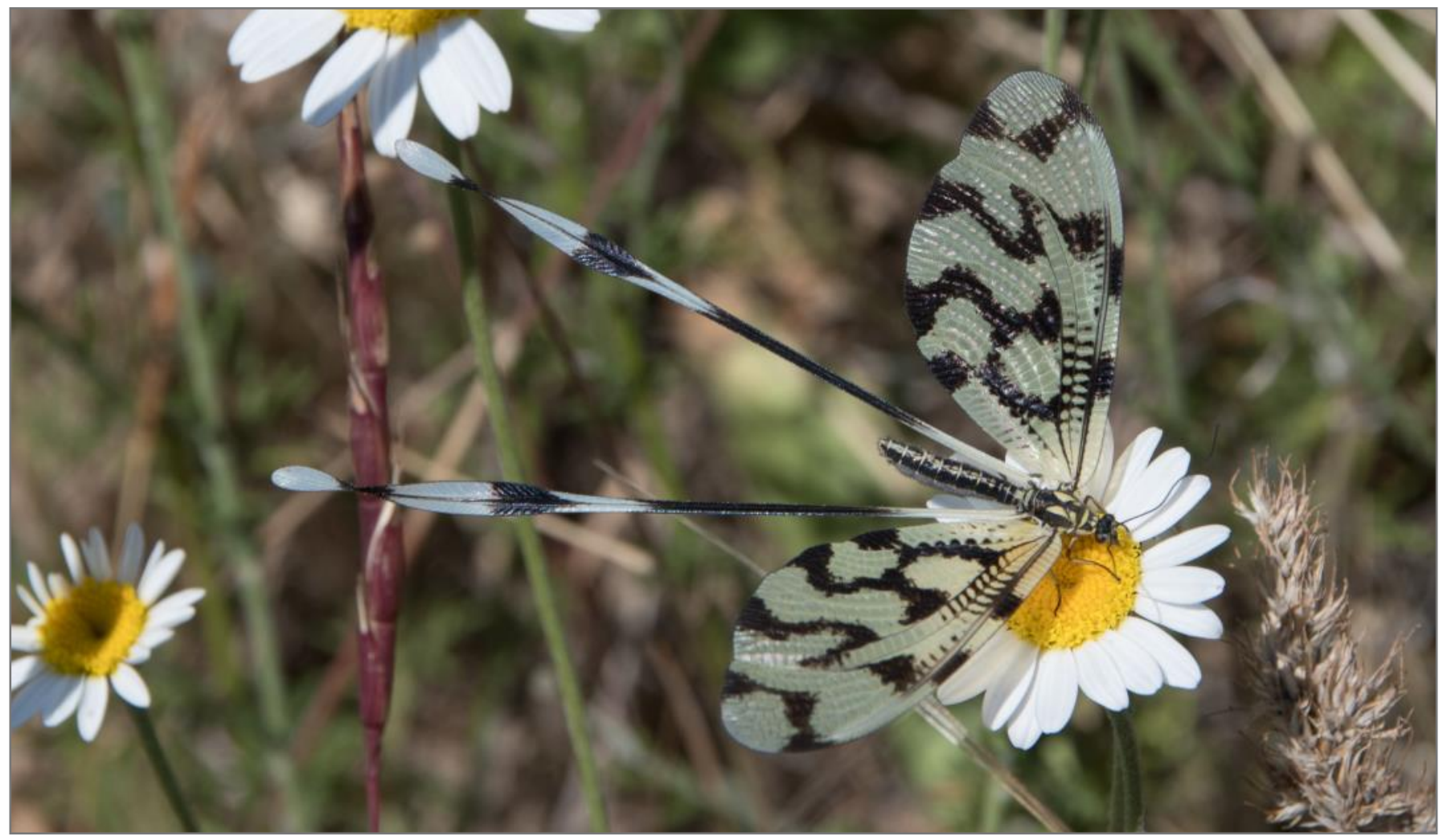

Nemoptera sinuata in Armenia. Photo: J. Dengler. 


\section{Keynotes}

AGC will offer three keynote presentations, which will provide comprehensive, enlightening and inspiring information on grasslands. At the beginning of each day, a distinguished scientist will present a keynote talk. We are pleased to welcome three brilliant scientists presenting on vegetation ecology, wildlife ecology and global change.

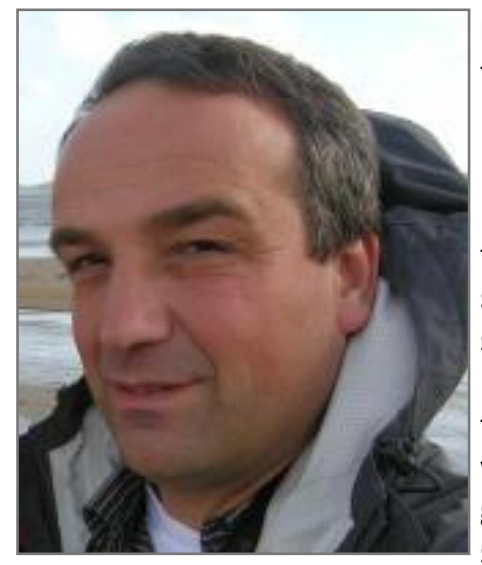

Prof. Norbert Hölzel, Institute of Landscape Ecology, University of Münster, Münster, Germany

Prof. Hölzel's research interests in grassland ecology spans restoration, landscape ecology, land use, biodiversity and ecosystem functioning interactions, vegetation patterns, ecology of rare and endangered species, seed ecology and the effects of global change on landscapes, habitats and species. He led or worked in several projects in Eurasia. His research group works intensively on a large-scale, longrunning project in Asia: land-use change and landscape dynamics in Western Siberia and Kazakhstan. Furthermore, he is a leading scientist in a long-term biodiversity research and monitoring project in Germany, the Biodiversity Exploratories. He is a member of the editorial board of several scientific journals and scientific organizations. His talk will focus on the impact of Post-Soviet land-use change on Central Asian steppe ecosystems.

\section{Profile University of Münster}

\section{Google Scholar}

ResearchGate

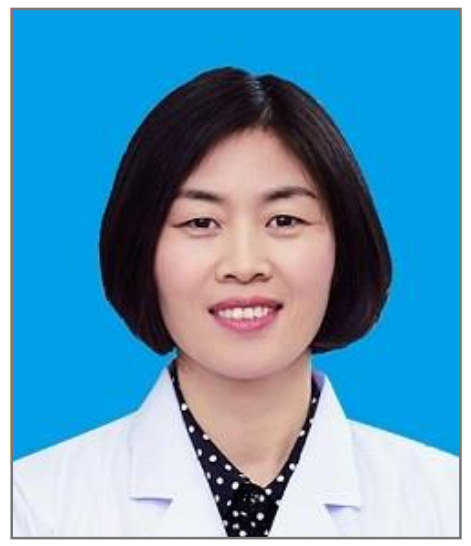

Prof. Shuli Niu, Institute of Geography and Natural Resources, Chinese Academy of Sciences, Beijing, China

Dr. Shuli Niu's research focuses on ecosystem carbon and nitrogen cycles and their coupling in response to global change. By setting up global change manipulative experiments in grasslands, her group has comprehensively studied biodiversity, community structure, and ecosystem functions in response to multiple global change factors. She has (co-) authored over 160 scientific articles that have been cited over 8500 times (data from Google Scholar). She is also in the chair board of AsiaFlux and serves as associate editor for the journals Ecology Letters, Functional Ecology, and Journal of Geophysical Research-Biogeosciences. Her keynote talk will be about the response of alpine grasslands to global change gradient.

\section{Profile IGSNRR}

Google Scholar

ResearchGate

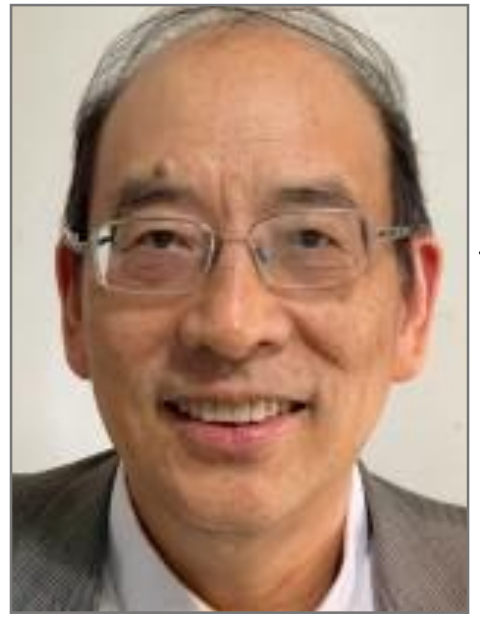

Prof. Jiang Zhigang, Institute of Zoology, Chinese Academy of Sciences, Beijing, China

Prof. Jiang's research focuses on the endangered species of wild fauna, particularly the ecology, diversity, behavior and conservation of mammals. He has authored more than 300 scientific publications and 20 books on those subjects, including: Principles of Conservation Biology, Field Methods for Nature Conservation, Principles of Animal Behavior, Methods of Species Conservation and Mammalian Diversity and Geographic Distribution in China. He is affiliated with commissions and institutes working on red lists, wildlife and endangered species conservation and national parks.

His keynote talk will focus on the wild ungulates of the grasslands in China, their status and conservation. China is the country with the most diverse ungulate species in the world (71 species, $21 \%$ endemic), of which, more than one third ( 25 species) inhabit various grassland habitats. Moreover, several are endangered and flagship species. He will explore the diversity, distribution and conservation of wild ungulates and ask the question of how to achieve conservation goals on grasslands which are increasingly used for production purposes.

Profile IOZ

Google Scholar

ResearchGate 


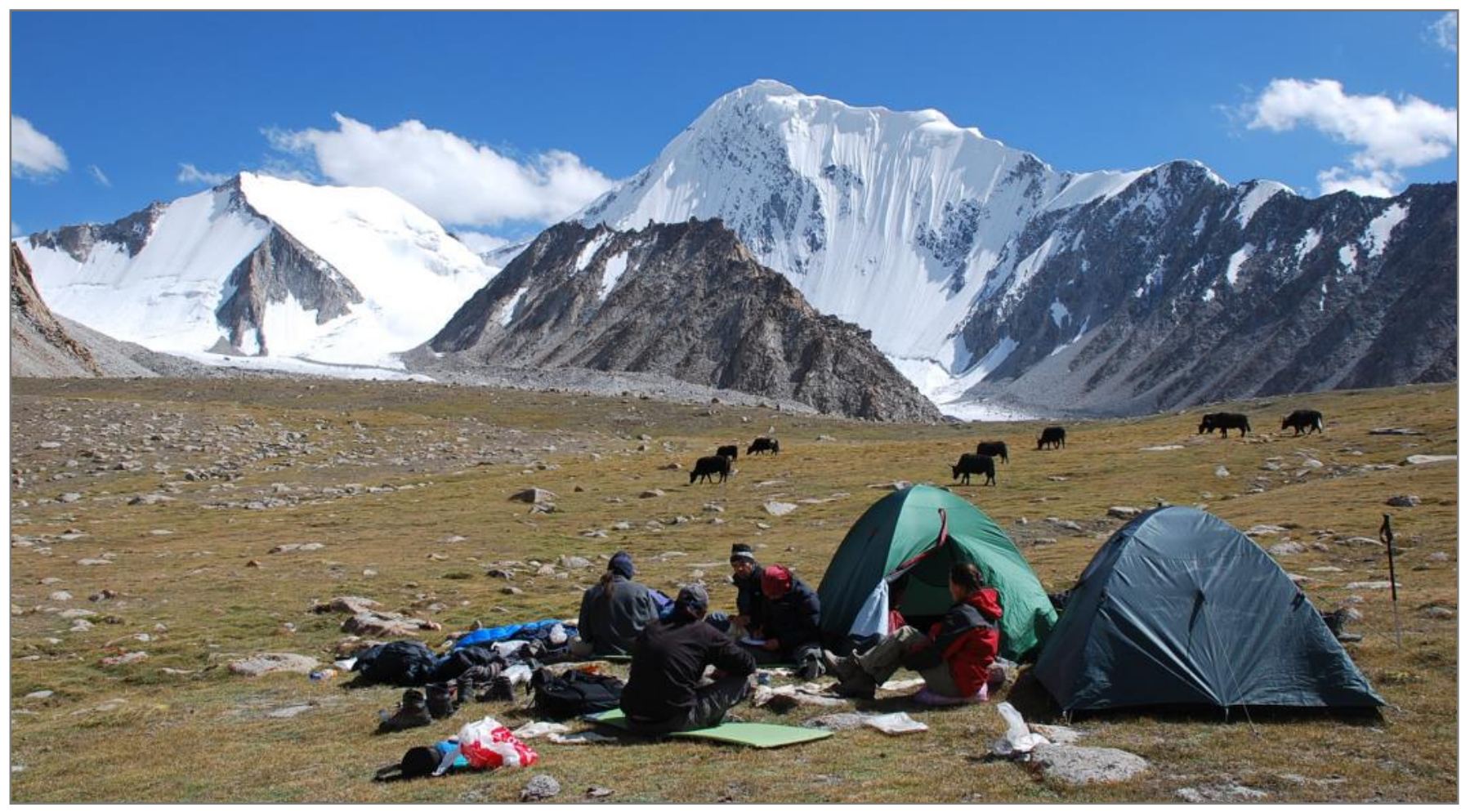

Research camp in Ladakh, Himalaya. Photo: J. Dolezal.

\section{Side events}

Apart from scientific presentations, the AGC will provide plenty of space for side events that facilitate individual exchange and networking. Below, you can find short descriptions of events already planned. Full details will be provided in the Second Call. If you would like to organise a specific side event at the AGC, please contact with the Organising Committee (see below).

During the registration, you will be able to register for these (optional) side events. This information will enable us to plan a schedule that minimizes clashes regarding the interests of registered participants. We reserve the right to cancel side-events that do not raise an adequate level of interest.

- Happy Hour: At the end of the daily sessions, the participants are invited to join a happy hour where they can interact with other participants freely and talk. For this purpose, we will offer a virtual event space where people can meet and talk. Guests will be able to find and talk to the persons they would like to contact or join to conversations in small groups.

- Introducing the Eurasian Dry Grassland Group (EDGG): For newcomers we will present our organisation with its multitude of activities, such as the Eurasian Grassland Conferences, the EDGG Field Workshops (research expeditions), our diamond open access journal Palaearctic Grasslands, our Special Features and edited books, our vegetation-plot database GrassPlot, our website and our online tool GrassPlot Diversity Explorer. This will provide a good opportunity to get into contact with the EDGG Chairs.
- Meet the Editors: This interactive event aims to bring participants and editors of journals together. The participants can ask their questions about all stages of publishing a scientific article, such as submission, evaluation criteria, language issues, or how to reply to reviewers. The participants will have the opportunity to learn more about the "kitchen" of publishing. On the podium there will be several experienced editors from a wide range of international journals:

- Jürgen Dengler (Chief Editor of Vegetation Classification and Survey, Guest Editor of Journal of Vegetation Science and Tuexenia, Editorial Board of Applied Vegetation Science)

- Péter Török (Editor of Restoration Ecology, Applied Vegetation Science, Flora and Land Degradation \& Development)

- Orsolya Valkó (Editor of Biological Conservation, speciality chief editor of Frontiers of Ecology and Evolution, Guest Editor of Hacquetia)

- Jianshuang Wu (Editor of Frontiers in Ecology and Evolution and Frontiers in Environmental Science)

- Initiation of IAVS Regional Section(s) for Asia: EDGG is an official Working Group of the International Association for Vegetation Science (IAVS; www.iavs.org). While IAVS has several well-organised Regional Sections or Working Groups for Europe, North America, Latin America and the Caribbean as well as Africa, vegetation ecologists in the largest of all continents are currently not formally organised across borders. We will discuss whether there is sense/need to establish a network for Asian vegetation ecologists within IAVS, whether one or several Regional 
Sections would make sense, what could be aims of such Regional Sections and who would like to be active within these. We intend to invite also selected vegetation ecologists from Asian countries specialised in forests, wetlands, alpine, segetal and urban habitats.

- Workshop on the long term monitoring of grassland ecosystems: The aim of this workshop is to exchange information and ideas to generate a multi-purpose regional time-series database of Asian grasslands. The participants will exchange information and ideas on identification of (i) a common goal, objectives and strategy for a standard monitoring across Asia, (ii) a network of important grasslands across the continent, (iii) previously studied grasslands that can be directly used for further monitoring, (iv) establishing a baseline towards standard guidelines and protocols for collecting baseline data for grassland monitoring in Asia.

- Workshop on the vegetation typologies in Asia and their crosswalks to/overlaps with phytosociological syntaxa: The aim of this workshop is to better understand vegetation typologies of Asia from a global point-of-view. Specifically, we would like to harmonize Asian typologies with that of GrassPlot, an EDGG-associated database of multi-scale vegetation-plot data of Palaearctic grasslands and other open habitats. All the vegetation plots incorporated in the GrassPlot database are assigned to a vegetation typology, which include 22 vegetation types grouped into six coarse units (see Appendix S2 in Biurrun et al. 2021). While this two-level classification, along with its syntaxonomic crosswalk, is reasonably tested for Europe, many "grey" and undefined zones remain for the Asian continent, both on the side of the GrassPlot classification and on the side of the syntaxonomic classification. Any contribution about the phytosociological classification of grasslands and other open habitats from any part of the Asian continent, as well as any critical review of the so far applied GrassPlot typological classification are highly welcome to this workshop. If successful, a publication could arise from such a workshop.

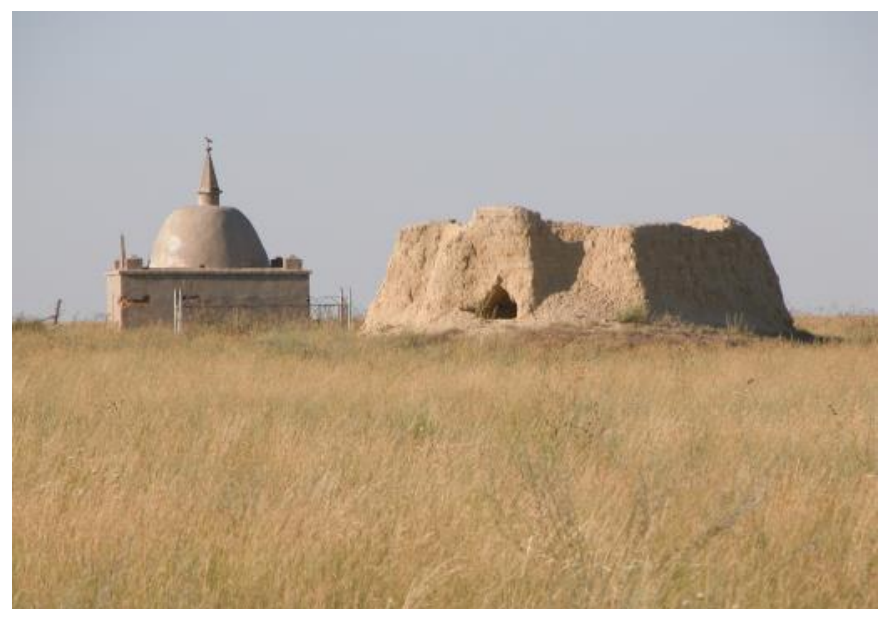

Historical heritage near Altyn Dala (Golden Steppe). Kostanay region, Kazakhstan. Photo: T.M. Bragina.

- Young Investigator Competition: The aim is to award young scientists for an excellent presentation of their research. Young scientists (less than 30 years old) will be asked during registration if they wish to participate in the contest. During her/his presentation, the applicant needs to explain clearly her/his contribution to the presented work.

- Asian Grassland Photo and Video Competition: This event aims to present the beauty and diversity of grasslands in Asia, where scientists can challenge each other with photographic and video contributions. A jury will select the best contributions, which will be presented in the concluding session of the AGC, on the EDGG website and in the subsequent issue of Palaearctic Grasslands.

- Notice board: We are planning to set up a notice board where participants can share their announcements (including job posts, events etc.) with all participants. All announcements will be collected in advance after the Second Call.

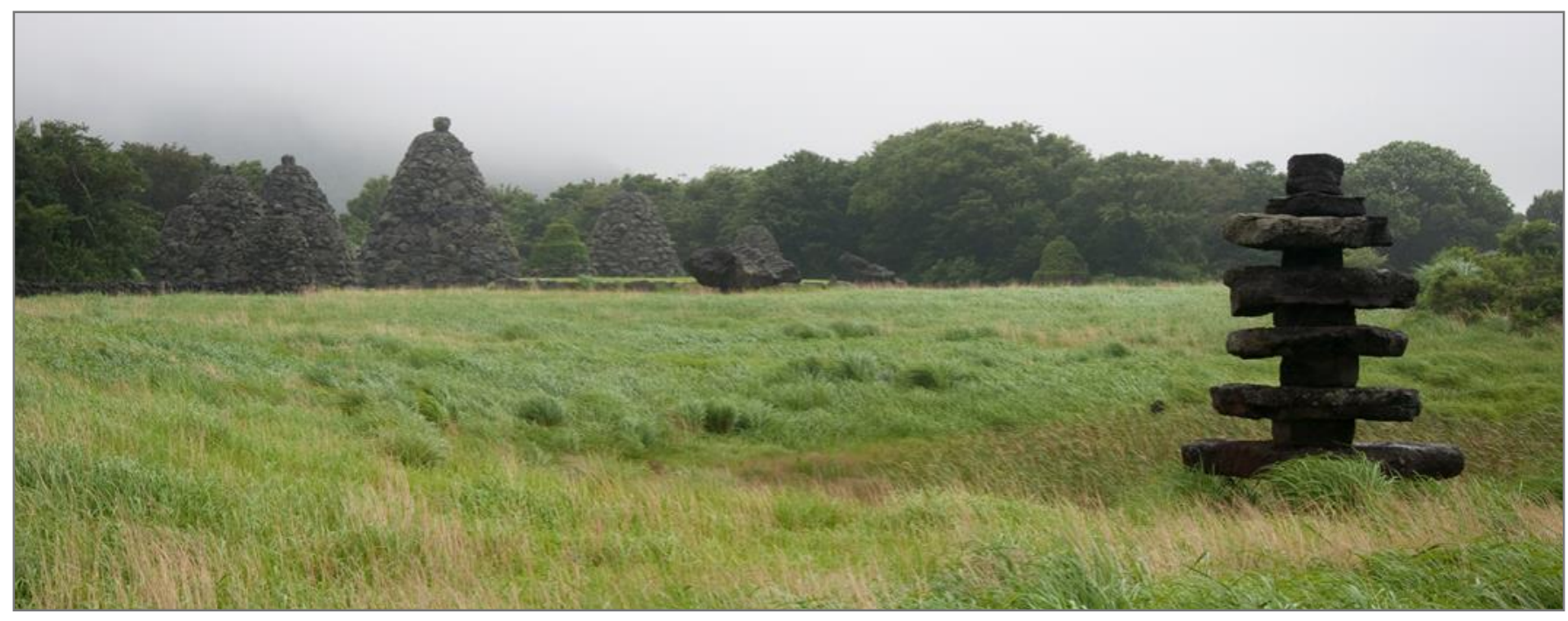




\section{Special Features}

EDGG regularly publishes Special Features (SF) in international journals on topics related to ecology, biodiversity, classification, conservation and management of Palaearctic grasslands. Publishing in EDGG Special Features typically comes with significant visibility and therefore our Special Feature articles on average receive more citations than "normal" articles in the respective journal. Therefore, we are planning to organize three SFs to give the participants the opportunity to make their research more visible in a topical SF. Depending on the subject and quality of their presentation, participants will be able to choose from three SFs in international, peer-reviewed journals :

- High-level journal (Biodiversity and Conservation under consideration) (Chair of Guest Editors: Didem Ambarlı): For the outstanding contributions of the AGC.

- Hacquetia (approved; Chair of Guest Editors: Orsolya Valkó): For good contributions that are not outstanding enough for a leading international journal.

- Vegetation Classification and Survey (approved; Guest Editors: Jürgen Dengler, Arkadiusz Nowak \& Alireza Naqinezhad): For any paper that deals with the development or application of a classification system of Asian grasslands.

\section{Registration and costs}

The registration and abstract submission will be launched in autumn 2021 with the Second Call. The registration and all side events will be free of charge to ensure maximum participation without financial barriers. Participants can preregister by sending their name, e-mail address and affiliation to edgg.agc@gmail.com. We will save the contact information and contact you via an e-mail once the registration is open.

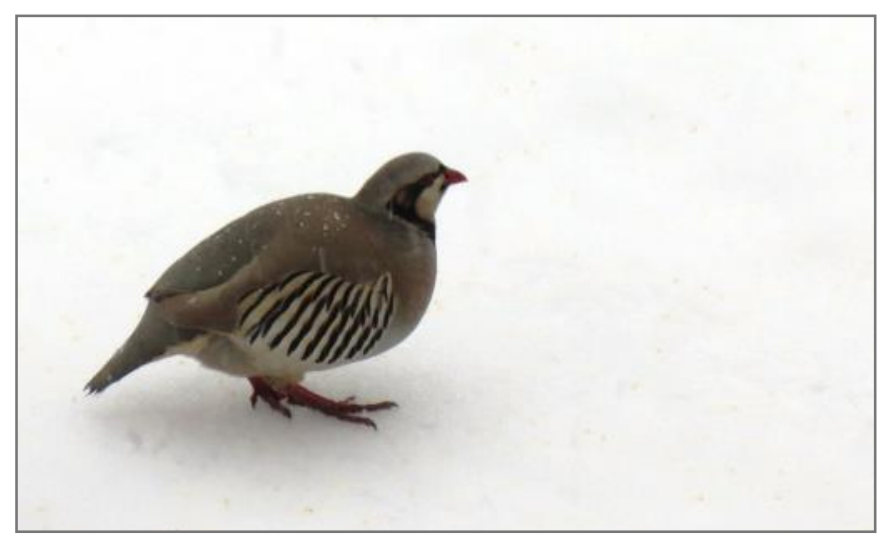

Chukar Partridge (Alectoris chukar) on snow, Turkey. Photo: D. Ambarlı.

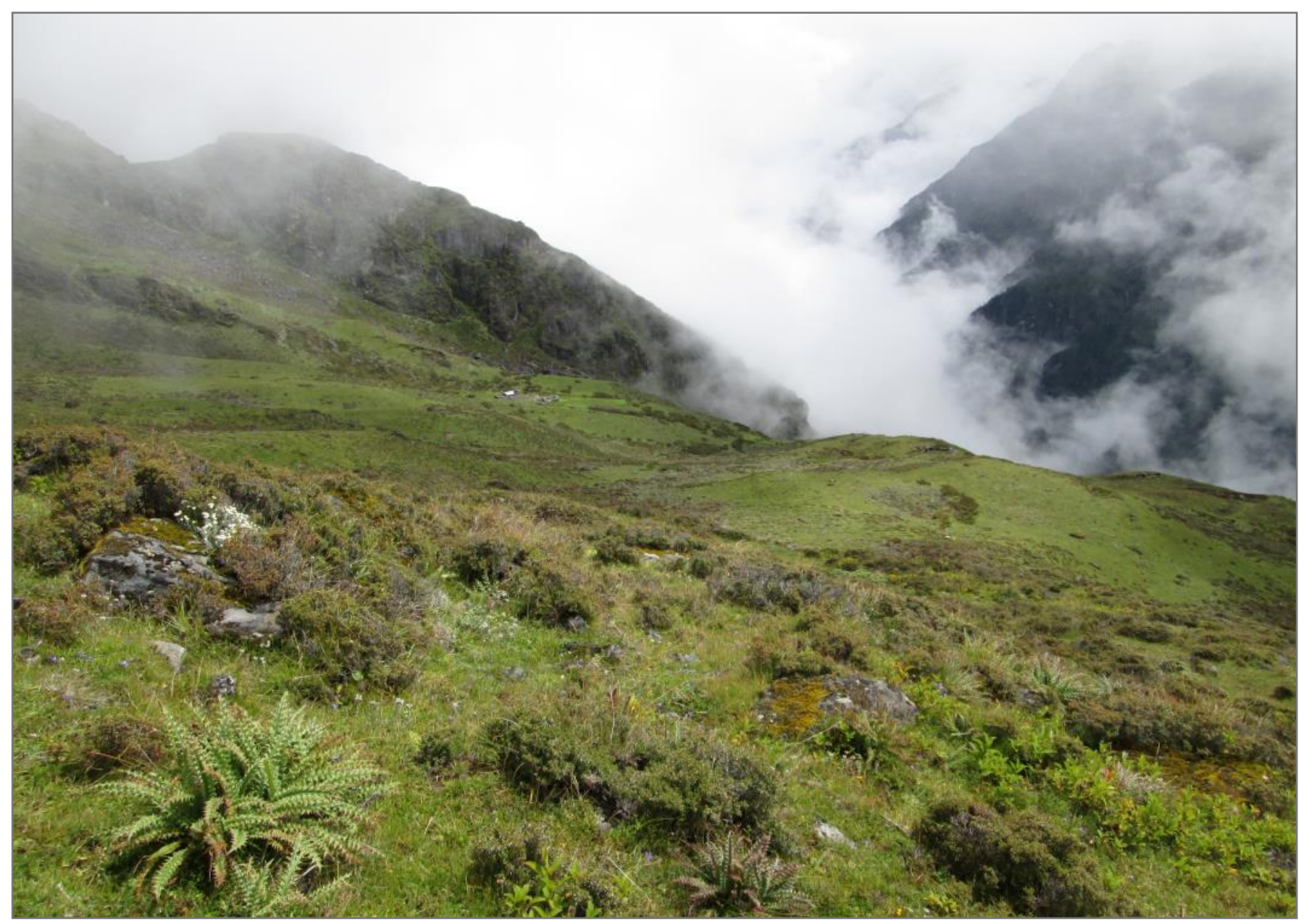




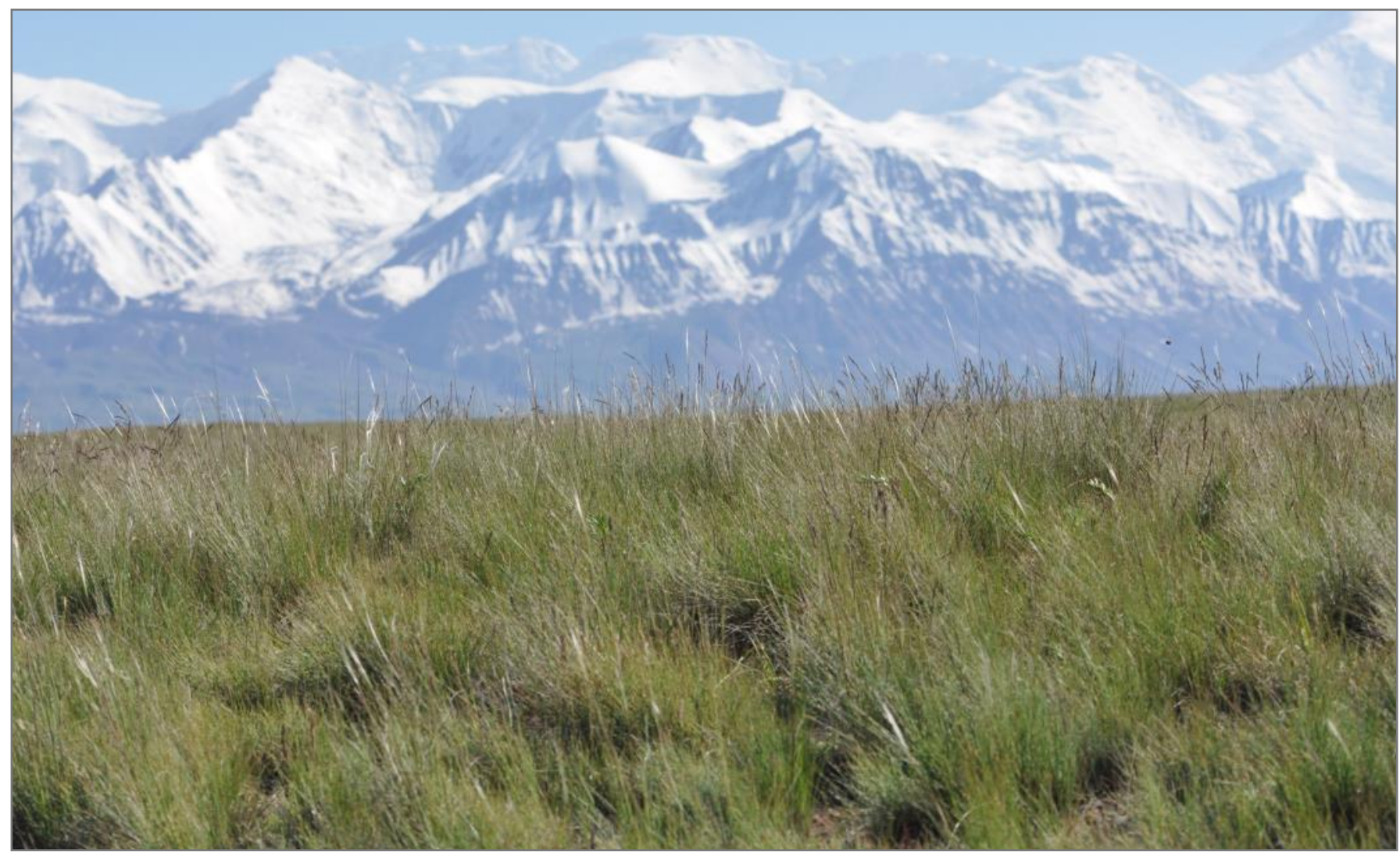

Littledaleo alaicae-Stipetum trichoidis in the Allay valley, Kyrgyzistan. Photo A. Nowak.

\section{Scientific Committee}

Alla Aleksanyan, Institute of Botany after A.L. Takhtajyan NAS RA, Yerevan, Armenia

Didem Ambarlı, Düzce University, Turkey

Kuber Bhatta, University of Bergen, Norway

Idoia Biurrun, University of the Basque Country UPV/EHU, Bilbao, Spain

Tatyana M. Bragina, Kostanay Regional University named after A. Baitursynov, Kazakhstan

Elena Bykova, Academy of Sciences of the Republic of Uzbekistan, Tashkent, Uzbekistan

Iwona Dembicz, University of Warsaw, Poland

Jürgen Dengler, Zurich University of Applied Sciences (ZHAW), Wädenswil, Switzerland

Jiri Dolezal, Czech Academy of Sciences, Prague, Czech Republic

Choimaa Dulamsuren, University of Freiburg, Germany

Riccardo Guarino, University of Palermo, Italy

Monika Janisova, Slovak Akademy of Sciences, Banská Bystrica, Slovakia

Anna Kuzemko, National Academy of Sciences of Ukraine, Kyiv, Ukraine
Rocco Labadessa, National Research Council (CNR), Bari, Italy

Frank Yonghong Li, Inner Mongolia University, Hohhot, China

Diqiang Li, Chinese Academy of Forestry, Beijing, China

Alireza Naqinezhad, University of Mazandaran, Bābolsar, Iran

Arkadiusz Nowak, Polish Academy of Sciences Botanical Garden, Opole, Poland

Ilya Smelansky, Siberian Environmental Center, Novosibirsk, Russia

Marcelo Sternberg, Tel Aviv University, Israel

Péter Török, University of Debrecen, Hungary

Atushi Ushimaru, Kobe University, Japan

Orsolya Valkó, Centre for Ecological Research, Vácrátót, Hungary

Steven Venn, University of Helsinki, Finland

Karsten Wesche, Senckenberg Museum of Natural History Görlitz, Germany

Jianshuang $\mathbf{W u}$, Chinese Academy of Agricultural Sciences, Beijing, China 

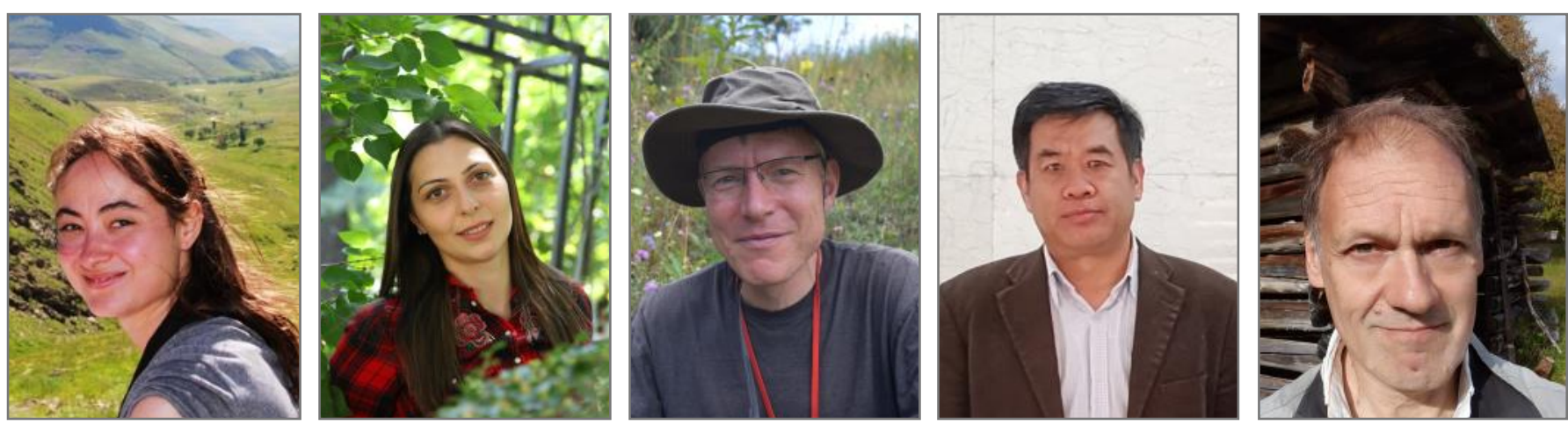

\section{Organizing Committee}

For any questions, suggestions and requests, please contact the Organizing Committee:

Didem Ambarlı (Chair), Düzce University, Turkey, didem.ambarli@gmail.com

Alla Aleksanyan, Institute of Botany after A.L. Takhtajyan NAS RA, Yerevan, Armenia, alla.alexanyan@gmail.com

Jürgen Dengler, Zurich University of Applied Sciences (ZHAW), Wädenswil, Switzerland, dr.juergen.dengler@gmail.com

Frank Yonghong Li, Inner Mongolia University, Hohhot, China, lifyhong@126.com

Stephen Venn, University of Helsinki, Finland, stephen.venn@helsinki.fi

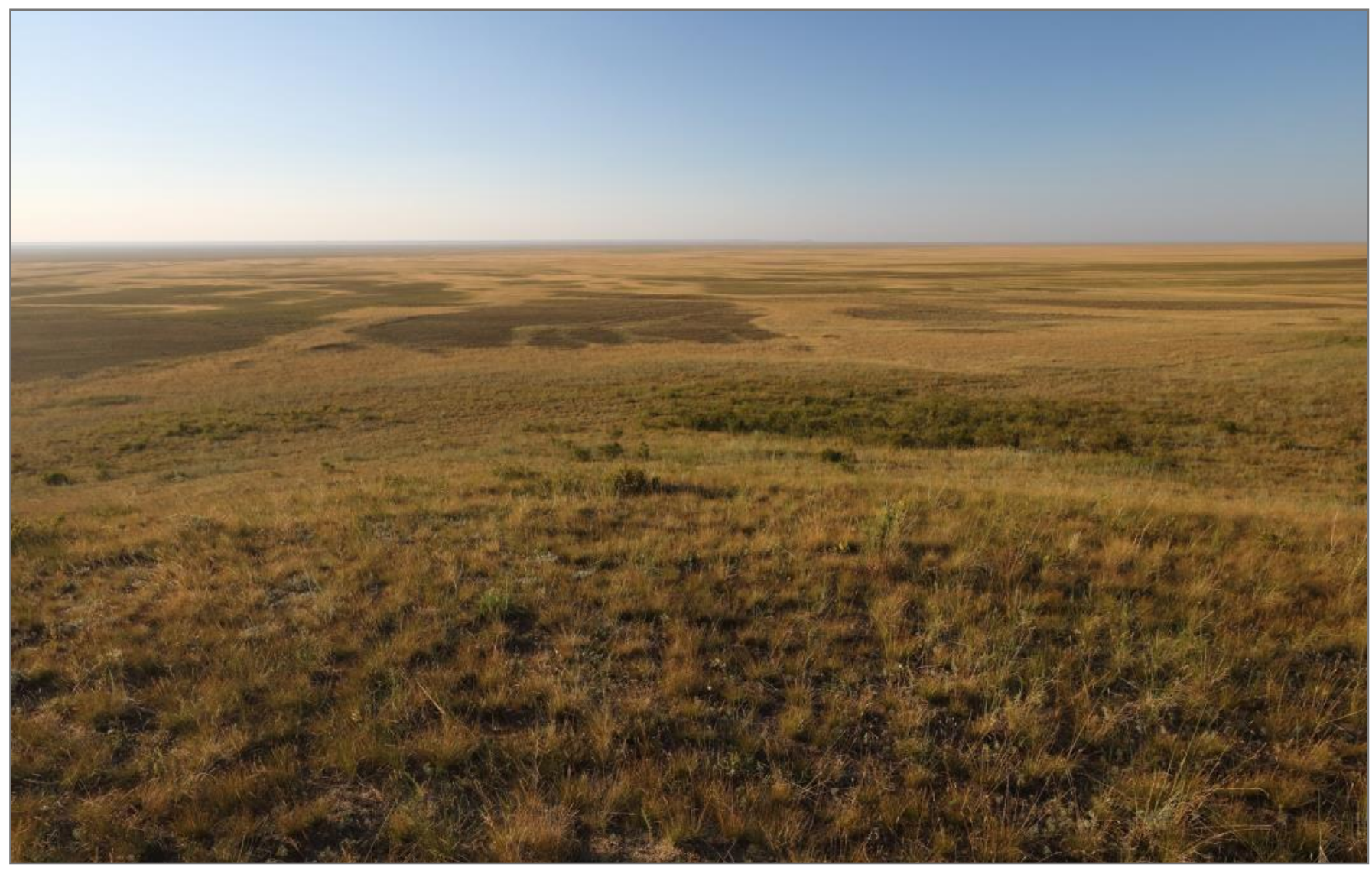

Turgay Steppe, Kazakhstan. Photo: B. Deák. 


\section{EDGG Publication}

\section{Grassland book now as paperback}

In 2018, EDGG co-edited "Grasslands of the world" (Squires et al. 2018), containing a major section on "Grasslands of the Palaearctic Region". This section consists of one synthesising chapter (Török \& Dengler 2020) and seven regional chapters, covering nearly the complete Palaearctic biogeographic realm. In these chapters, leading EDGG experts introduce the grasslands of their region in a comprehensive and consistent manner. That way this book has become a major source of reference (see review by Biurrun 2019). Unfortunately, the hardcopy of the book is quite expensive (173.34 US \$ at Amazon), preventing its wider distribution. Luckily, now a paperback version has been released, which costs far less (59.47 US $\$$ at Amazon). There is also an ebook (Kindle; 42.95 US $\$$ at Amazon). We hope that these two less expensive options will contribute to a wider distribution of our work.

\section{References}

Biurrun, I. 2019. Book Review. Squires, V.R., Dengler, J., Feng, H. \& Hua, L. (eds.) Grasslands of the World. Diversity, Management and Conservation. CRC Press, Boca Raton. Palaeartic Grasslands 42: 28-29.

Squires, V.R., Dengler, J., Feng, H. \& Hua, L. (eds.) 2018. Grasslands of the world: diversity, management and conservation. CRC Press, Boca Raton, US

Török, P. \& Dengler, J. 2018. Palaearctic grasslands in transition: overarching patterns and future prospects. In: Squires, V.R., Dengler, J., Feng, H. \& Hua, L. (eds.) Grasslands of the world: diversity, management and conservation, pp. 15-26. CRC Press, Boca Raton, US.

Jürgen Dengler, Switzerland dr.juergen.dengler@gmail.com
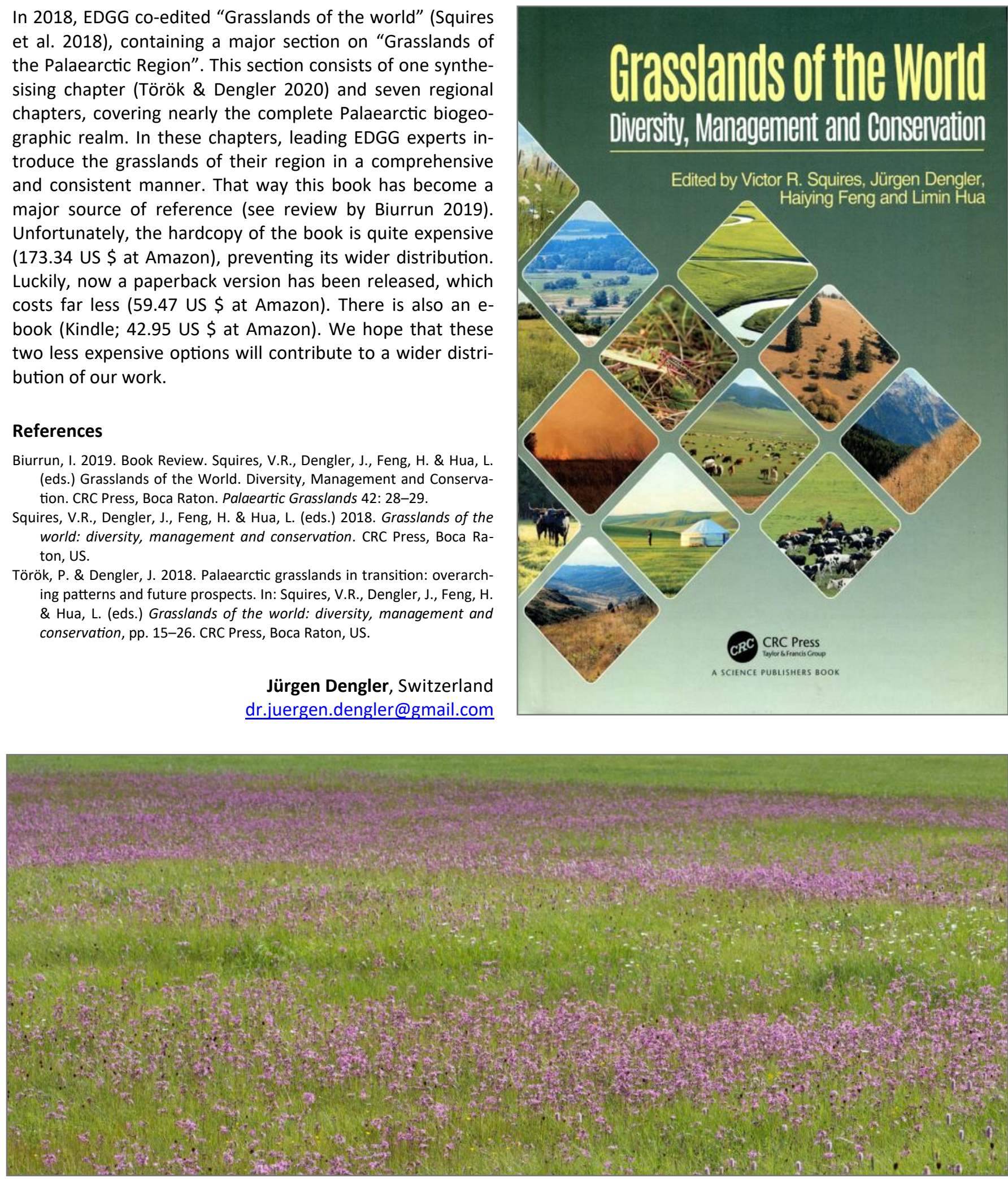


\title{
Photo Story
}

\section{"Sinozhati" - the sacred place of Pokuttya (Western Ukraine) as a center of meadow-steppe diversity preservation}

\author{
Photos and text by Vasyl Budzhak ${ }^{1}$, Illia Chorney ${ }^{1}$, Alla Tokariuk $^{1}$ \& Anna Kuzemko ${ }^{2}$
} ${ }^{1}$ Yuriy Fedkovych Chernivtsi National University, Yuriy Fedkovych str., 11,
58022, Chernivtsi, Ukraine; e-mails: V. Budzhak: $\underline{\text { budzhakv@gmail.com, I. }}$
Chorney: iichorney@ukr.net, Alla Tokariuk: a.tokaryuk@chnu.edu.ua

Between the rivers Prut and Cheremosh lie the lands of Pokuttya, a historical region of Western Ukraine with a unique landscape and natural conditions. Not far $(20 \mathrm{~km}$ to the east) from Kolomyia (cultural center of Pokuttya, distric center of the Ivano-Frankivsk oblast), hides the small village Stary Hvizdets, surrounded by oak and hornbeam forest. The first settlements in this area appeared in the Bronze Age, as evidenced by two mounds on its northern outskirts. The first written mention of Hvizdets dates us back to 15 December, 1373. Stary Hvizdets is located on the northeastern macroslope of the Hvizdets-Turkivska ridge between the sources of the unnamed right tributary of the Chornyava River (left tributary of the Prut River). The relief of this territory is ridge-ravine of erosion-tectonic genesis. Height range from $295 \mathrm{~m}$ a. s. I. at the bottom of the valley of the nameless stream, up to $335 \mathrm{~m}$ a. s. I. on the tops of erosive remains. The soil spectrum includes varieties of dark gray, podzolic chernozems, meadow chernozems, in some areas and meadow-swamp soils in the bottoms of valleys. The climate is moderately cold with significant average annual precipitation $(728 \mathrm{~mm}$ ). Human economic activity significantly changed the surrounding landscape, most of which were plowed, and centuries-old oaks were cut down. But on the northern outskirts of the village there is a unique place, shrouded in legends and beliefs of local people Manychivsky Forest and Sinozhati.

\footnotetext{
${ }^{2}$ M.G. Kholodny Institute of Botany of the National Academy of Sciences of Ukraine, Tereshchenkivska str., 2, 01601, Kyiv, Ukraine; e-mail: anyameadow.ak@gmail.com
}

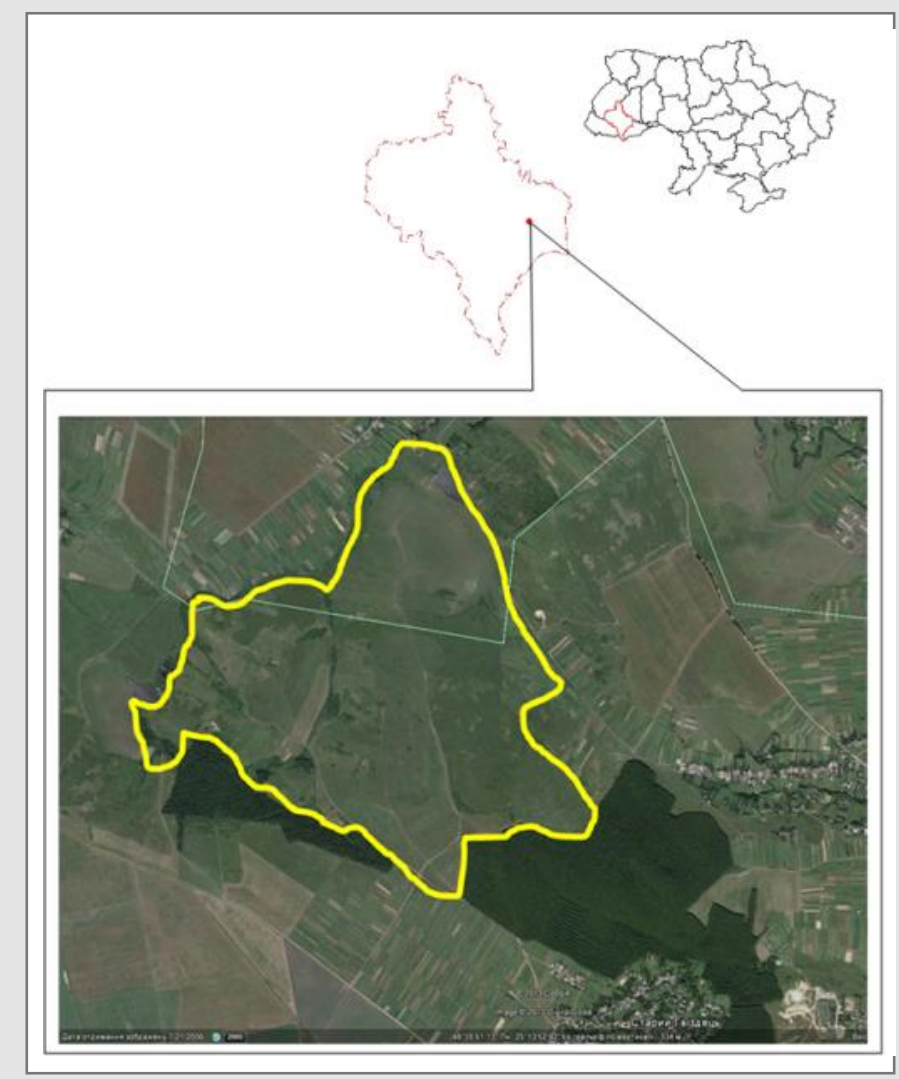

Location of the Sinozhati site.

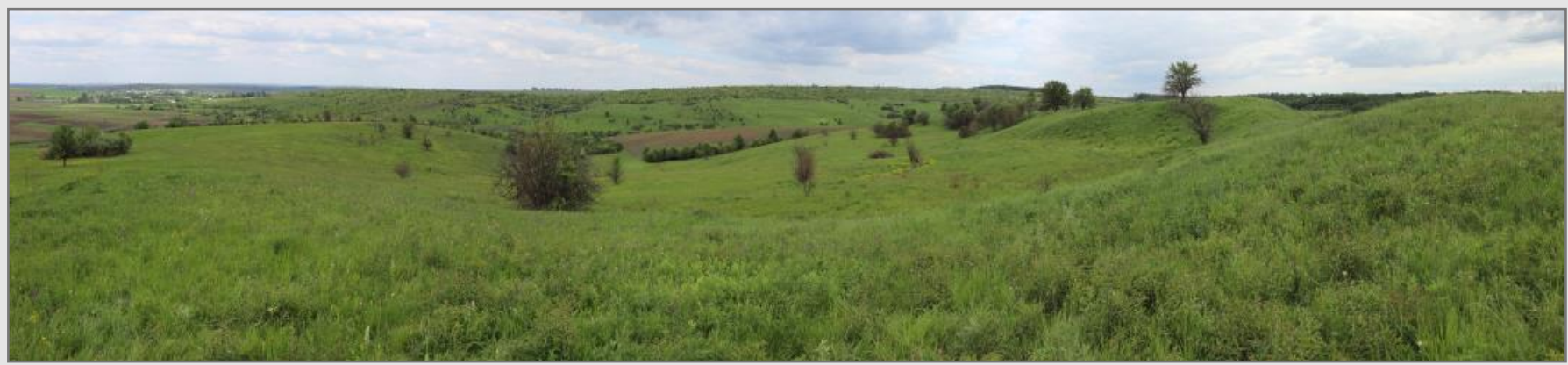

General view of the Sinozhati site. Photo: V. Budzhak. 


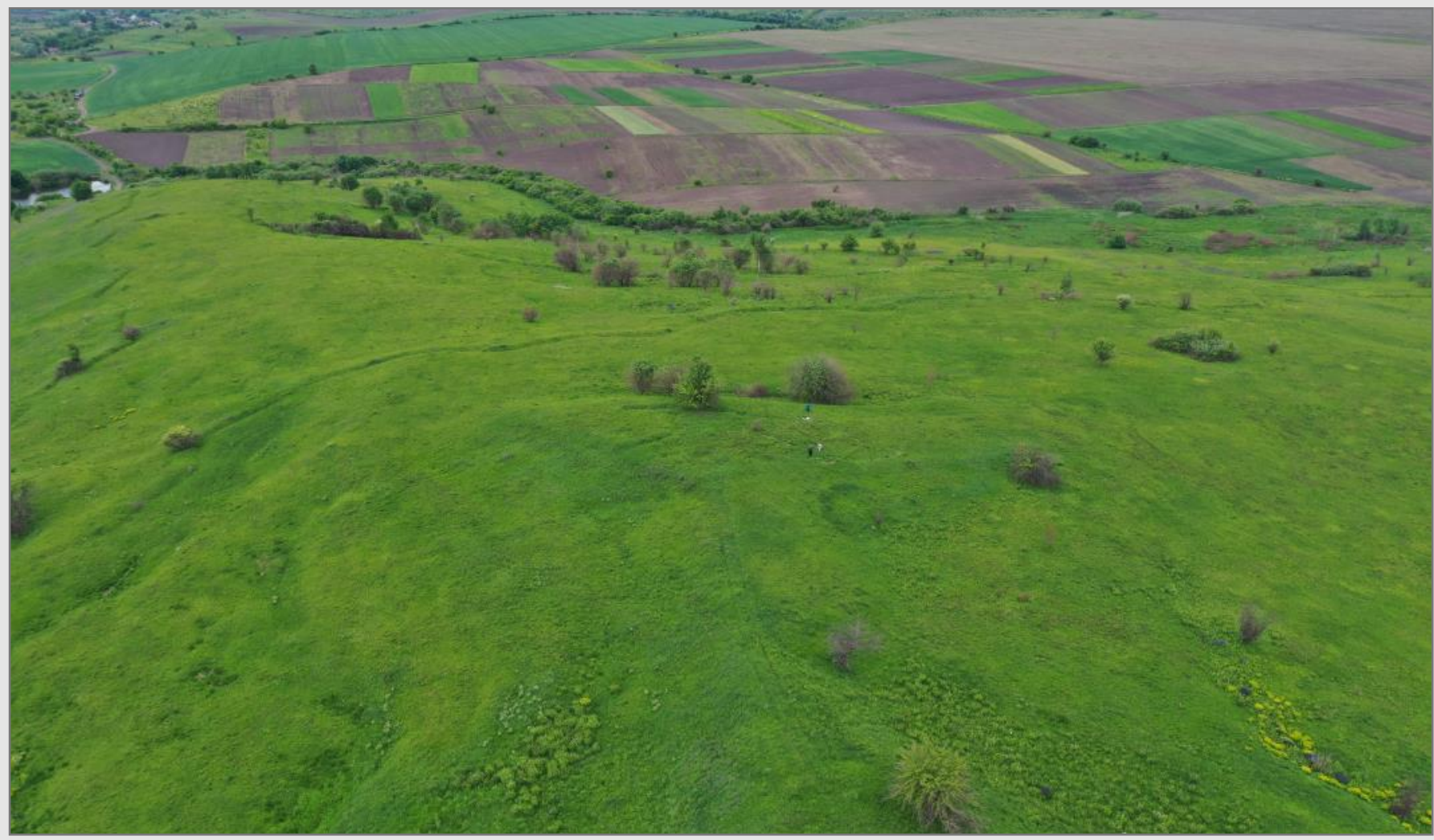

Bird's eye view of Sinozhati. Photo: V. Budzhak.

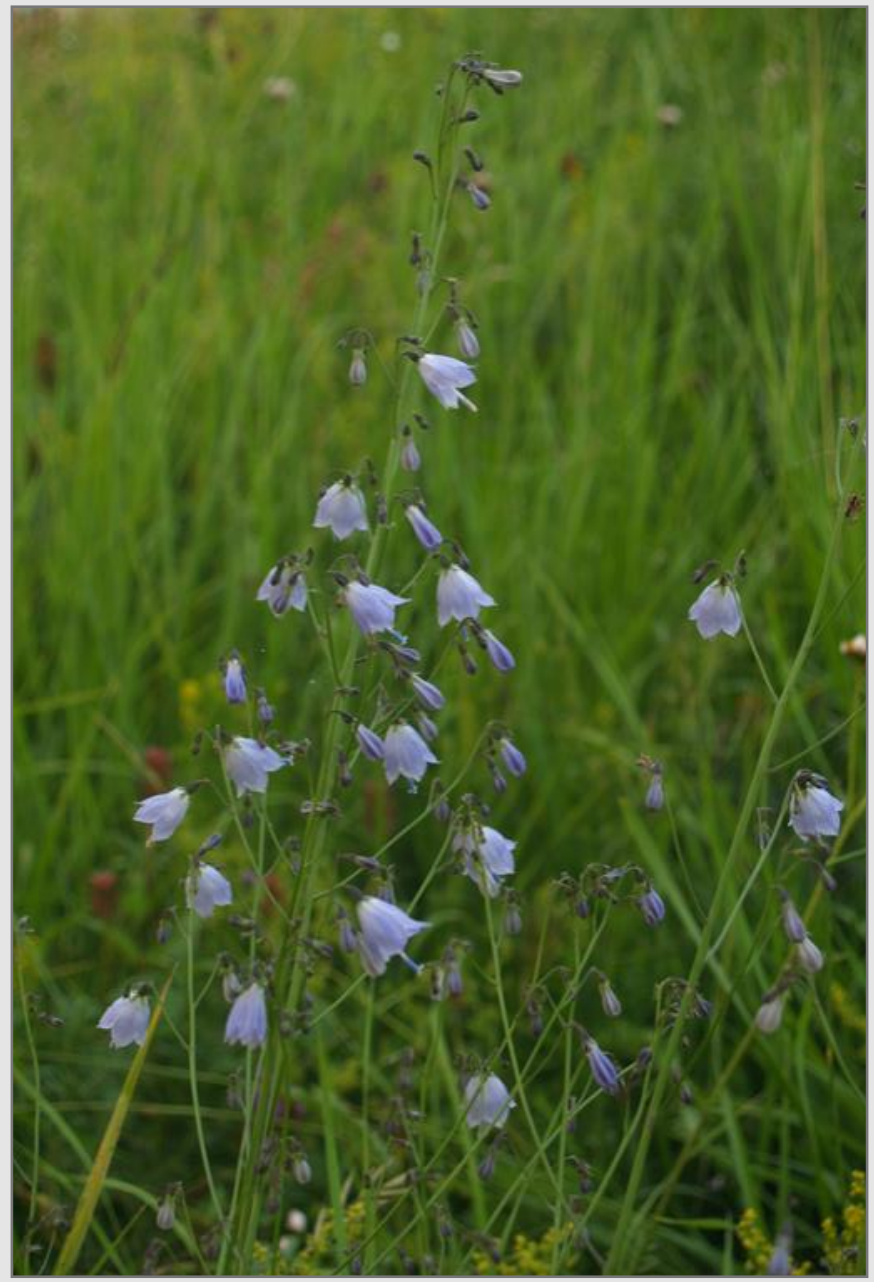

Adenophora lilifolia. Photo: V. Budzhak.
The forest really looks mysterious and unfriendly, as if enticing in its coolness, but as the ancients of these places say "will absorb and will not let go back." The colorful, friendly grasslands filled with the aroma of honey look completely different. In the middle of this massif, on the highest site (most likely the remains of a former settlement), there is an old, half-decayed cross, and none of the locals remember why it was placed there. These places become especially mysterious in July, when locals celebrate the feast Ivana Kupala (John the Baptist) and local healers go there for healing herbs. It is these meadows, which have survived thanks to the locals and have long been used exclusively as hayfields, and have attracted our attention because they have escaped the attention of Polish researchers of the 20th century. They were also not known by modern botanists until recently.

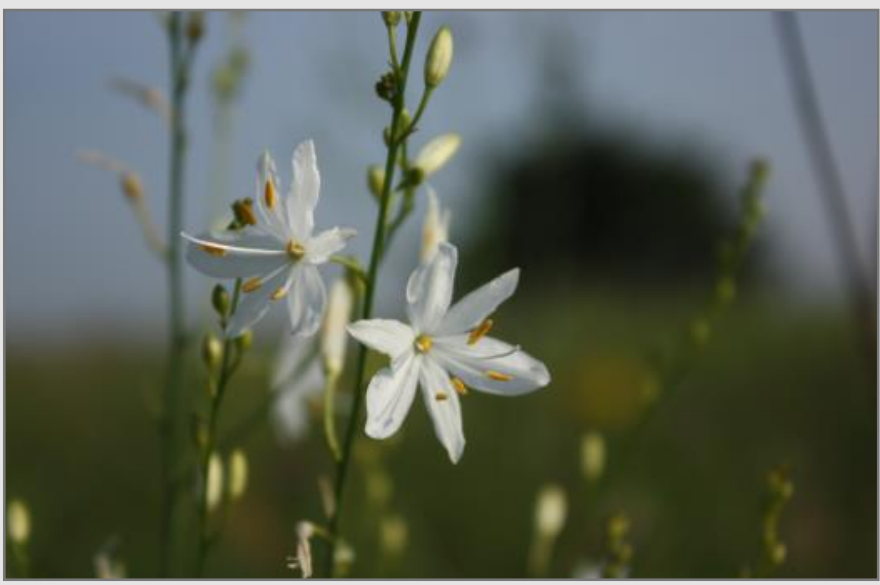

Anthericum ramosum. Photo: A. Kuzemko. 
The first expedition of professional botanists to this area was in 2015 and caused a real "botanical" shock - 19 species from the Red Book of Ukraine were revealed in a small area (70.54 hectares): Colchicum autumnale, Gladiolus imbricatus, Iris sibirica, Fritillaria meleagris, Lilium martagon, Cytisus albus, Adonis vernalis, Pulsatilla vulgaris subsp. grandis, P. patens, Anacamptis morio, Dactylorhiza incarnata, Gymnadenia conopsea, Neotinea ustulata, Neottia ovata, Platanthera bifolia, Traunsteinera globosa, Stipa capillata, S. pulcherrima. S. tirsa as well as five species from Annex I of the Resolution 6 of the Bern Convention: Echium russicum, Iris aphylla subsp. hungarica, Pulsatilla vulgaris subsp. grandis, P. patens, Adenophora lilifolia, and Klasea lycopifolia.

On the territory of the "Sinozhati" site large areas are occupied by habitat type included in Annex I of the Habitat Directive: 6210 Semi-natural dry grasslands and scrubland facies on calcareous substrates (Festuco-Brometalia) (*important orchid sites) and to Resolution 4 of the Bern

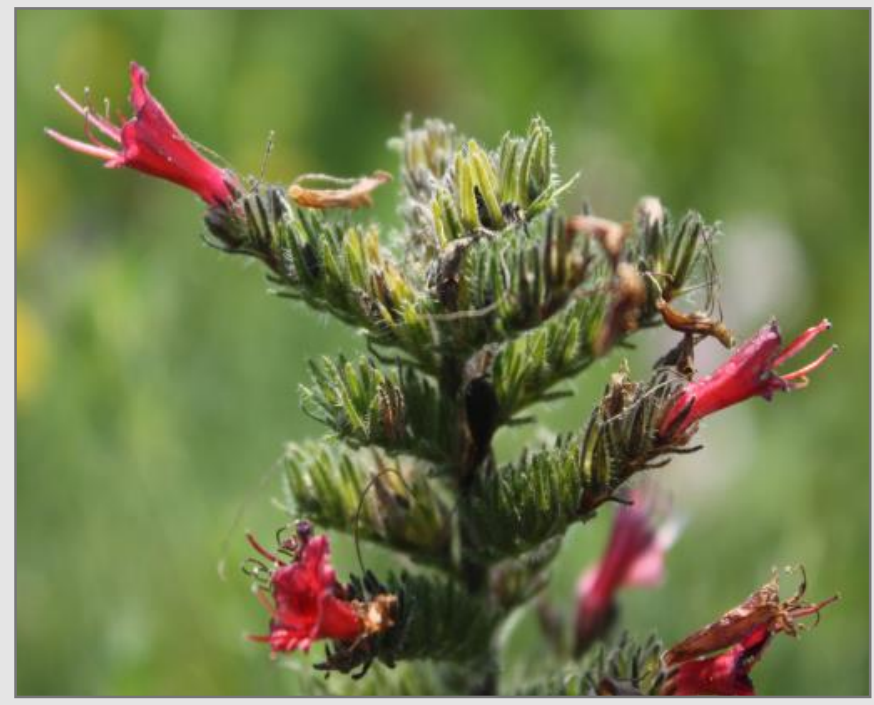

Echium russicum. Photo: A. Kuzemko.

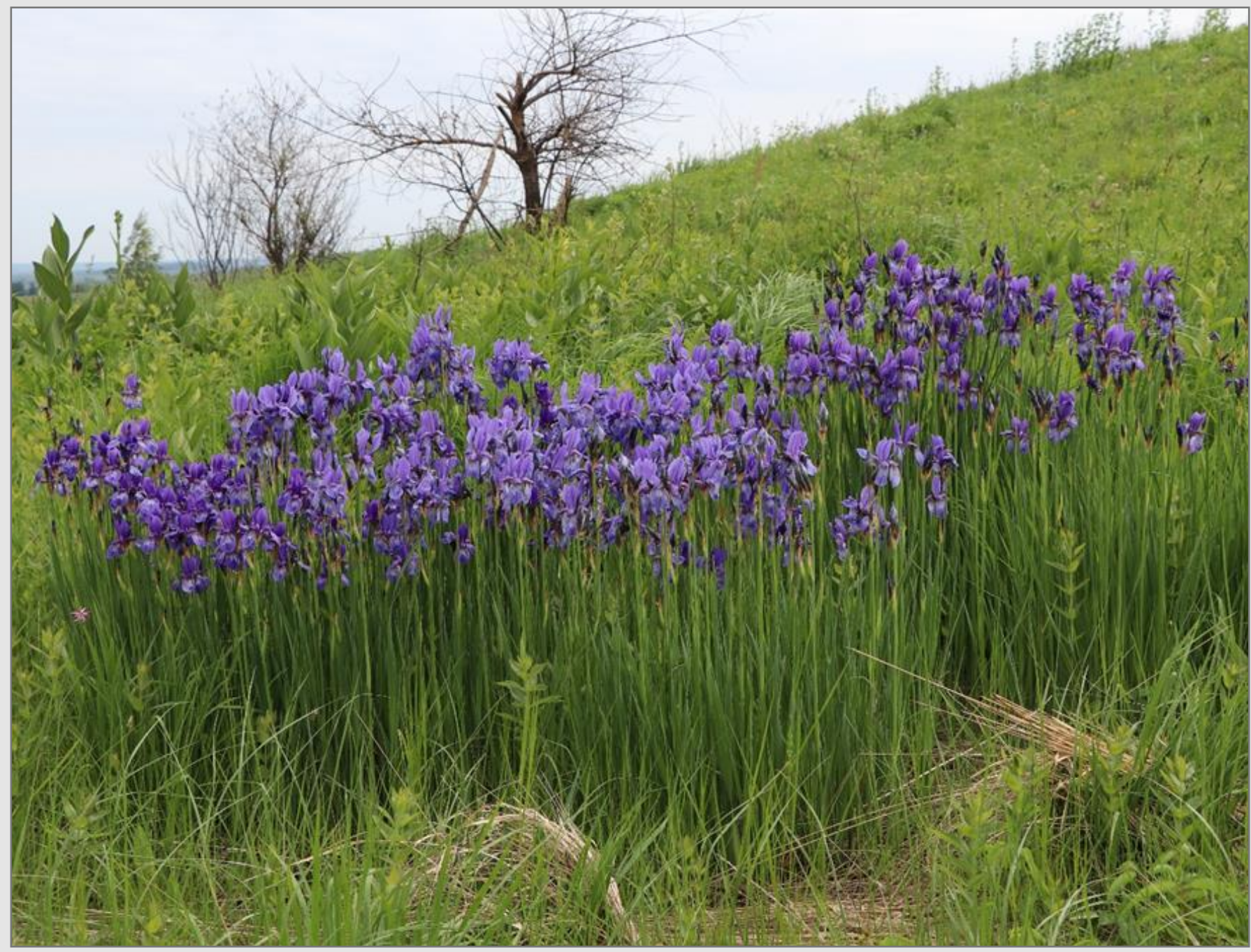

Clones of Iris sibirica in relief depressions. Photo: V. Budzhak. 


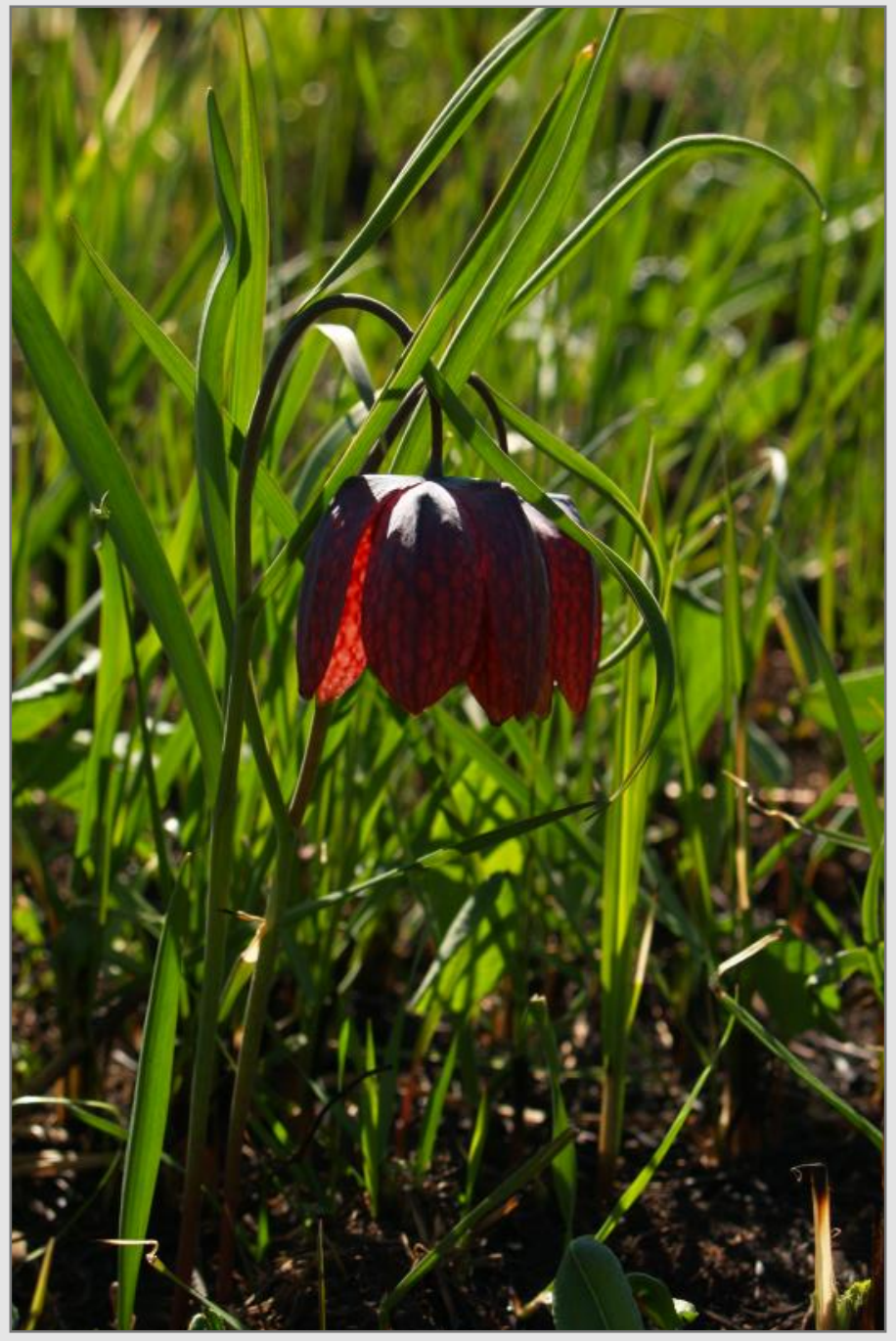

Fritillaria meleagris. Photo: V. Budzhak.
Convention: E1.2 Perennial calcareous grassland and basic steppes.

In 2019, the authors of this story prepared proposals for the inclusion of this area in the Emerald network and in 2020 the site was designated as UA0000361 - Sinozhati.

The meadow-steppe communities of the Sinozhati were studied within the project entitled "Carpathian grasslands - a genuine celebration of cultural and biological diversity" lead by Monika Janišová (National Geographic Grant NGS-288R-18). In 2021, a permanent monitoring plot was established at the site within the project entitled "Grassland habitats of Ukraine of pan-European importance: current status, losses and conservation strategy in the context of global climate change and anthropogenic transformation of the environment" (supported by National Research Foundation of Ukraine, project № 2020.01 / 0140).

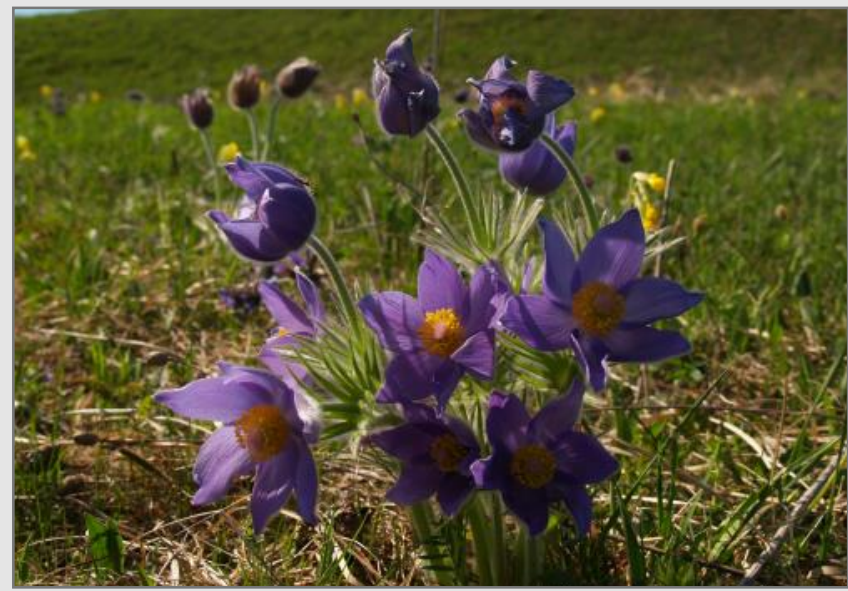

Pulsatilla vulgaris subsp. grandis. Photo: V. Budzhak.

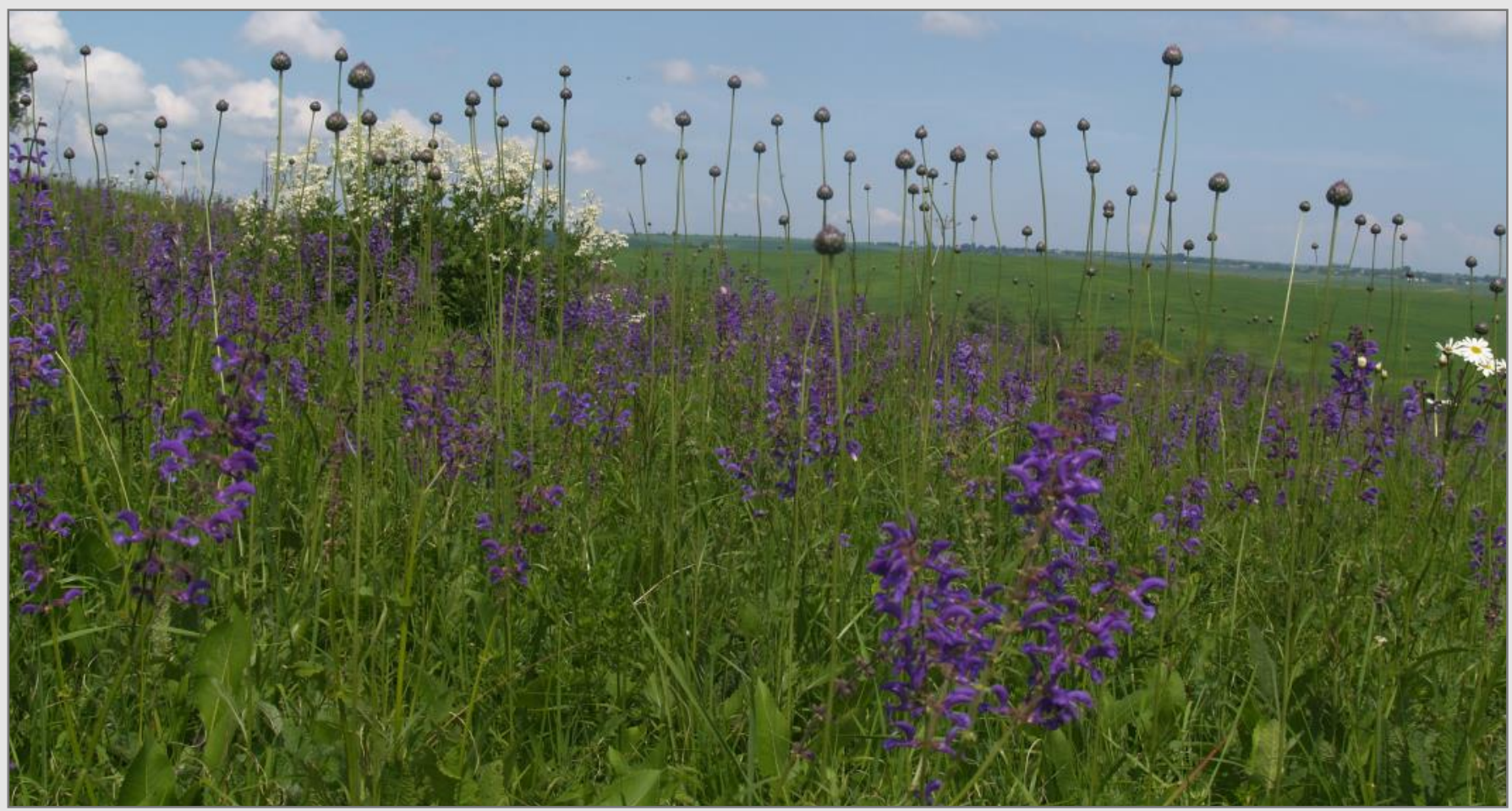




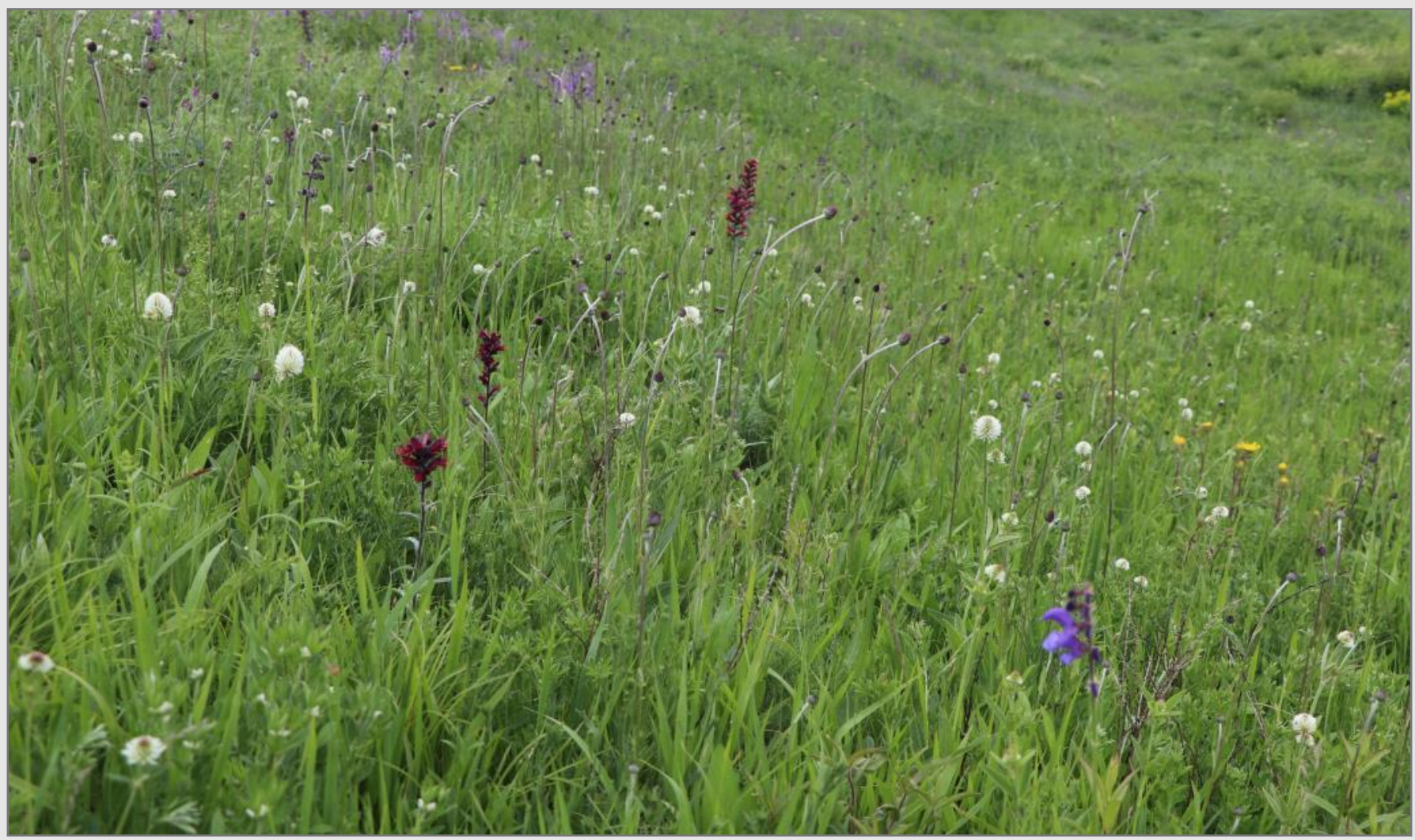

Semi-dry grassland. Photo: V. Budzhak.

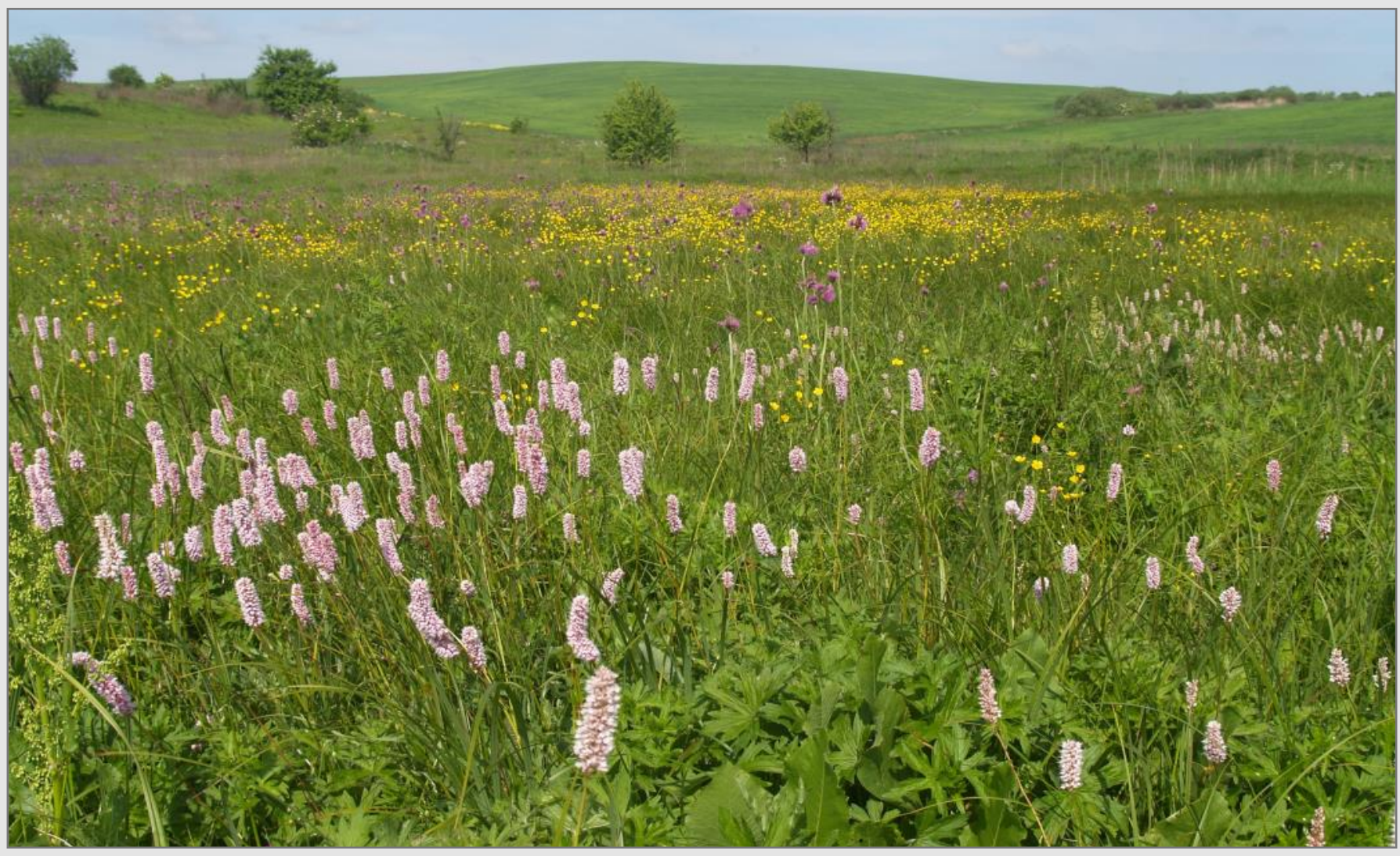

Wet grassland. Photo: A. Tokariuk. 

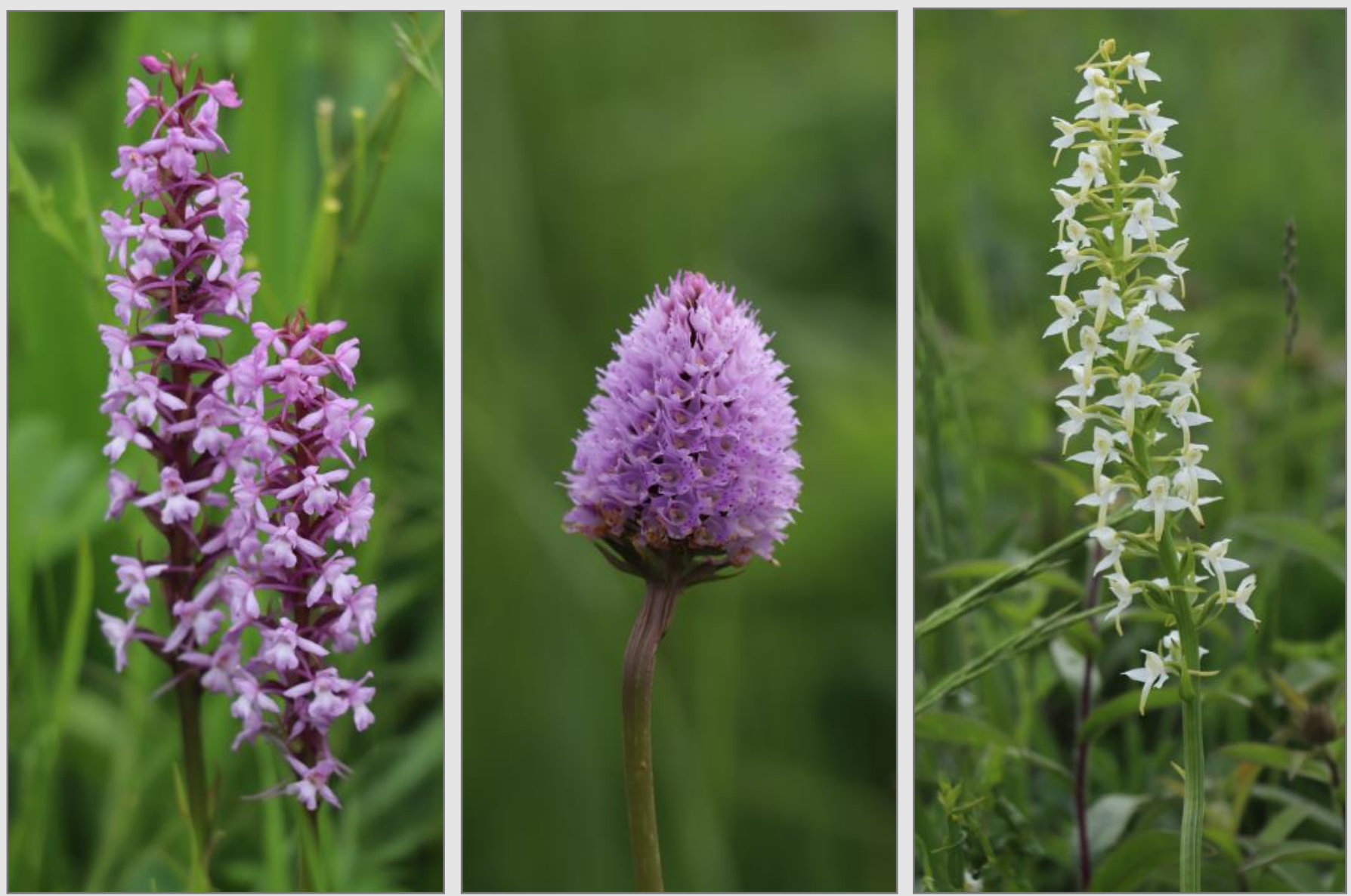

Gymnadenia conopsea, Traunsteinera globosa and Platanthera bifolia. Photos: V. Budzhak.
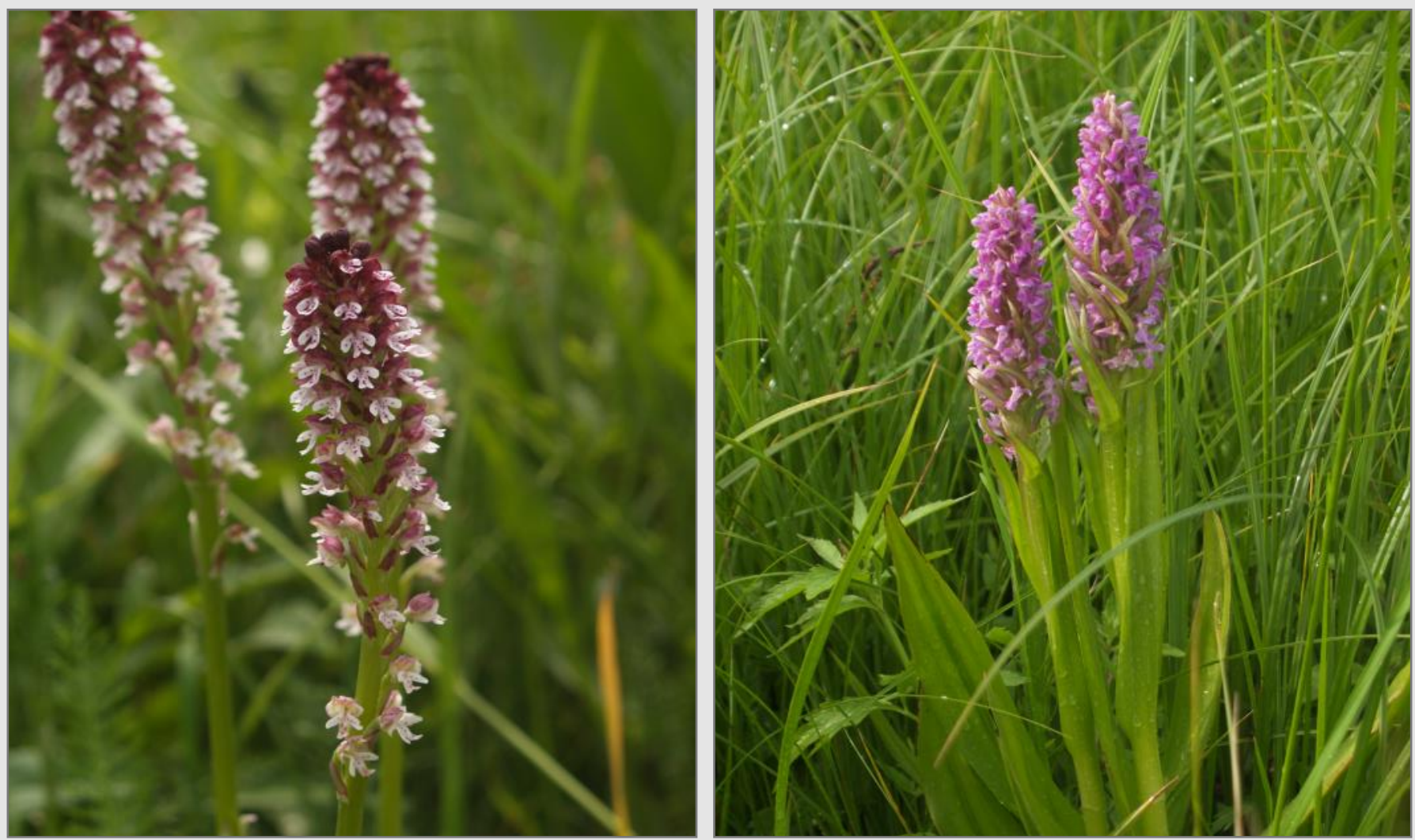

Neotinea ustulata and Dactylorhiza incarnata. Photo: A. Tokariuk. 


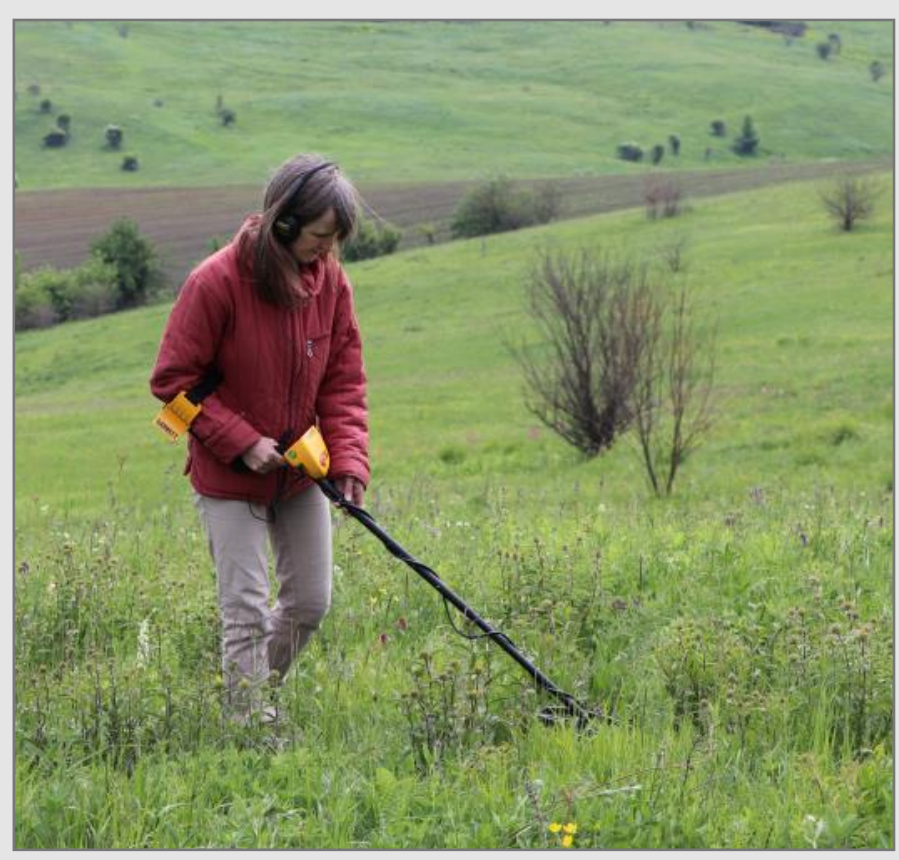

Alla Tokaryuk in search of markers from the permanent plot during 2018. Photo: I. Chorney.

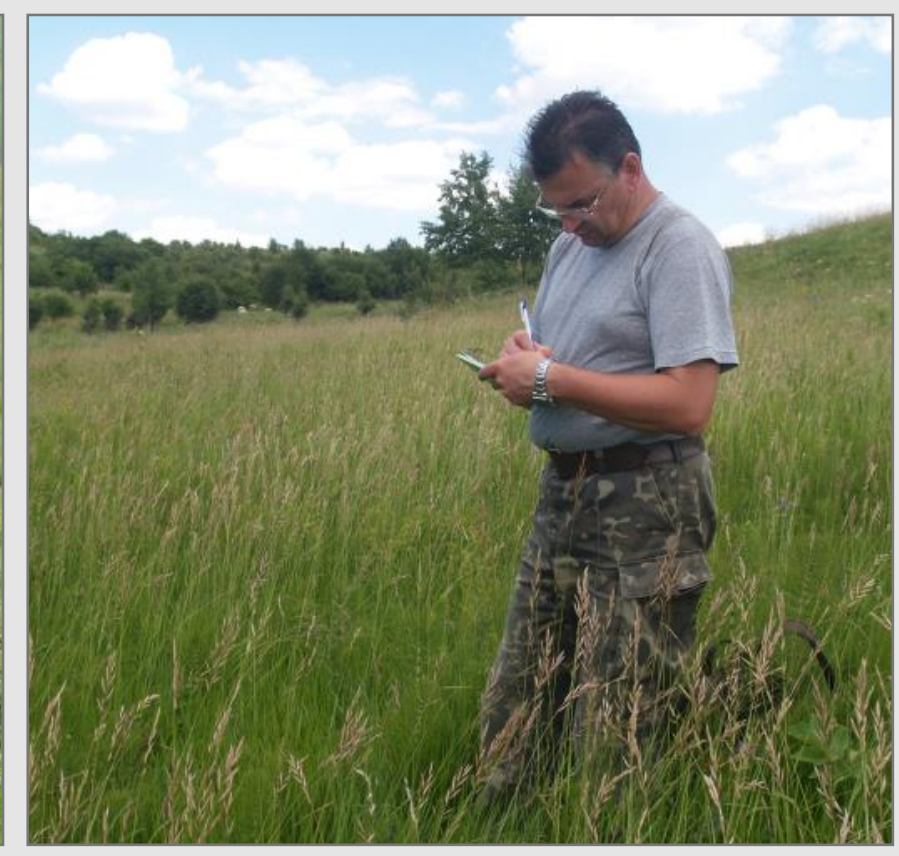

Vasyl Budzhak making a relevé in semi-dry grasslands. Photo: A. Tokariuk.

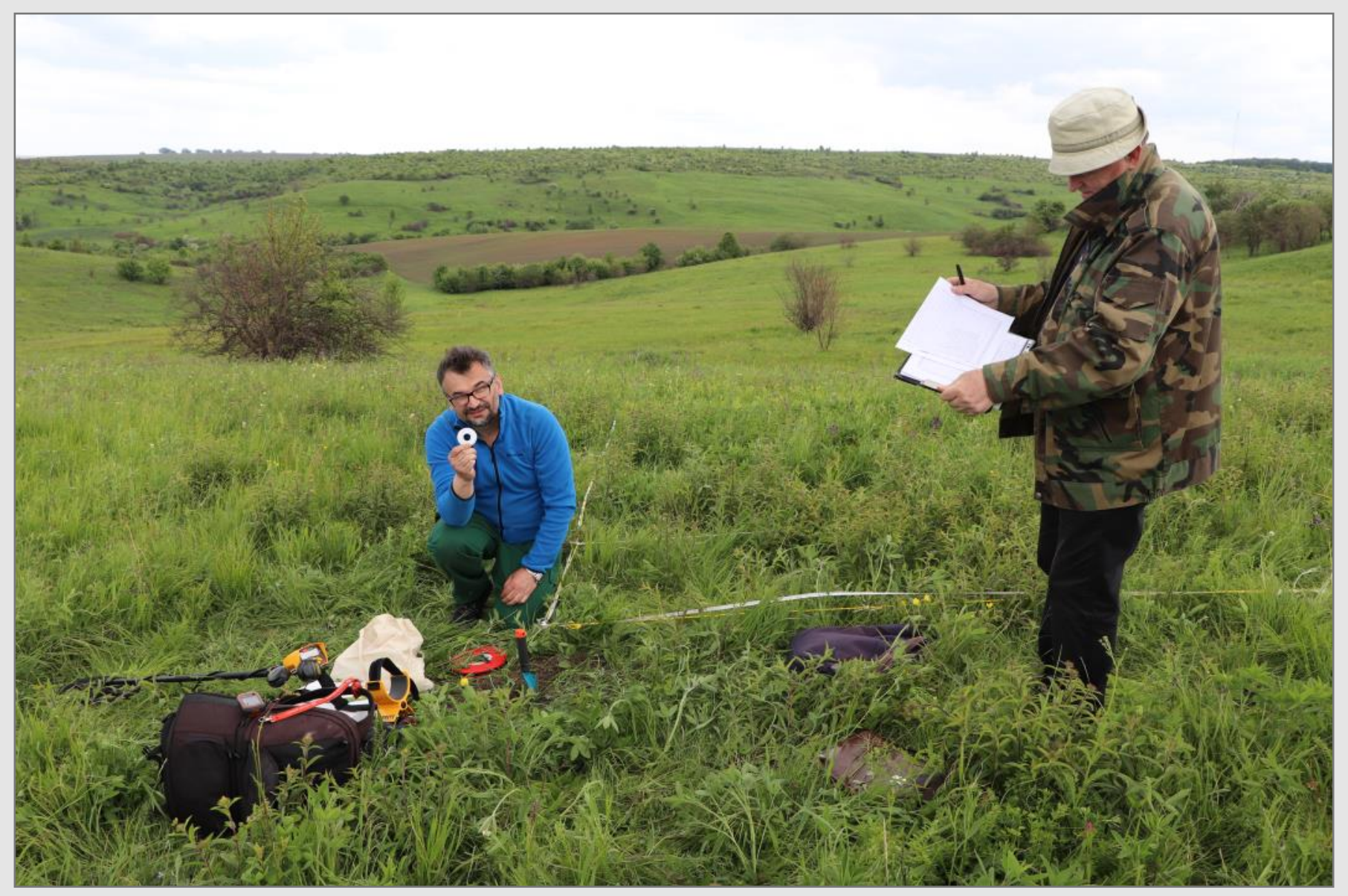

Vasyl Budzhak and Illia Chorney are establishing permanent monitoring plots in 2021. Photo: A. Tokariuk. 


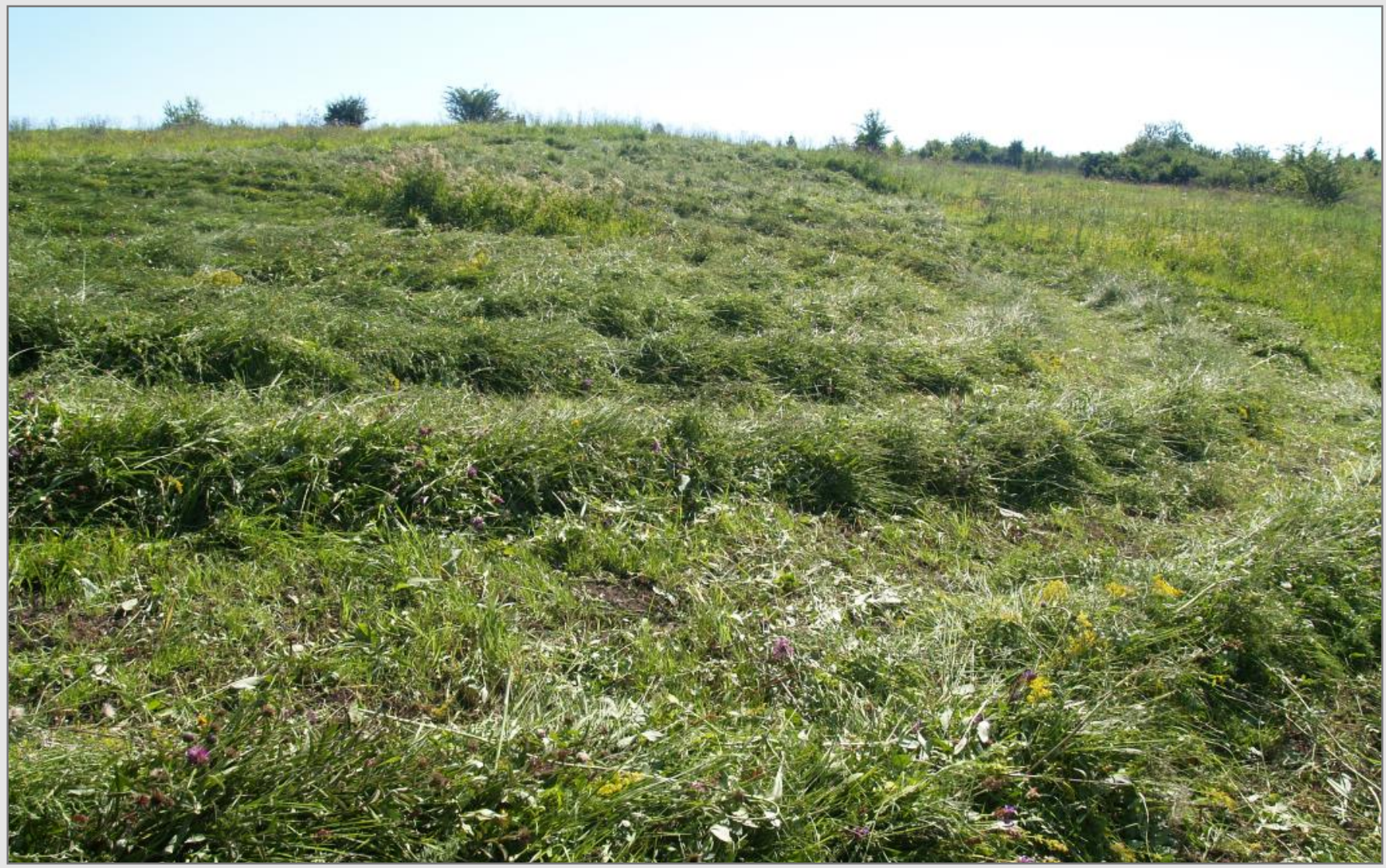

The first mowing. Photo: V. Budzhak.

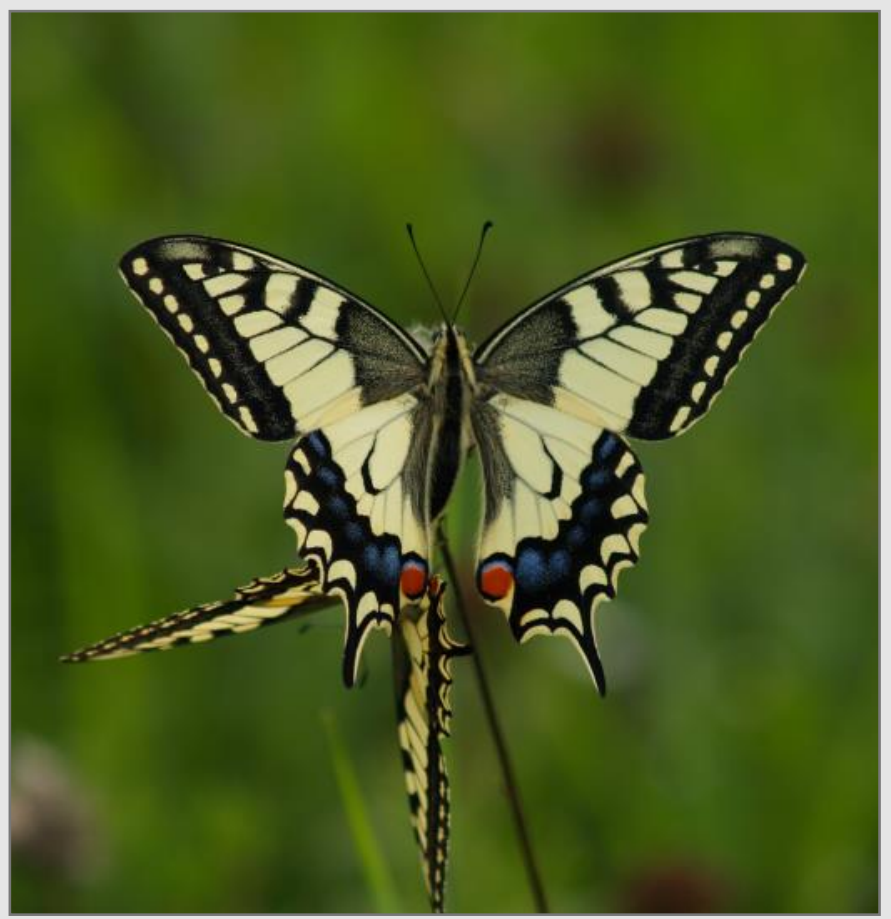

Papilio machaon - the most famous butterfly of Ukraine, adornment of the "Sinozhati" site. Photo: V. Budzhak.

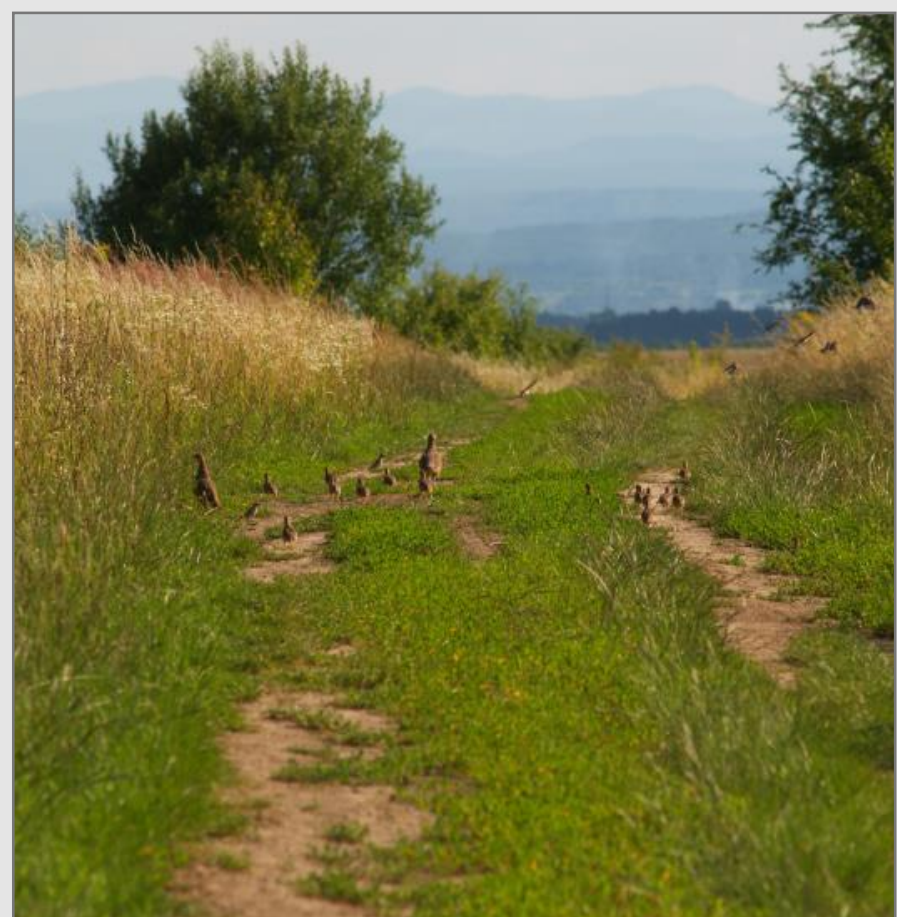

Perdix perdix - a typical inhabitant of forest-steppe lands. Photo: V. Budzhak. 


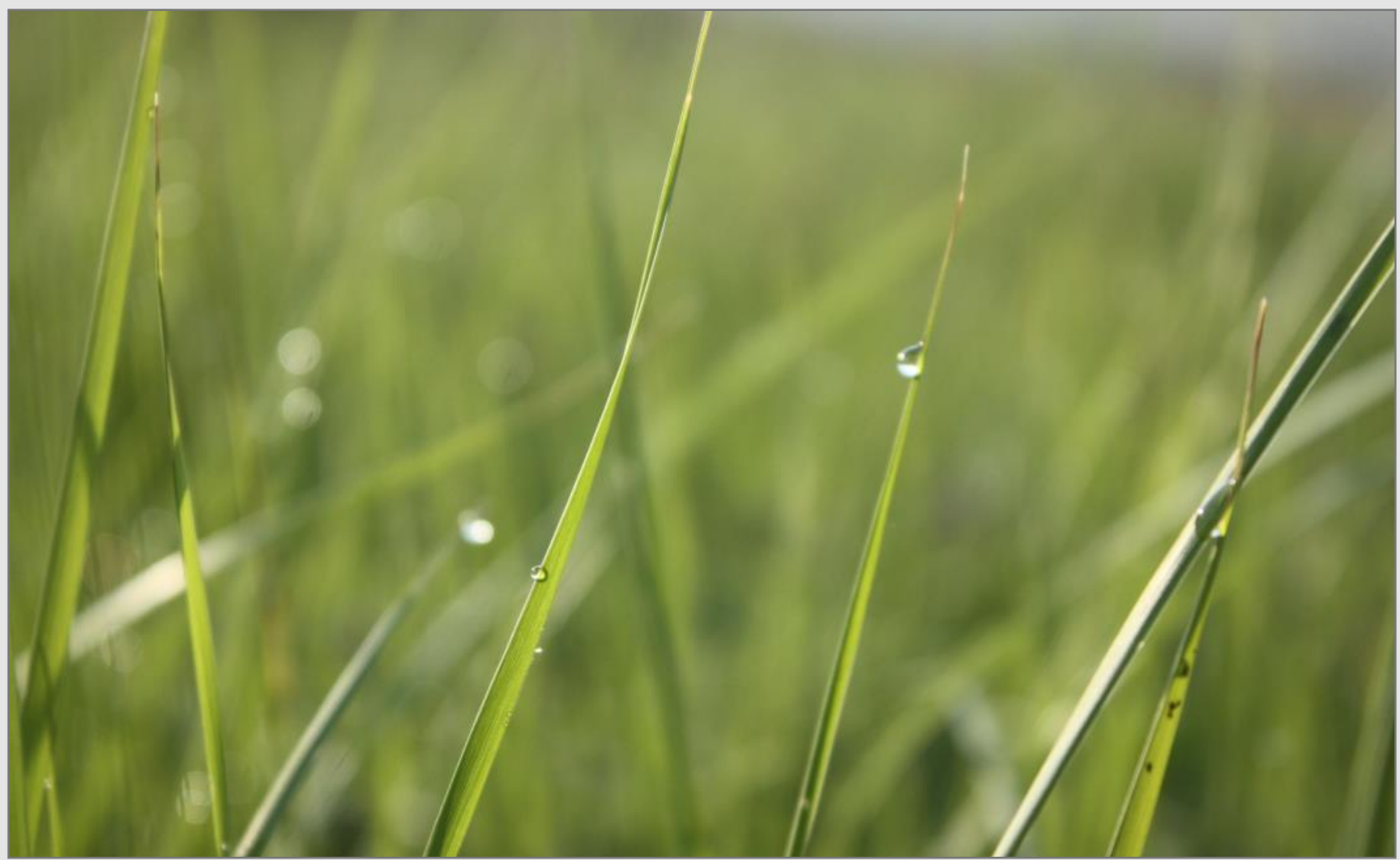

Healing morning dew. Photo: A. Kuzemko.

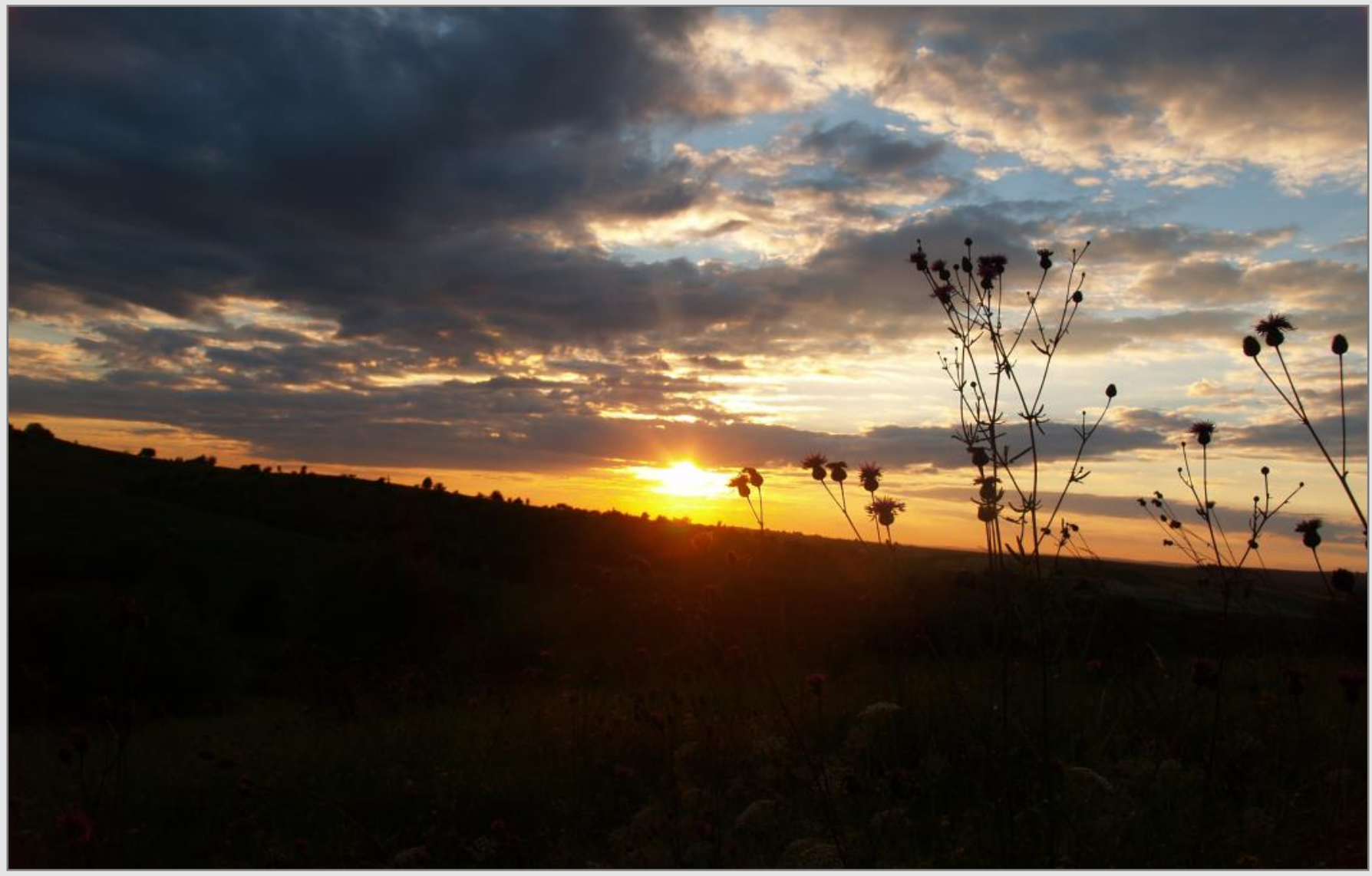

Evening in Sinozhaty. Photo: V. Budzhak. 


\section{Glimpses of a Grassland}

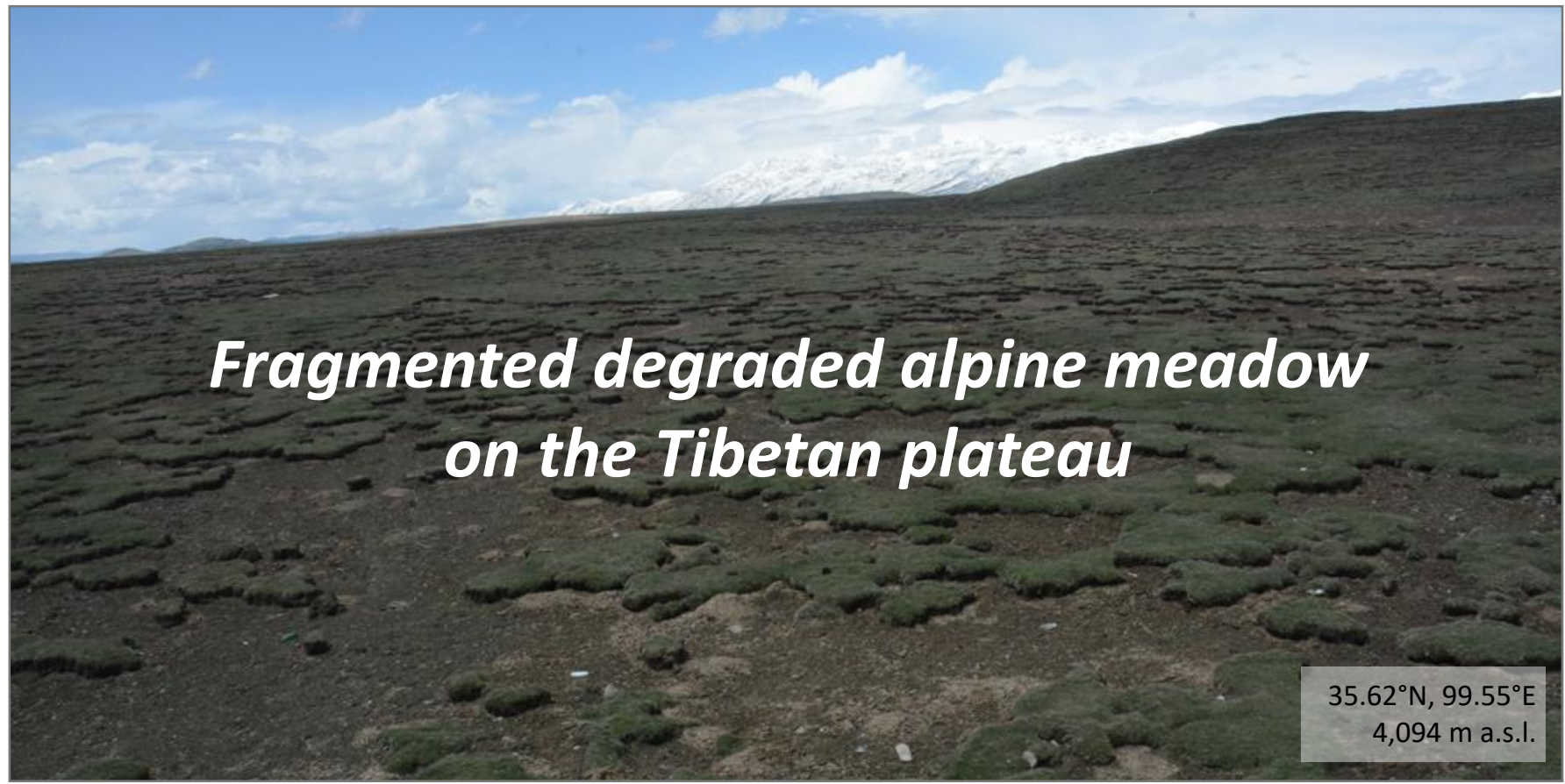

The Tibetan plateau is the world's highest and largest plateau, known as "the roof of the world", the "third pole", and the "Asian water tower" due to the high elevation and mountain systems, cold environment and the rich river systems. The area of the plateau is about 2.5 million $\mathrm{km}^{2}$, stretching between $26^{\circ} 00^{\prime}-39^{\circ} 47^{\prime} \mathrm{N}, 73^{\circ} 19^{\prime}-104^{\circ} 47^{\prime} \mathrm{E}$. A large part of the plateau lies at elevations above 4,000 to 5,000 meters. The unique physical and geographical environment of the Tibetan plateau supports a variety of alpine ecosystems, most of which are classified as alpine rangelands. The area of alpine rangelands account for about $50 \%$ of the total land area of the Qinghai-Tibet Plateau. Most of the rangelands feature a fragile alpine tundra-like environment, which is difficult to restore once destroyed. The main natural rangeland types include alpine deserts, alpine steppes, alpine meadows, and alpine swamp meadows. Of these grassland types, the alpine meadows are the most widely distributed and cover the largest area within the alpine rangelands. The alpine meadows of the eastern Tibetan Plateau, where the average annual temperature is around $0^{\circ} \mathrm{C}$, with an annual precipitation in the range of 400 $-600 \mathrm{~mm}$. The dominant species in the alpine meadow with a proper stocking rate are Poaceae and Cyperaceae plants, with a sward height of around $20-50 \mathrm{~cm}$ and vegetation cover of $90-100 \%$. Tightly grazed, golf course-like 'lawns' are covered by Kobresia with a very low vegetation height develop where the grassland is overgrazed. Kobresia lawns develop a dense root network (a felt-like root-mat) that not only protects soils against intensive trampling by grazing animals but also aids in coping with increasing productivity and the competitive ability of the roots to protect against leaching and other losses.
In recent decades, due to multiple factors such as human disturbance and climate warming, the alpine meadow habitat in the Tibetan Plateau has been degraded on a large scale. This has led to the loss of biodiversity which has intensified from the 1980s, resulting in serious damage and degradation of the structure and function of the alpine ecosystem. Fragmented, degraded alpine meadow is a symbolic sight of alpine ecosystem degradation on the Tibetan Plateau and it is also the most serious and special manifestation of alpine meadow degradation. Areas of this type of degraded alpine meadow in Western China are referred to as Heitutan (or 'black soil beach') and cover vast areas of the Tibetan Plateau, with around $49,000 \mathrm{~km}^{2}$ in this condition in the entire South Qinghai Province.

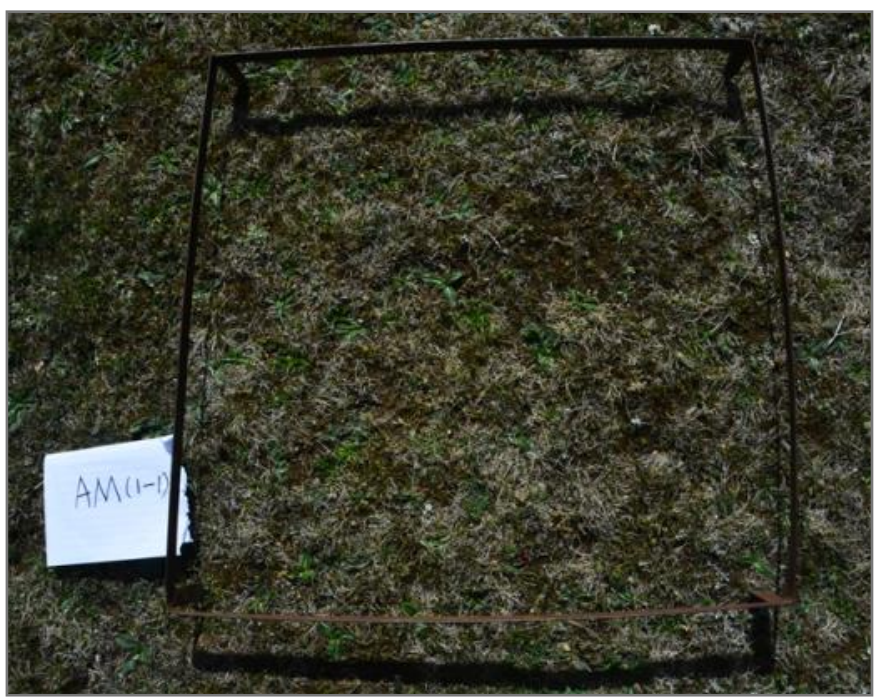

Alpine turf with very low vegetation height. Photo: Y. Niu. 


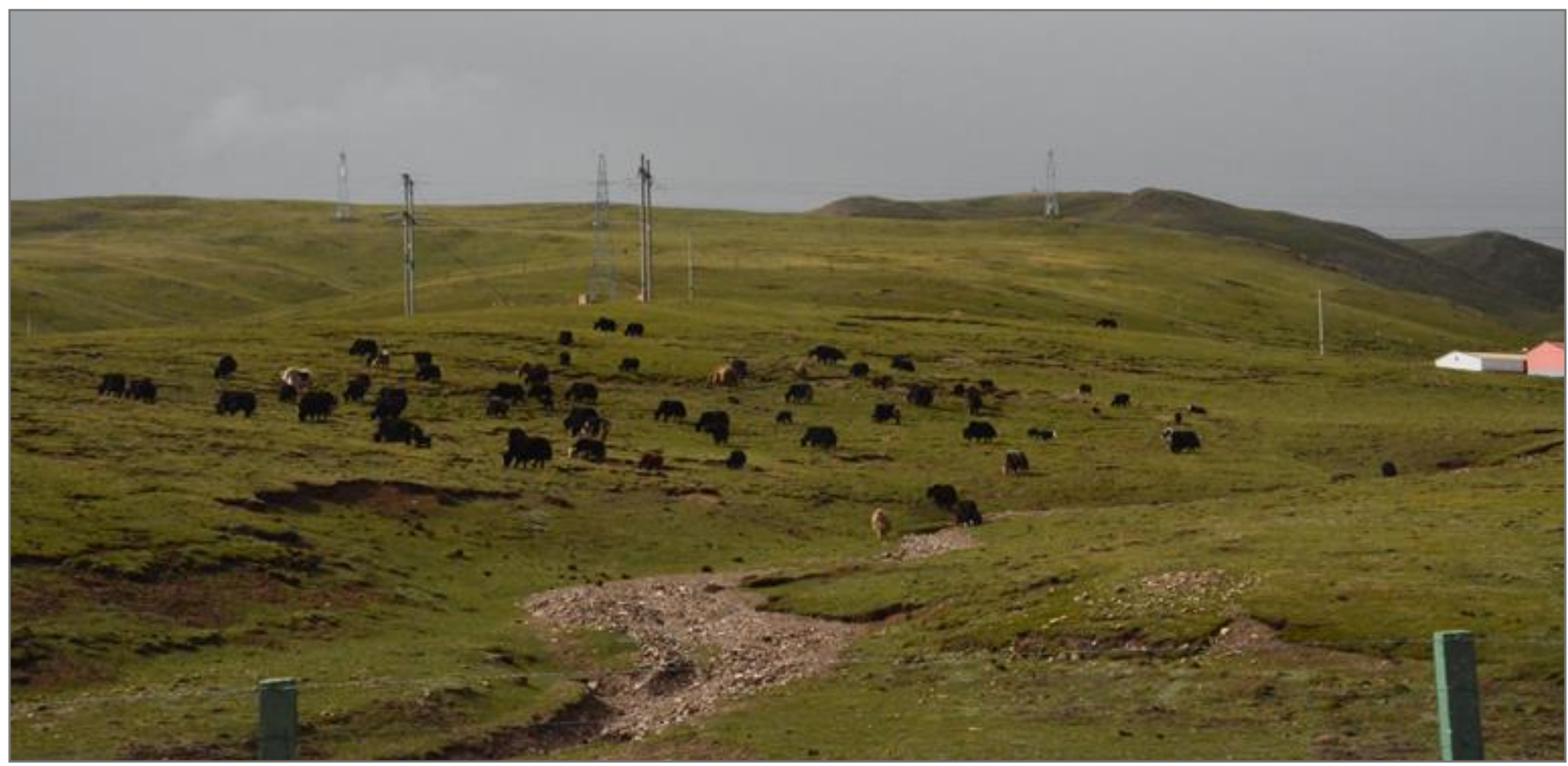

Yak grazing in the alpine meadows on the Tibetan Plateau. Photo: Y. Niu.

Heitutan has a very typical appearance and geomorphological characteristics; these are specifically manifested by the erosion of part or all of the Kobresia lawn layer in the moderately and severely degraded alpine meadows, showing the isolated turf with bald patches and accompanied by a high density of rodent burrows. The degraded alpine ecosystem is very difficult to repair due to the short growing season, low nutrient utilization and limited recruitment from seed. Preventing degradation before it occurs is the best restoration strategy.

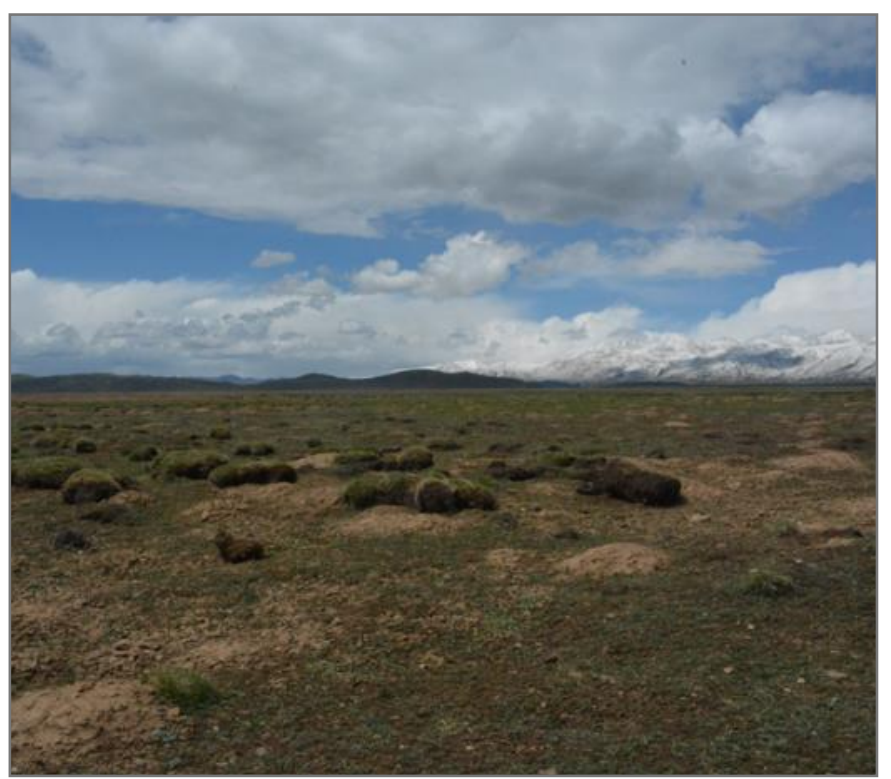

The turf patches are eroded. Photo: Y. Niu.

\section{Further reading}

Niu, Y., Zhu, H., Yang, S., Ma, S., Zhou, J., Chu, B., Hua, R. \& Hua, L. 2019. Overgrazing leads to soil cracking that later triggers the severe degradation of alpine meadows on the Tibetan Plateau. Land Degradation \& Development 30: 1243-1257.

Niu, Y., Yang, S., Zhu, H., Zhou, J., Chu, B., Ma, S., Hua, R., Wang, T. \& Hua, L. 2021. Plant community distribution induced by microtopography due to soil cracks developed in overgrazed alpine meadows on the Tibetan Plateau. Land Degradation \& Development 32: 3167-3179.

Yujie Niu, China/Germany yujie.niu@uni-bayreuth.de

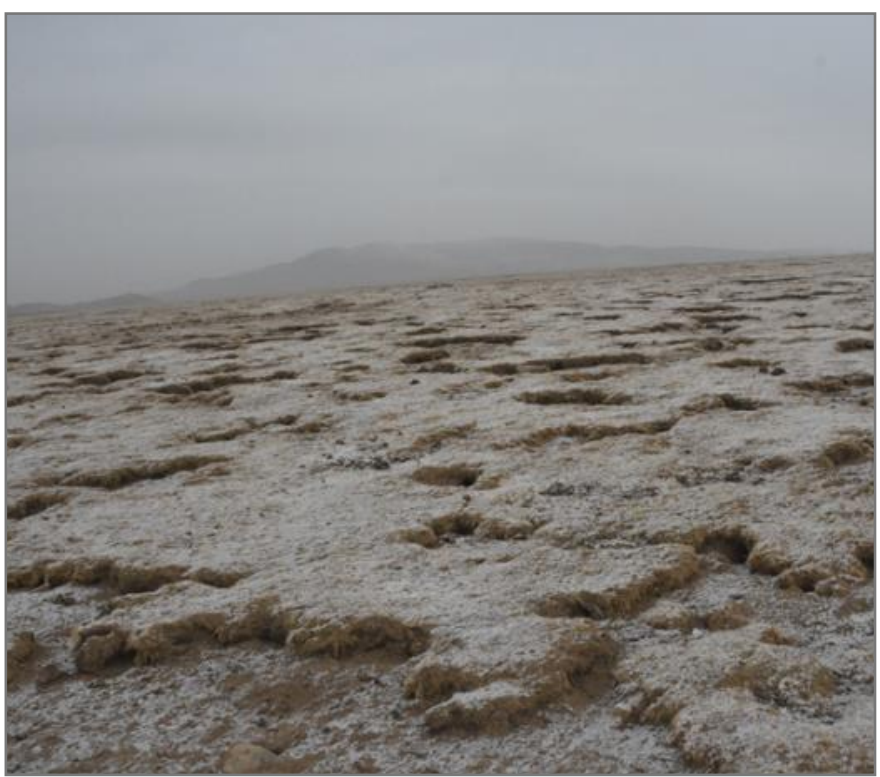

Rodent burrows in the degraded alpine meadow in winter. Photo: Y. Niu. 


\section{Glimpses of a Grassland}

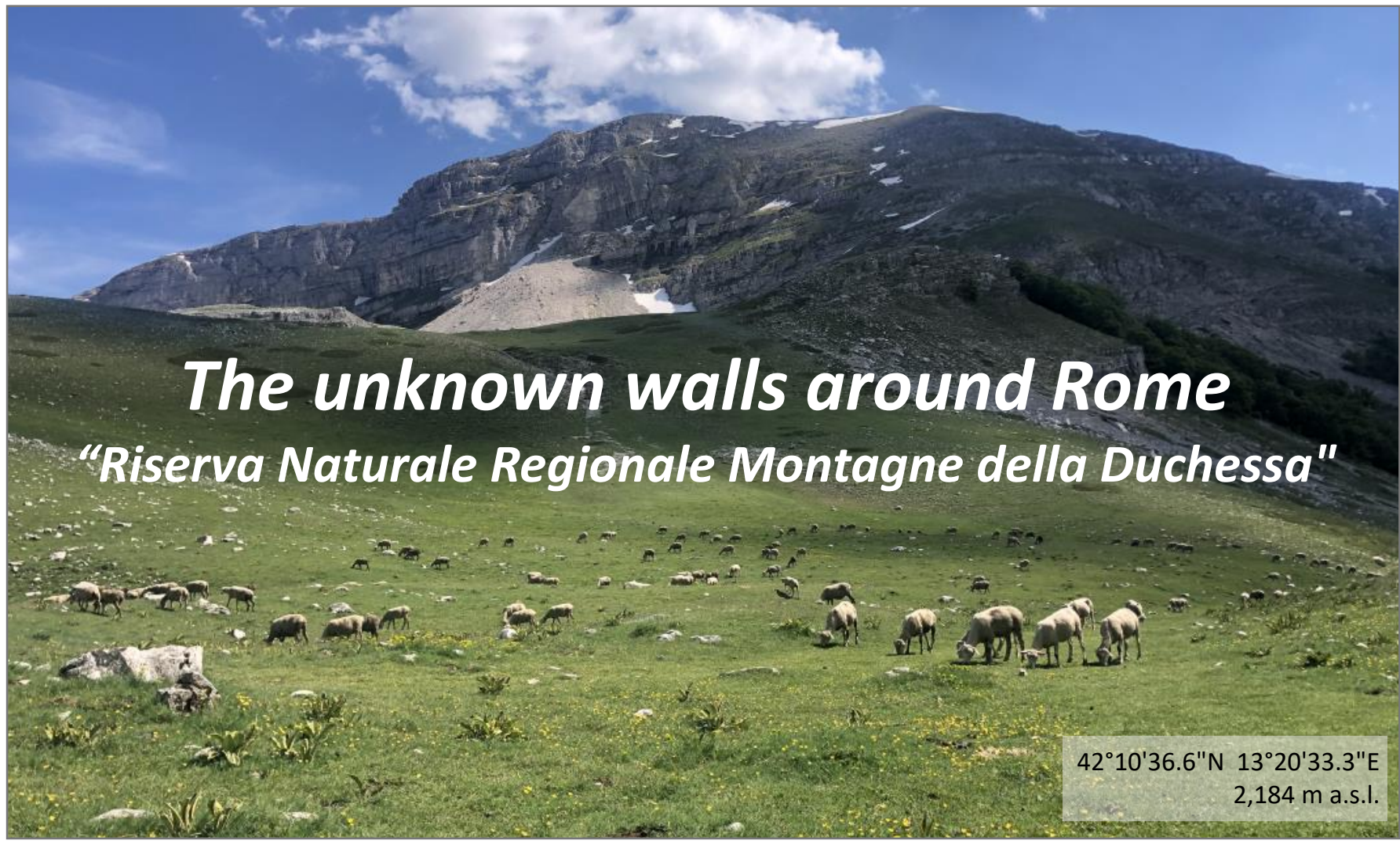

Rome is one of the most visited cities in the world. The ancient walls of the city enclose a never-ending list of historical buildings and renowned masterpieces.

Close to the Eternal City, other walls, made of stone, can surprise and delight grassland lovers. The "Murolungo" peak, meaning "long wall", reaches 2,184 meters above sea level, and the beginning of the footpath to it is only one hour's drive from Rome. It is part of the Regional Nature Reserve "Montagne della Duchessa" and of conservation interest for the extensive sheep grazing and occurrence of alpine vegetation.

On the way up the mountain, beyond the woodlands, one finds guided sheep flocks and traditional penning areas as part of a semi-natural grassland landscape. Near the peak, alpine vegetation occurs, with widespread patches of Dryas octopetala and Androsace villosa, and the yellow flowers of Primula auricula among the rocks.

Sabina Burrascano, Italy sabina.burrascano@uniroma1.it

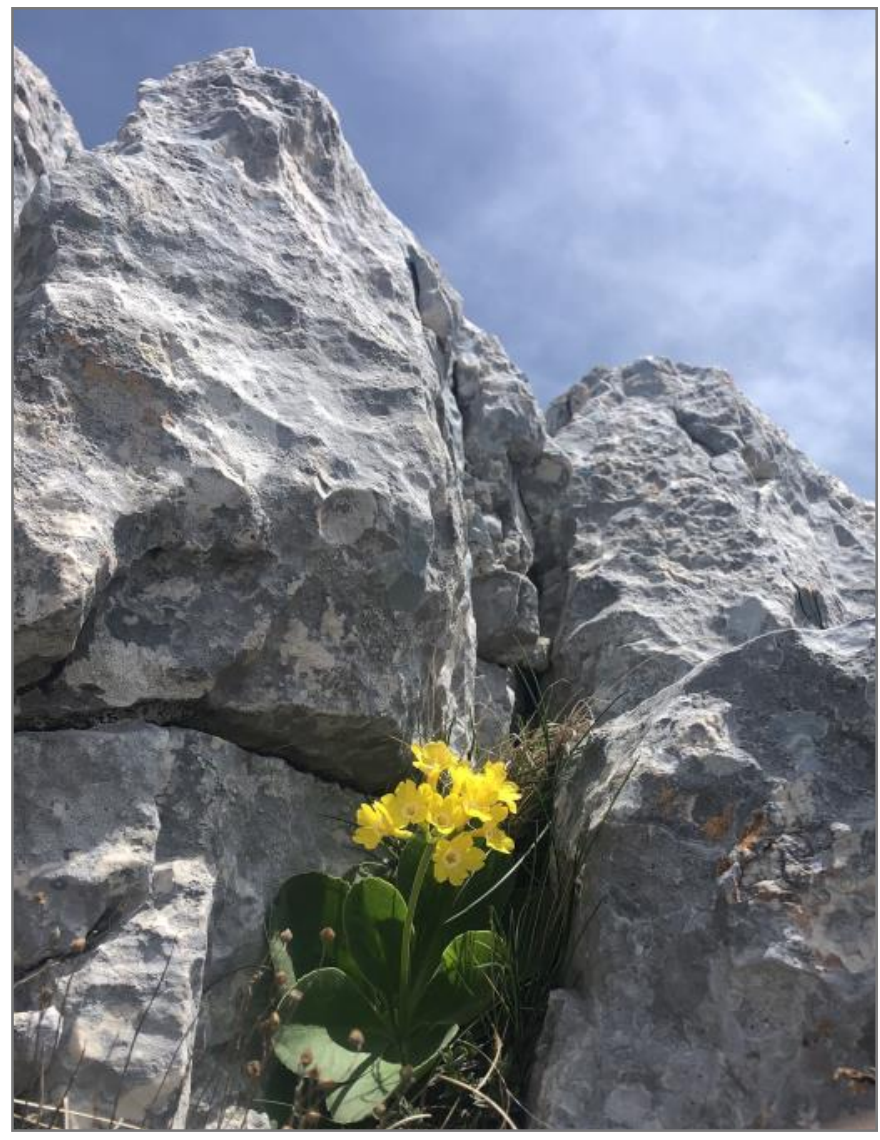

Primula auricula among the rocks of the Murolungo. Photo: S. Burrascano. 


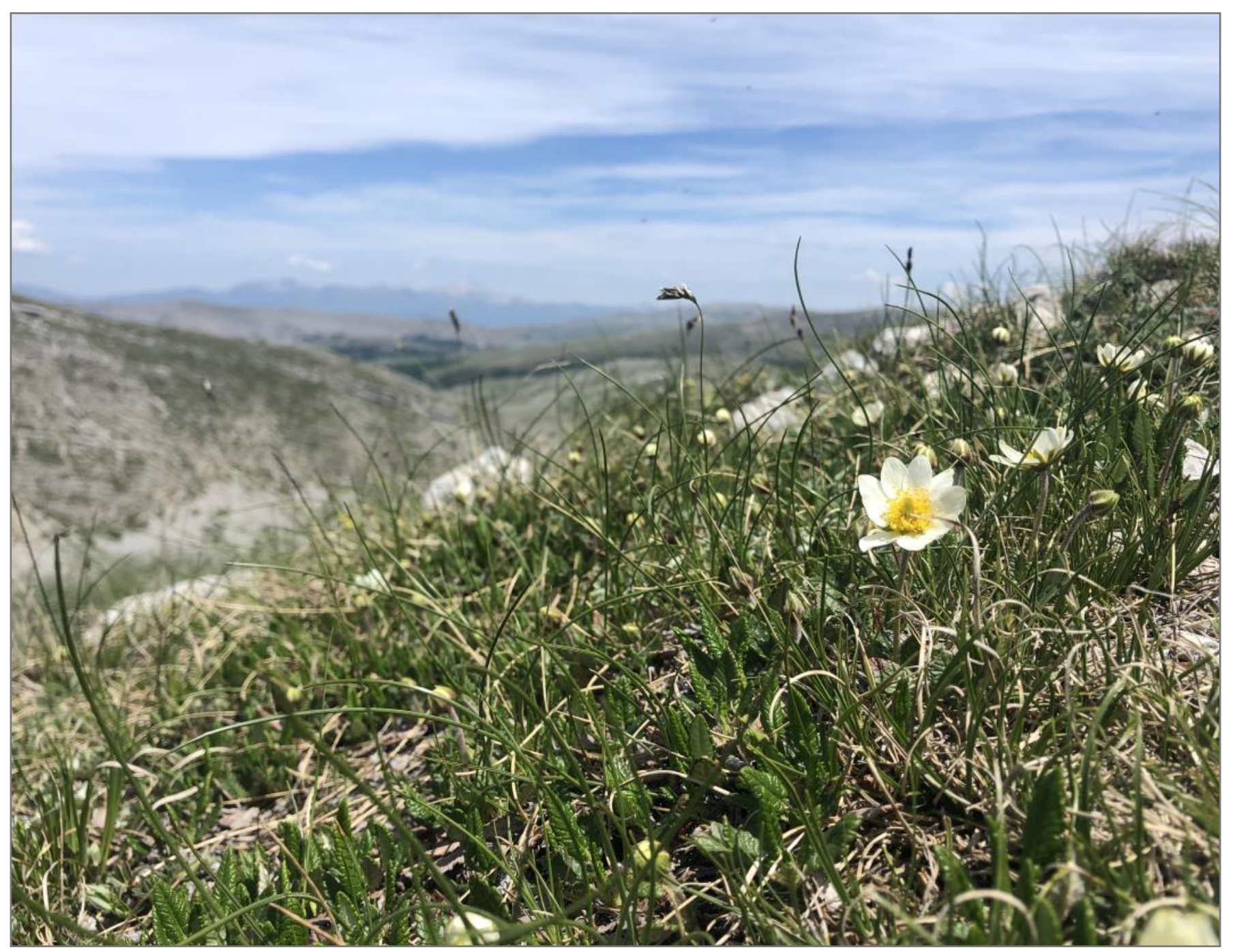

Dryas octopetala on the Murolungo peak. Photo: S. Burrascano. 


\section{Photo Competition}

\section{Best Shots on "Spirit of grasslands"}

Here are the three winners of the EDGG Photo Competition!

The Jury for the Photo Competition was composed of Edy Fantinato, Anna Kuzemko, Rocco Labadessa and Jim Martin.

$1^{\text {st }}$ place

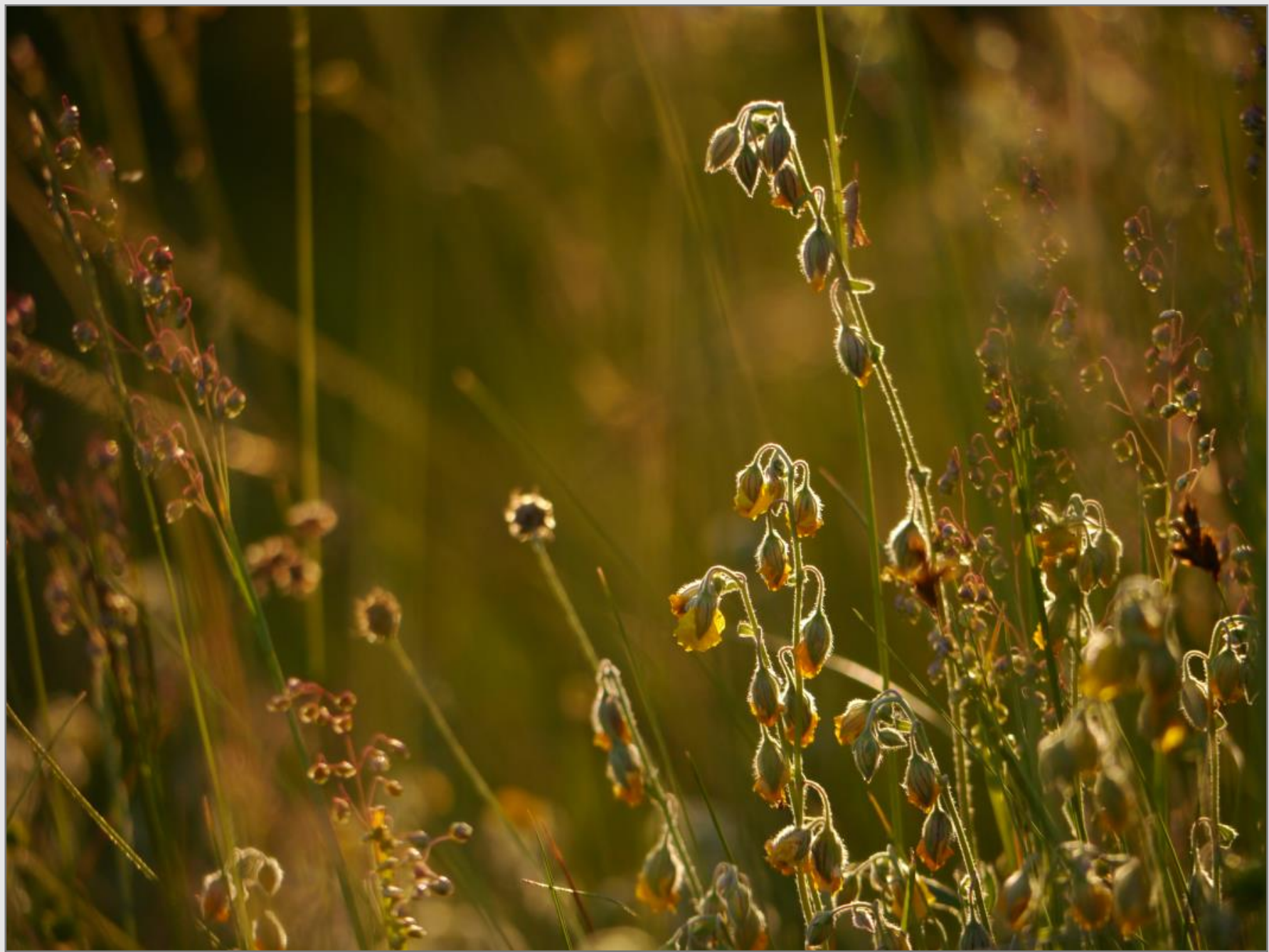

At sunset. Dry grassland with Helianthemum nummularium and Briza media (Narew valley, NE Poland).

Iwona Dembicz i.dembicz@gmail.com

Reviews from the Jury:

"A hidden grasshopper conducting an orchestra of flower bells. May this be the Spirit of such grassland?"

"The sunlight reveals the Genius loci of this grassland, a beautiful composition of shapes and colours, of plants and animals." 
$2^{\text {nd }}$ place:

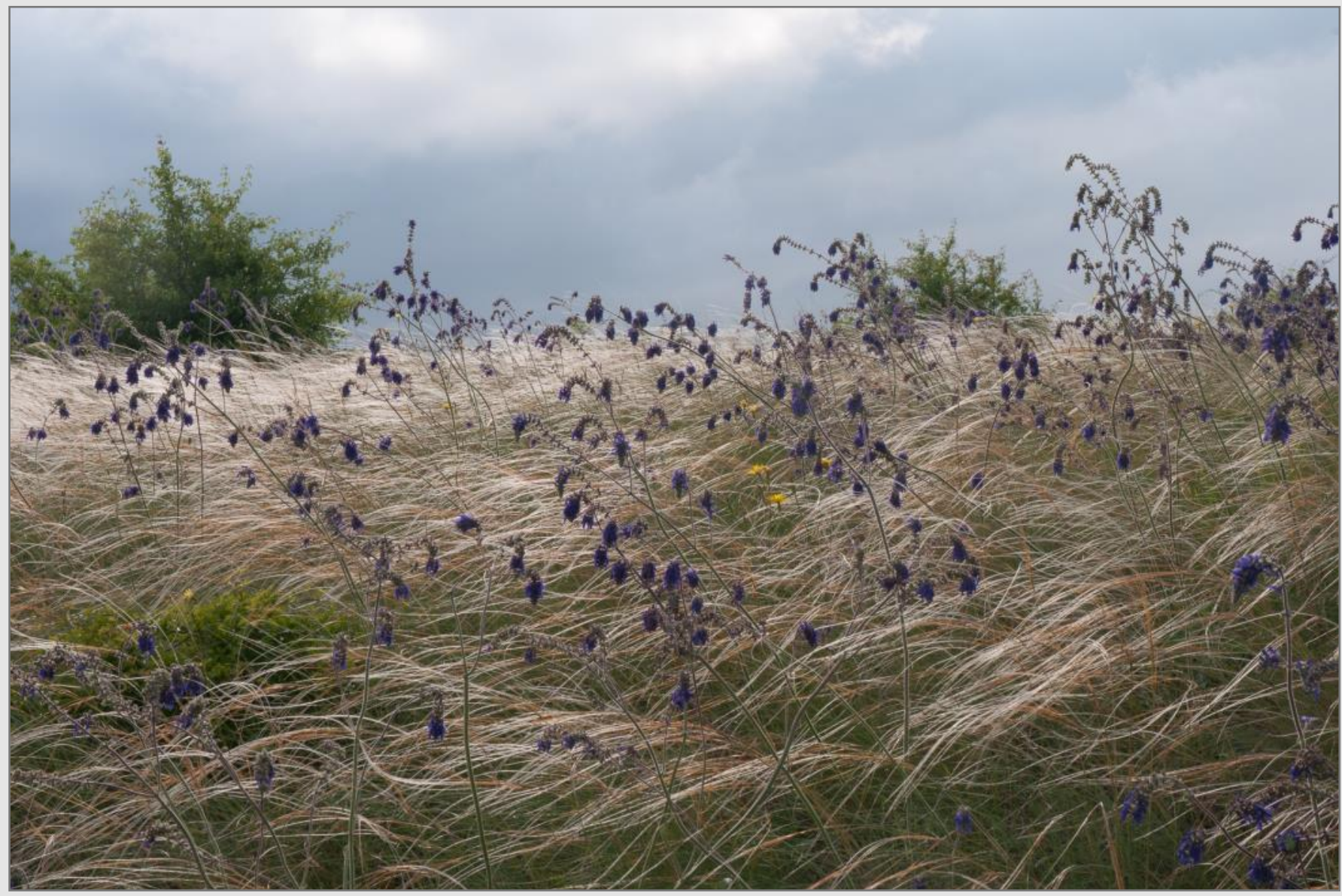

Steppe in Southern Ukraine with Salvia nutans, just before a thunderstorm.

Jürgen Dengler

dr.juergen.dengler@gmail.com

\section{Reviews from the Jury:}

"No one can doubt the magic of the wind that shakes feathergrass and nodding sage."

"Is the wind that blows on grasslands and reveal their powerful beauty the breath of the Spirit of grasslands?"

"There is a spiritual aspect to this photo which wonderfully exhibits the flowing grassland sward." 
$3^{3 d}$ place:

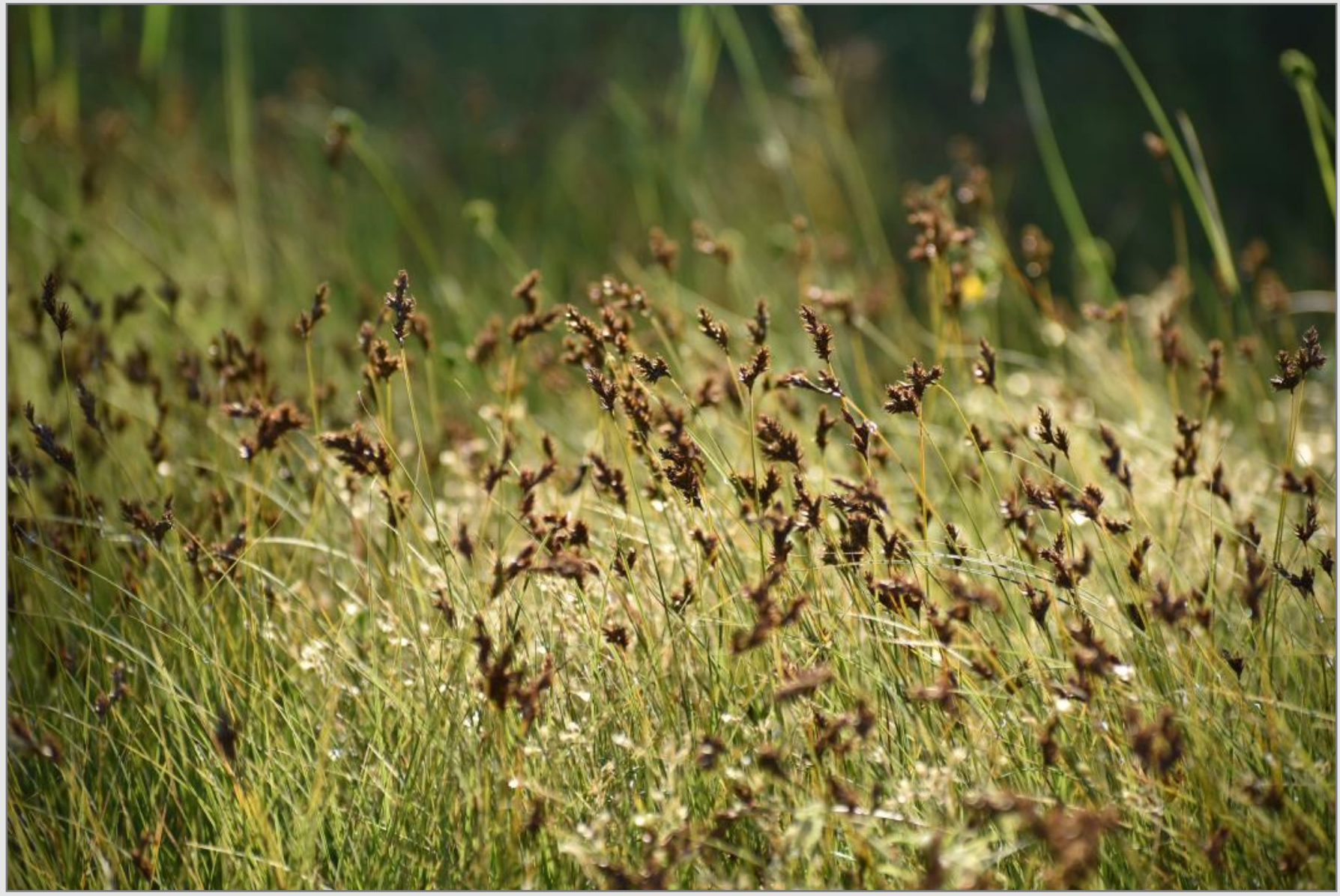

In the sunlight. Dry grassland with Carex praecox (Narew valley, NE Poland).

Iwona Dembicz

i.dembicz@gmail.com

\section{Reviews from the Jury:}

"Sometimes the Spirit of a grassland appears as a ray of light through sedge clearings. This is the case."

"May the Genius loci of this grassland be the vibrant symphony of ears of Carex praecox?"

"The spirit of this sedge-rich grassland is beautifully presented with a halo lighting up the centre of the composition." 
Bond, W.J. 2019. Open Ecosystems: ecology and evolution beyond the forest edge. - Oxford University Press, Oxford, 192 pp., ISBN (hardback): 9780198812456 - f58.00, ISBN (paperback): $9780198869306-£ 34.99$.

It is estimated that almost $60 \%$ of the Earth's land surface is covered by non-forested, open ecosystems (Dinerstein et al. 2017), yet grasslands and shrublands have been much less studied by scientists and much less appreciated by the general public than forests (Bond \& Parr 2010). It has been a long-held belief that in landscapes where the climate and the soil can support forest growth, open vegetation is secondary, degraded and that it is of anthropogenic origin. This prejudice against non-forest ecosystems is based on the 'one climate = one vegetation' assumption, in other words that climate is the single most important factor that determines the distribution of vegetation formations (e.g., Holdridge 1947). However, it is now known that a large share of the Earth's surface is in climate zones where ecosystems are uncertain (Whittaker 1975; Bond 2005), meaning that they can harbour strikingly different vegetation formations from open grasslands and shrublands to closed forests. Open ecosystems that occur in landscapes where the climate can also support forests are the main subject of this book.

This book is not an exhaustive review of the existing literature on open ecosystems. Rather, it sets up an argument and advances a point of view that these ecosystems, instead of being merely successional to climax forests, exist as Alternative Stable States (ASSs) alongside closed forests (Hirota et al. 2011; Staver et al. 2011). Thus, they are ancient systems with unique biota and ecological processes that deserve to be conserved in their own right. The book develops this crucial argument in nine chapters, each starting with a subsection introducing the reader to the topic of the chapter, and most ending with a summary.

Chapter 1 is an introduction to open ecosystems and explains how the occurrence of open vegetation in landscapes that also harbour forests are a global anomaly. This is demonstrated using the example of fynbos shrublands, and briefly summarises the history of research on open ecosystems. Chapter 2 explores the extent to which actual and potential vegetation differs on a global scale and describes the climates under which these mismatches mostly occur, i.e., climate zones where ecosystems are uncertain. The conceptual framework of uncertain ecosystems is introduced in Chapter 3. It explores the concepts that have emerged to explain the existence of uncertain ecosystems, most notably the Alternative Stable States (ASS) theory and its implications. Chapter 4 discusses the surprisingly understudied nature of open ecosystems, including their diversity,

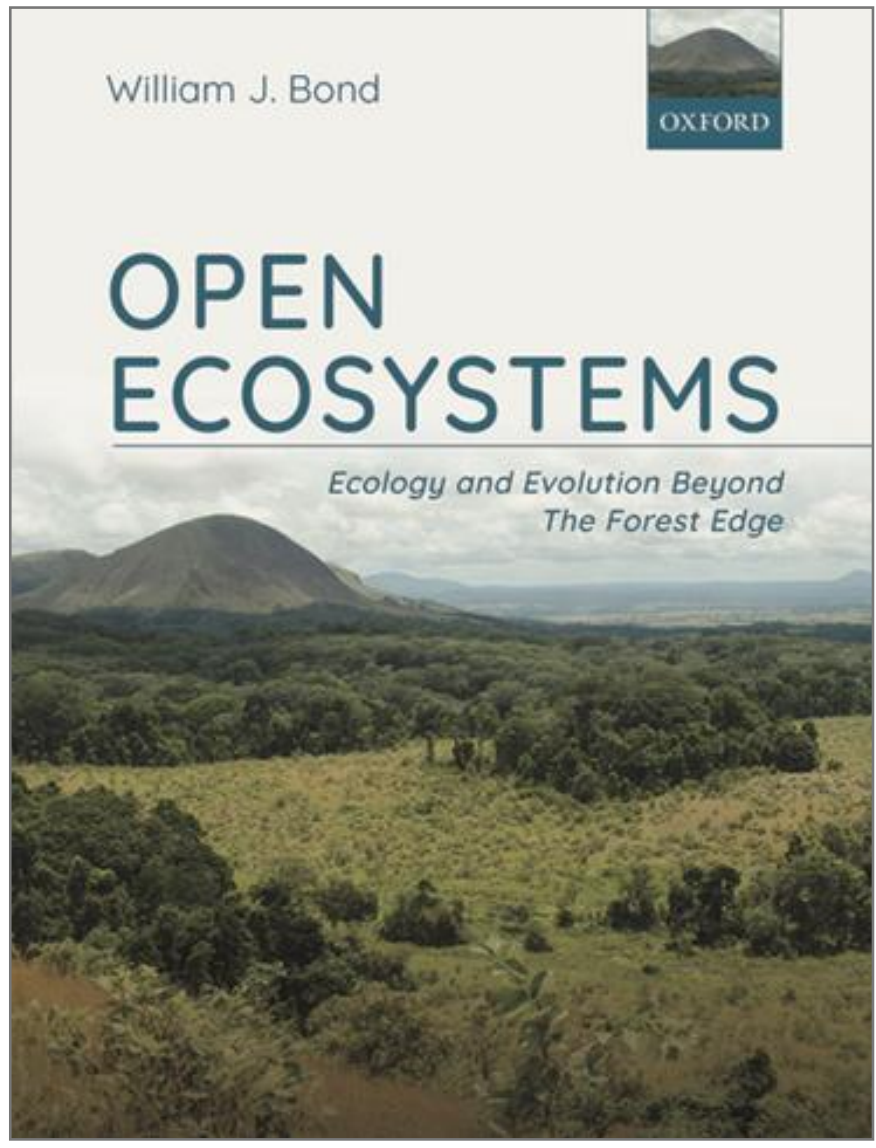

endemism and antiquity, plus the functional traits of plant and animal species of different types of open ecosystems. Chapter 5 focuses on the origins of open and closed ecosystems and their biota based on fossil and phylogenetic evidence. It sheds light on the antiquity of these ecosystems which is crucial for recognizing their value despite the obvious but unjustified preference for forests by public policy and practice. The influence of soils on forest distribution is discussed in Chapter 6. This chapter also explores how soils can affect tree growth through their physical and chemical properties and also draws the attention to plant-soil feedbacks which have been largely under-appreciated in the past. Chapter 7 explores the extent to which fire, a generalist consumer, accounts for the existence and distribution of open ecosystems, shedding light on the fact that fire has helped to maintain open vegetation for millions of years. Chapter 8 focuses on vertebrate herbivory and its effects on ecosystems, demonstrating that fire and large herbivores can be competing consumers that drive ecosystems towards divergent functional compositions. Chapter 9 looks into the future and discusses how atmospheric changes, including increasing $\mathrm{CO}_{2}$ concentrations, might change the fundamental characteristics of open ecosystems and thereby threaten their existence. 
The text is accompanied by numerous informative tables, graphs, maps, and photos, some of which are also presented on separate colour plates. A minor point of criticism is that some of the maps are presented both in black and white and on colour plates, but they are undiscernible without colours, so presenting them in black and white in the text seems to be redundant and useless. The author is from Cape Town, which is presumably why the book is mostly focussed on (sub)tropical ecosystems, especially those in Africa. This could be seen as a shortcoming by readers from the Palaearctic. However, I found it refreshing and eyeopening to learn of certain issues and phenomena that otherwise are not well-known by those of us unfamiliar with tropical ecosystems.

Bond's major motivation for writing this book was his concern over international plans to afforest large areas of open ecosystems to tackle increasing atmospheric $\mathrm{CO}_{2}$ concentrations and climate change. As open ecosystems are largely perceived as inferior to forests, legislation and international policies often run contrary to their maintenance, including legislation for fire suppression to protect forests and funding for eliminating open ecosystems by 'reforesting' them. This complete disregard of the accumulating scientific evidence of the antiquity and intrinsic value of open ecosystems is likely to cause severe damage to the diversity of life on Earth. Readers of Palaearctic Grasslands are probably already interested in and fascinated by open ecosystems.
However, I am sure that reading this book will convince many to become more interested in their ecology and more committed to the conservation of these remarkable ecosystems.

\section{References}

Bond, W.J. 2005. Large parts of the world are brown or black: a different view on the 'Green World' hypothesis. Journal of Vegetation Science 16: 261-266.

Bond, W.J. \& Parr, C.L. 2010. Beyond the forest edge: ecology, diversity and conservation of the grassy biomes. Biological Conservation 143: 23952404.

Dinerstein, E., Olson, D., Joshi, A., Vynne, C., Burgess, N.D., Wikramanayake, E., Hahn, N., Palminteri, S., Hedao, P., (...) \& Saleem, M. 2017. An ecoregion-based approach to protecting half the terrestrial realm. BioScience 67: 534-545.

Hirota, M., Holmgren, M., Van Nes, E.H. \& Scheffer, M. 2011. Global resilience of tropical forest and savanna to critical transitions. Science 334: 232-235.

Holdridge, L.R. 1947. Determination of world plant formations from simple climatic data. Science 105: 367-368.

Staver, A.C., Archibald, S. \& Levin, S.A. 2011 The global extent and determinants of savanna and forests alternative biome states. Science 334 : 230-232.

Whittaker, R.H. 1975. Communities and ecosystems. McMillan, New York, USA.

Judit Sonkoly, Hungary

judit.sonkoly@gmail.com

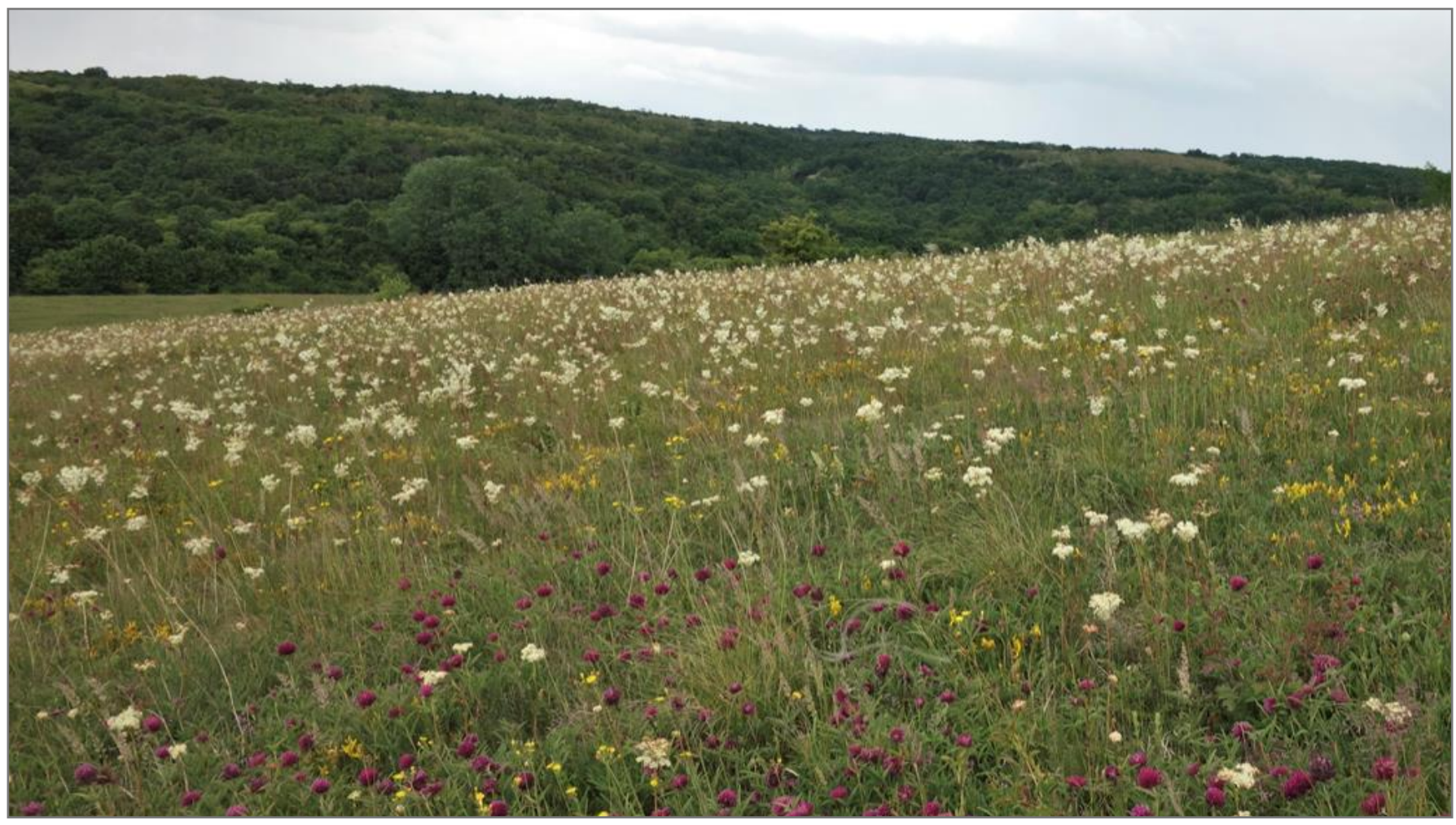




\section{Recent Publications of our Members}

In this section, the contents of which will also be made available via our homepage, we want to facilitate an overview of grassland-related publications throughout Eurasia and to improve their accessibility. You are invited to send lists of such papers from the last three years following the format below to Iwona Dembicz, i.dembicz@gmail.com. We will include your e-mail address so that readers can request a pdf. For authors who own full copyright, we can also post a pdf on the EDGG homepage.

\section{Biodiversity \& ecology}

Biurrun, I., Pielech, R., Dembicz, I., Gillet, F., Kozub, $Ł$, Marcenò, C., Reitalu, T., Van Meerbeek, K., Guarino, R., (...) \& Dengler, J. 2021. Benchmarking plant diversity of Palaearctic grasslands and other open habitats. Journal of Vegetation Science 32: e13050.

Dembicz, I., Dengler, J., Steinbauer, M.J., Matthews, T.J., Bartha, S., Burrascano, S., Chiarucci, A., Filibeck, G., Gillet, F., (...) \& Biurrun, I. 2021. Fine-grain beta diversity of Palaearctic grassland vegetation. Journal of Vegetation Science 32: e13045.

Fristoe, T.S., Chytrý, M., Dawson, W., Essl, F., Heleno, R., Kreft, H., Maurel, N., Pergl, J., Pyšek, P., Seebens, H., (...), Dengler, J., (...) \& van Kleunen, M. 2021. Dimensions of invasiveness: links between abundance, geographic range size and habitat breadth in Europe's alien and native floras. Proceedings of the National Academy of Sciences of the USA 118: e2021173118.

Laughlin, D.C., Mommer, L., Sabatini, F.M., Bruelheide, H., Kuyper, T.W., McCormack, M.L., Bergmann, J., Freschet, G.T., GuerreroRamírez, N.R., (...), Dengler, J., (...) \& Weigelt, A. 2021. Root traits explain plant species distributions along climatic gradients yet challenge the nature of ecological trade-offs. Nature Ecology \& Evolution 5: 1123-1134.

Napoleone, F., Giarrizzo, E. \& Burrascano, S. 2021. Habitat conservation state and plant diversity respond to different drivers in semi-natural grasslands. Journal of Vegetation Science 32: e13055.

Poteau, R., Biurrun, I., Brunel, C., Chytrý, M., Dawson, W., Essl, F., Fristoe, T., Haveman, R., Hobhom, C., Jansen, F., Kreft, H., Lenoir, J., Lenzner, B., Meyer, C., Erenskjold Moeslund, J., Pergl, J., Pyšek, P., Svenning, J.-C., Thuiller, W., Weigelt, P., Wohlgemuth, T., Yang, Q. \& van Kleunen, M. 2021. Potential alien ranges of European plants will shrink in the future, but less so for already naturalized than for not yet naturalized species. Diversity and Distributions [in print]: DOI:10.1111/ ddi.13378.

Pouteau, R., Thuiller, W., Hobohm, C., Brunel, C., Conn, B.J., Dawson, W., de Sá Dechoum, M., Dufour-Dror, J.-M., Ebel, A.L., Essl, F., (...) Dengler, J., (...) \& van Kleunen, M. 2021. Climate and socio-economic factors explain differences between observed and expected naturalization patterns of European plants around the world. Global Ecology and Biogeography 30: 1514-1531.
Wang, Z., Zhang, J., Li, Z., Liu, H., Wang, L., Wang, W., Wang, Y. \& Liang, C. 2021. Single grazing is more detrimental to grasslands than mixed grazing: evidence from the response of functional traits of dominant plants to grazing systems. Frontiers in Ecology and Evolution 9: 682289.

Zhang, J., Gillet, F., Bartha, S., Alatalo, J.M., Biurrun, I., Dembicz, I., Grytnes, J.-A., Jaunatre, R., Pielech, R., (...) \& Dengler, J. 2021. Scale dependence of species-area relationships is widespread but generally weak in Palaearctic grasslands. Journal of Vegetation Science 32: e13044.

\section{Conservation \& restoration}

Kun, R., Babai, D., Csathó, A.I., Vadász, Cs., Kálmán, N., Máté, A. \& Malatinszky, Á. 2021. Simplicity or complexity? Important aspects of high nature value grassland management in nature conservation. Biodiversity and Conservation [in print]: $\underline{\mathrm{DOl}}$ $\underline{10.1007 / s 10531-021-02262-z}$

\section{Methodology, classification, databases}

Bruelheide, H., Jansen, F., Jandt, U., Bernhardt-Römermann, M., Bonn, A., Bowler, D., Dengler, J., Eichenberg, D., Grescho, V., Kellner, S., (...) \& Wesche, K. 2021. A checklist for using Beals' index with incomplete floristic monitoring data - Reply to Christensen et al. 2021. Problems in using Beals' index to detect species trends in incomplete floristic monitoring data. Diversity and Distributions 27: 1328-1333.

Sabatini, F.M., Lenoir, J., Hattab, T., Arnst, E.A., Chytrý, M., Dengler, J., De Ruffay, P., Hennekens, S.M., Jandt, U., (...) \& Bruelheide, H. 2021. sPlotOpen - An environmentally balanced, open-access, global dataset of vegetation plots. Global Ecology and Biogeography 30: 1740-1764.

\section{Contact persons:}

Sabina Burrascano: sabina.burrascano@uniroma1.it András István Csathó: csatho@verge.hu Idoia Biurrun: idoia.biurrun@ehu.es Iwona Dembicz: i.dembicz@gmail.com Jürgen Dengler: $\underline{\text { dr.juergen.dengler@gmail.com }}$ Jinghui Zhang: jhzhang1001@126.com 


\section{Forthcoming Events}

50th Annual Meeting of the Ecological Society of Germany, Austria and Switzerland

30 August 2021 - 3 September 2021, Virtual event

Conference website: https://www.gfoe-conference.de/

International Symposium in honor

of Salvador Rivas Martínez

1-3 September 2021, León, Spain

Conference website: https://simposiosalvadorrivasmartinez.com

29th Meeting of the European Vegetation Survey (EVS)

Revegetating Europe - contributions of the EVS to the ecological restoration decade

6-7 September 2021, Virtual event

Conference website: http://www.evs2020roma.info

12th European Conference on Ecological Restoration SER 2021

7-10 September 2021, Virtual event

Conference website: https://www.sere2021.org/

1st Congress of the Spanish Botanical Society (SEBOT) 2nd Congress of the Spanish Society for Geobotany (SEG) 8-10 September 2021, Toledo, Spain

Conference website: $\underline{\text { https:// }}$

www.congresosebot2021toledo.com

63th Symposium of the International Association for Vegetation Science (IAVS)

20-23 September 2021, Virtual event

Conference website: https://www.iavs.org/page/

Symposium2021 AnnualSymposiumHome

\section{Ecology Across Borders 2021}

12-15 December 2021, Liverpool, UK

Conference website: https://www.britishecologicalsociety.org/ events/bes-annual-meeting-2020/ecology-across-borders-2021/

\section{$30^{\text {th }}$ International Congress for Conservation Biology} (ICCB) 2021

12-16 December 2021, Kigali, Rwanda

Conference website: https://conbio.org/mini-sites/iccb-2021

Asian Grassland Conference (AGC) of the EDGG

22-24 February 2022, Virtual event

See details in this issue, on pp. 9-16.

EDGG Field Workshop "Latitudinal transect in Ukraine" May 2022, Ukraine

Eurasian Grassland Conference (EGC) of the EDGG September 2022, Tolosa, Spain

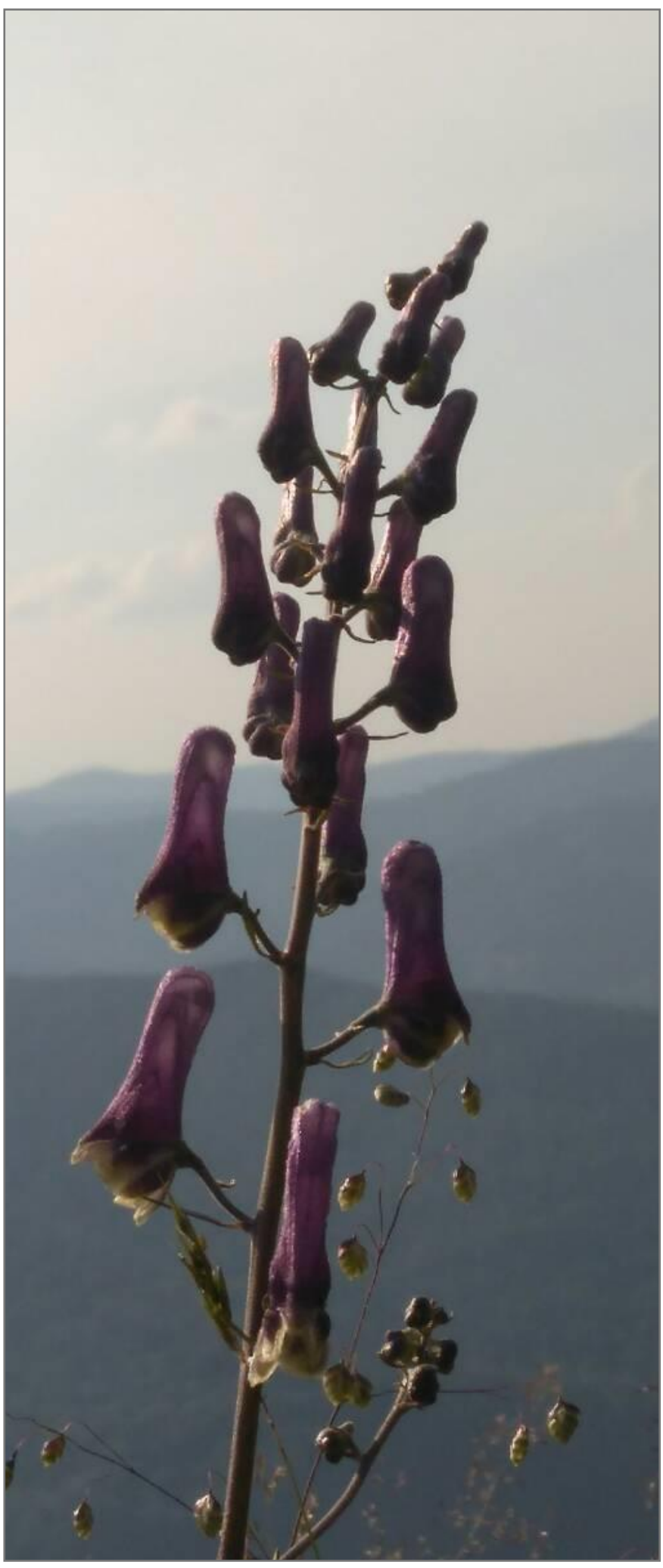

Aconitum moldavicum, Makovitsa Mt., Ukraine. Photo: 0. Yaroshko. 


\section{eDGG}

Grass[ลฺฺ] research and conservation
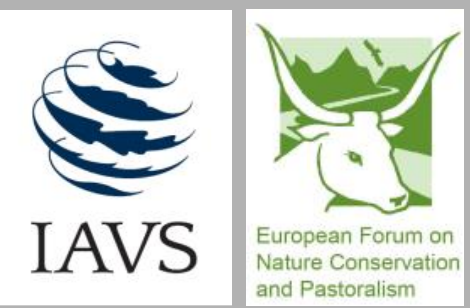

EDGG on the web:

http://www.edgg.org

EDGG in Facebook:

https://www.facebook.com/groups/938367279561202

The Eurasian Dry Grassland Group (EDGG), founded in 2008, is a working group of the International Association for Vegetation Science (IAVS) and member of the European Forum on Nature Conservation and Pastoralism (EFNCP). On 25 August 2021, it had 1352 members from 64 countries.

The Eurasian Dry Grassland Group (EDGG) is a network of researchers and conservationists interested in any type of Palaearctic natural and semi-natural grasslands. It is an official Working Group of IAVS (http://www.iavs.org) but one can join our group without being an IAVS member. We live from the activities of our members. Everybody can join the EDGG without any fee or other obligation.

The EDGG covers all aspects related to grasslands, in particular: plants - animals - fungi - microbia - soils - taxonomy - phylogeography - ecophysiology - population biology - species' interactions - vegetation ecology - syntaxonomy - landscape ecology - biodiversity - land use history - agriculture - nature conservation - restoration - environmental legislation - environmental education.

\section{EDGG Executive Committee and responsibilities of its members}

Alla Aleksanyan, Armenia, alla.alexanyan@gmail.com Editor of Website; Deputy Conference Coordinator; member of the Editorial Board of Palaearctic Grasslands

Didem Ambarlı, Turkey, didem.ambarli@gmail.com Conference Coordinator, Deputy Secretary-General; Deputy Coordinator for Special Features, member of the Editorial Board of Palaearctic Grasslands

Idoia Biurrun, Spain, idoia.biurrun@ehu.es

Membership Administrator; Deputy Treasurer and Representative to IAVS; Chief Editor of Palaearctic Grasslands; Deputy Field Workshop Coordinator

Iwona Dembicz, Poland, i.dembicz@gmail.com Field Workshop Coordinator; member of the Editorial Board of Palaearctic Grasslands
Jürgen Dengler, Switzerland, dr.juergen.dengler@gmail.com Secretary-General; Treasurer and Representative to IAVS; Special Feature Coordinator; Chief Editor of Palaearctic Grasslands

Anna Kuzemko, Ukraine, anyameadow.ak@gmail.com Chief Editor of Palaearctic Grasslands; Deputy Social Media Administrator

Rocco Labadessa, Italy, rocco.labadessa@gmail.com Chief Editor of Palaearctic Grasslands; Deputy Editor of Website

Stephen Venn, Finland, stephen.venn@helsinki.fi Social Media Administrator; Deputy Conference Coordinator; member of the Editorial Board of Palaearctic Grasslands

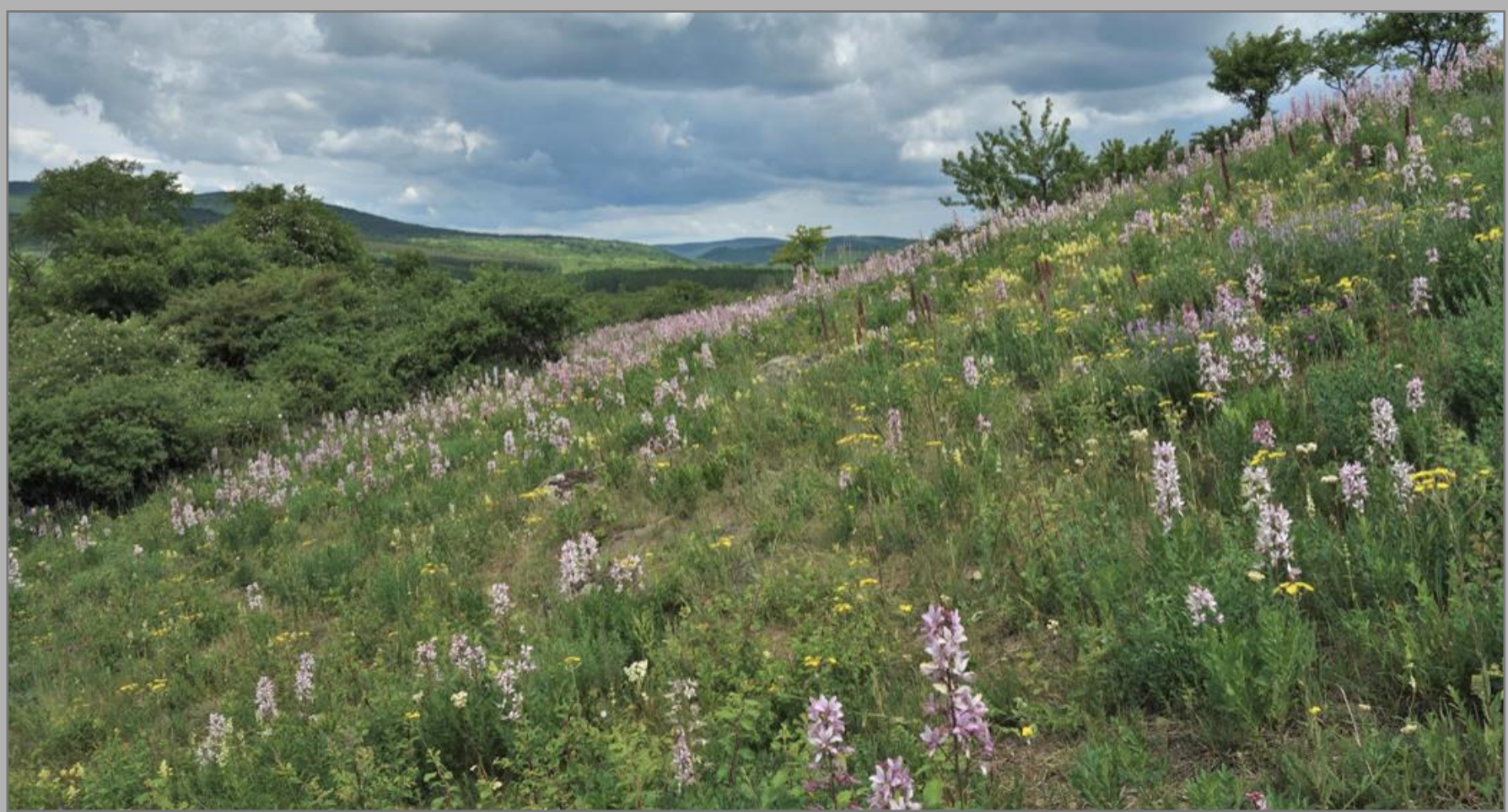

Dry grassland with Dictamnus albus and Echium maculatum in the North Hungarian Mountains region, Hungary. Photo: J. Sonkoly. 